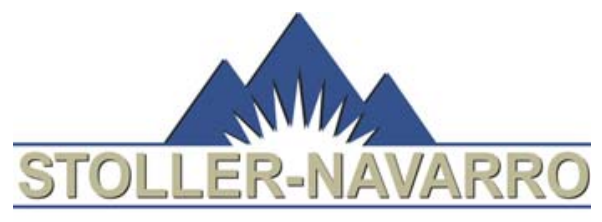

\title{
A User's Guide to the
} Comprehensive Water

Quality Database for

Groundwater in the Vicinity of the Nevada Test Site

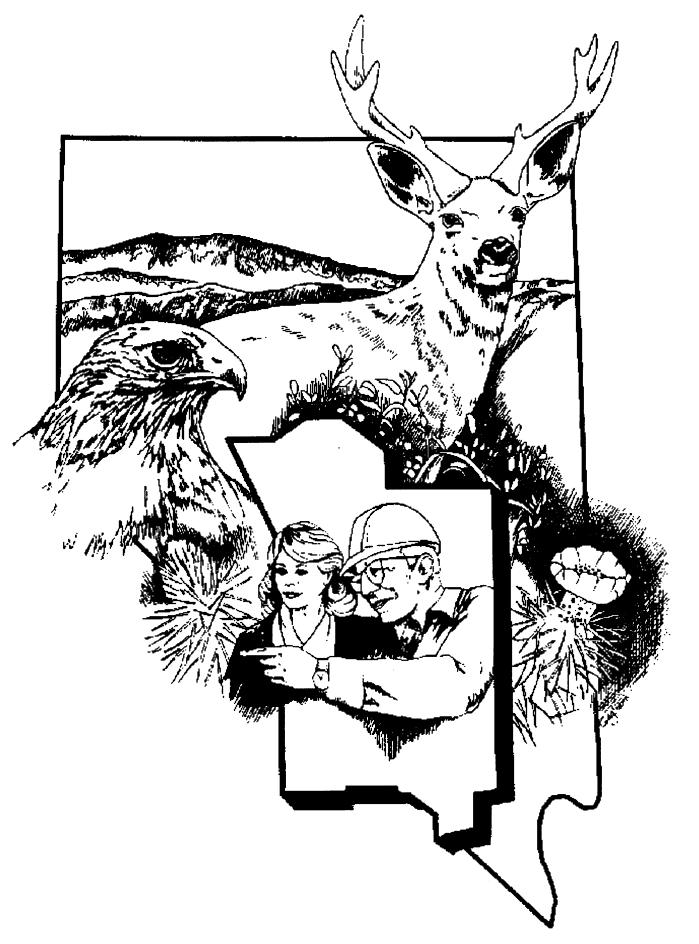

Rev. 1

September 2006

Prepared for U.S. Department of Energy under Contract No. DE-AC52-03NA99205. Approved for public release; further dissemination unlimited 


\section{A USER'S GUIDE TO THE COMPREHENSIVE WATER QUALITY DATABASE FOR GROUNDWATER IN THE VICINITY OF THE NEVADA TEST SITE}

Revision 1

September 2006

Stoller-Navarro Joint Venture

7710 W. Cheyenne, Bldg. 3

Las Vegas, Nevada 89129

Prepared for U.S. Department of Energy under Contract No. DE-AC52-03NA99205

Approved for public release; further dissemination unlimited 


\section{A USER'S GUIDE TO THE COMPREHENSIVE WATER QUALITY DATABASE FOR GROUNDWATER IN THE VICINITY OF THE NEVADA TEST SITE}

\footnotetext{
Approved by: $\quad$ Approved signature $\quad$ Date: $\underline{\text { 9-25-06 }}$

John McCord, Project Manager

Underground Test Area
} 


\section{Table of Contents}

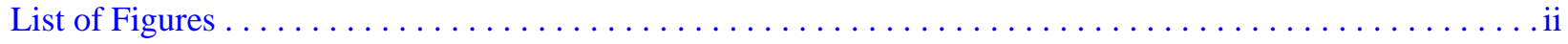

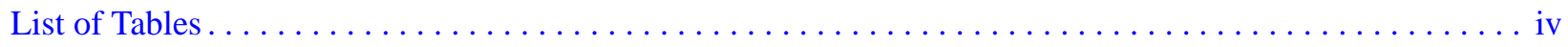

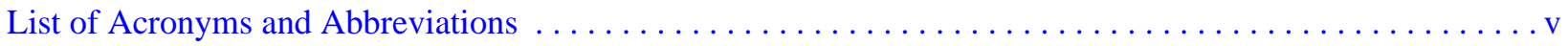

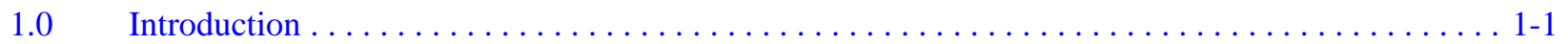

$2.0 \quad$ Presentation of Data. . . . . . . . . . . . . . . . .

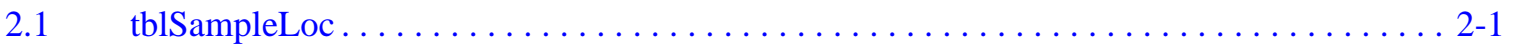

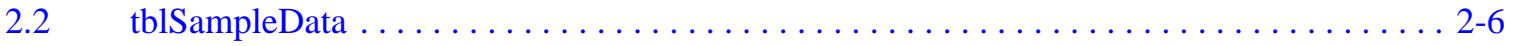

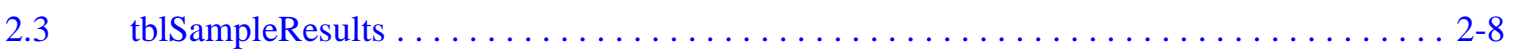

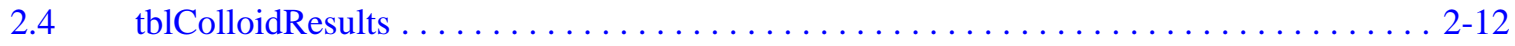

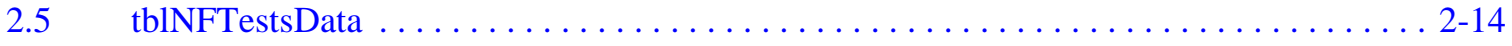

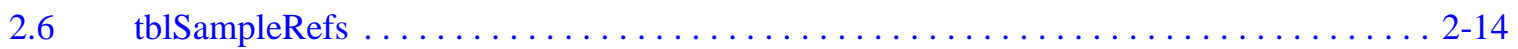

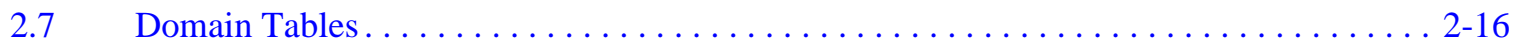

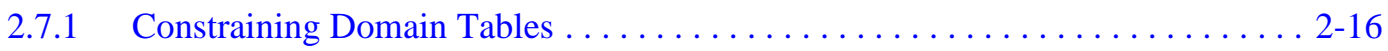

2.7.2 Additional Domain Tables............................ 2-17

$2.8 \quad$ Comment Tables . . . . . . . . . . . . . . . . . . . . . . . . . . . . . .

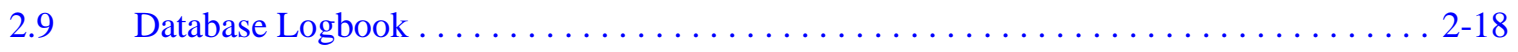

3.0 Database Installation and Navigation $\ldots \ldots \ldots \ldots \ldots \ldots \ldots \ldots \ldots \ldots \ldots \ldots \ldots \ldots \ldots \ldots \ldots \ldots \ldots \ldots$

3.1 GeochemXX.mdb Installation Instructions $\ldots \ldots \ldots \ldots \ldots \ldots \ldots \ldots \ldots \ldots \ldots \ldots \ldots \ldots \ldots \ldots \ldots$

3.2 Start-Up Navigation and Available Menu Options . . . . . . . . . . . . . . . . $3-2$

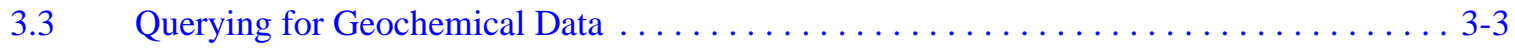

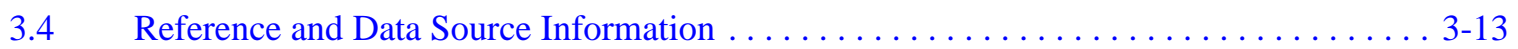

3.5 Generating a Time-Series Concentration Plot ..................... 3-14

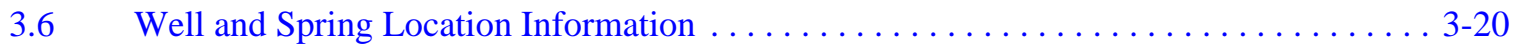

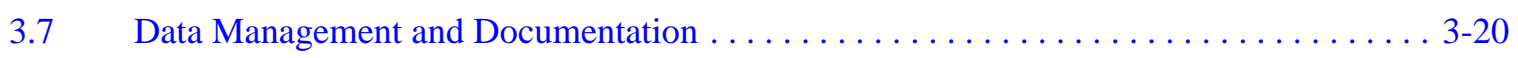

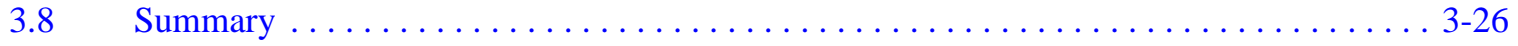

4.0 Data Sources and the Quality Control Program $\ldots \ldots \ldots \ldots \ldots \ldots \ldots \ldots \ldots \ldots \ldots \ldots \ldots$

$4.1 \quad$ Editing and Reconciliation Procedures $\ldots \ldots \ldots \ldots \ldots \ldots \ldots \ldots \ldots \ldots \ldots \ldots \ldots \ldots \ldots \ldots \ldots \ldots$

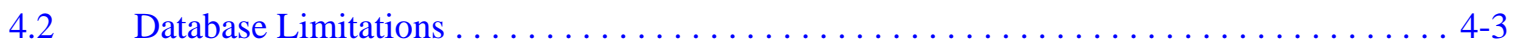

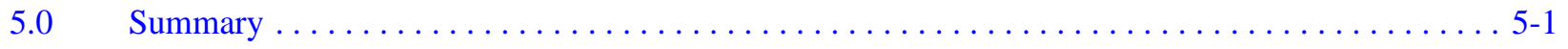

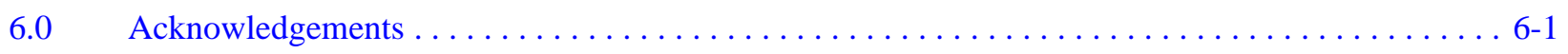




\section{List of Figures}

Number

2-1 Relationships Within GeochemXX.mdb $\ldots \ldots \ldots \ldots \ldots \ldots \ldots \ldots \ldots \ldots \ldots \ldots \ldots \ldots \ldots \ldots \ldots \ldots \ldots .2$

2-2 Relative Location of Section Modifiers ..............................

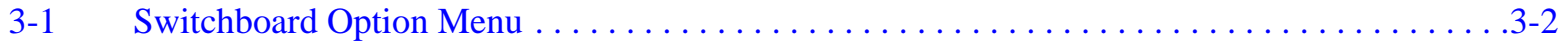

3-2 Viewing Objects Within the Database Window $\ldots \ldots \ldots \ldots \ldots \ldots \ldots \ldots \ldots \ldots \ldots \ldots \ldots \ldots \ldots$

3-3 Query for Geochemical Data Form. . . . . . . . . . . . .

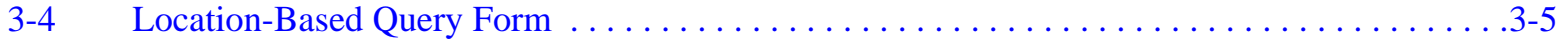

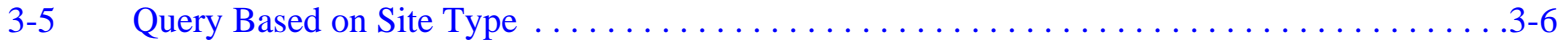

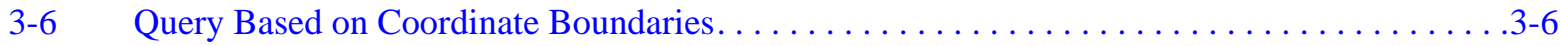

3-7 Query Based on Site Name Keyword. . . . . . . . . . . . . . . . . . . . . . .

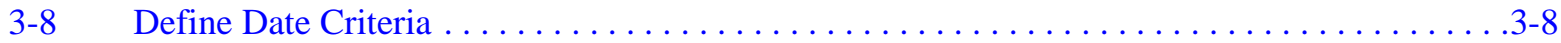

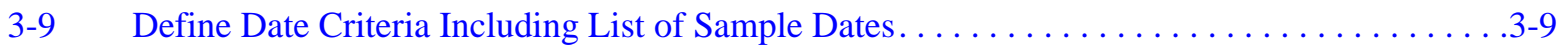

3-10 Define Parameter Criteria . . . . . . . . . . . .

3-11 Define Parameter Criteria Including Parameter Groupings . . . . . . . . . . . . . . . 3-10

3-12 Available Options for Viewing the Query Results . . . . . . . . . . . . . . . . . . . . . . . 3-11

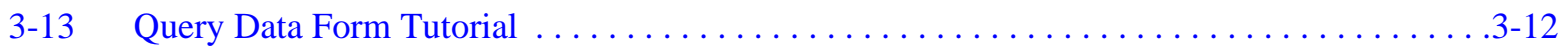

3-14 Advanced Query Design. . . . . . . . . . . . . . . . . . . . . . . . . . . . .

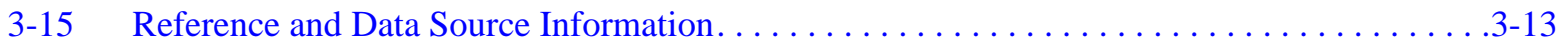

3-16 Viewing Reference and Available Data Source Information . . . . . . . . . . . . . . . 3-14

3-17 Options for Viewing the Data Associated with the Selected Reference and Data Source . . . . 3-15

3-18 Generating a Time-Series Concentration Plot $\ldots \ldots \ldots \ldots \ldots \ldots \ldots \ldots \ldots \ldots \ldots \ldots \ldots \ldots \ldots \ldots \ldots$

3-19 Time-Series Concentration Plot Single Location, Single Parameter . . . . . . . . . . . . . . 3-17

3-20 Time-Series Concentration Plot Single Location, Multiple Parameter . . . . . . . . . . . . . .3-18

3-21 Time-Series Concentration Plot Multiple Location, Single Parameter . . . . . . . . . . . . . .3-18

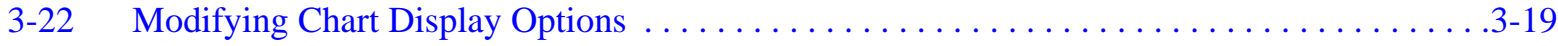

3-23 Browsing Well and Spring Location Information $\ldots \ldots \ldots \ldots \ldots \ldots \ldots \ldots \ldots \ldots \ldots \ldots \ldots \ldots \ldots$

3-24 Browse Database Documentation and Domain Tables. . . . . . . . . . . . . . .

3-25 Browse Database Documentation. . . . . . . . . . . . . . . . . . . . . . .

3-26 Table Summary and Data Field Information $\ldots \ldots \ldots \ldots \ldots \ldots \ldots \ldots \ldots \ldots \ldots \ldots \ldots \ldots \ldots \ldots$

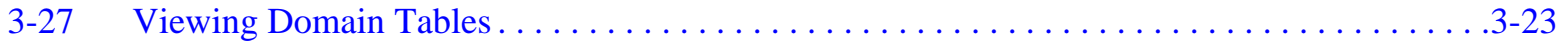

3-28 Parameter, Unit, and Procedural Information. . . . . . . . . . . . . . . . . . . 3-24 


\section{List of Figures (Continued)}

Number

Title

Page

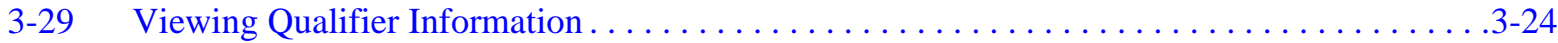

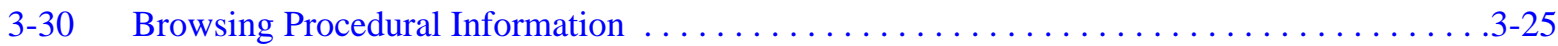

3-31 Data Documentation and Data Evaluation Flag Descriptions $\ldots \ldots \ldots \ldots \ldots \ldots \ldots \ldots . .25$ 


\section{List of Tables}

Number

Title

Page

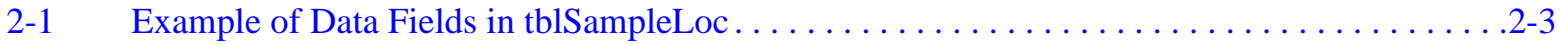

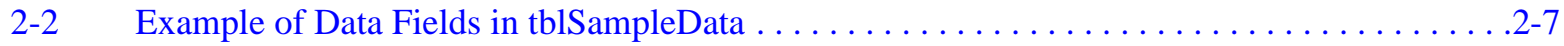

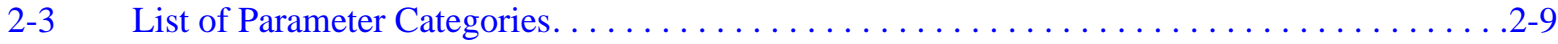

2-4 Example of Data Fields in tblSampleResults . . . . . . . . . . . . . . . . . . . 2-10

2-5 Example of Data Fields in tblColloid Results $\ldots \ldots \ldots \ldots \ldots \ldots \ldots \ldots \ldots \ldots \ldots \ldots \ldots \ldots \ldots$

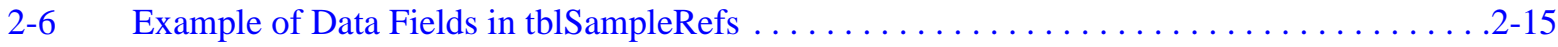

2-7 Constraining Domain Table Constituents.................... 


\section{List of Acronyms and Abbreviations}

ASTM American Society for Testing and Materials

BN Bechtel Nevada

${ }^{\circ} \mathrm{C} \quad$ Degrees Celsius

CD Compact disc

CDR Common Data Repository

DDF Data Documentation Flag

DEF Data Evaluation Flag

DOE U.S. Department of Energy

DRI Desert Research Institute

EPA U.S. Environmental Protection Agency

HRCES Harry Reid Center for Environmental Studies

IT IT Corporation

LANL Los Alamos National Laboratory

LLNL Lawrence Livermore National Laboratory

NNSA/NSO U.S. Department of Energy, National Nuclear Security Administration Nevada Site Office

NTS Nevada Test Site

NWIS National Water Information System

pCi/L Picocuries per liter

QA/QC Quality assurance/quality control

RCRA Resource Conservation and Recovery Act

REECo Reynolds Electrical \& Engineering Co., Inc.

SNJV Stoller-Navarro Joint Venture

UGTA Underground Test Area

USAF U.S. Air Force

USGS U.S. Geological Survey 


\subsection{Introduction}

This water quality database (viz.GeochemXX.mdb) has been developed as part of the Underground Test Area (UGTA) Program with the cooperation of several agencies actively participating in ongoing evaluation and characterization activities under contract to the U.S. Department of Energy (DOE), National Nuclear Security Administration Nevada Site Office (NNSA/NSO). The database has been constructed to provide up-to-date, comprehensive, and quality controlled data in a uniform format for the support of current and future projects.

This database provides a valuable tool for geochemical and hydrogeologic evaluations of the Nevada Test Site (NTS) and surrounding region. Chemistry data have been compiled for groundwater within the NTS and the surrounding region. These data include major ions, organic compounds, trace elements, radionuclides, various field parameters, and environmental isotopes. Colloid data are also included in the database.

The GeochemXX.mdb database is distributed on an annual basis. The extension "XX" within the database title is replaced by the last two digits of the release year (e.g., Geochem06 for the version released during the 2006 fiscal year). The database is distributed via compact disc (CD) and is also uploaded to the Common Data Repository (CDR) in order to make it available to all agencies with DOE intranet access. This report provides an explanation of the database configuration and summarizes the general content and utility of the individual data tables. In addition to describing the data, subsequent sections of this report provide the data user with an explanation of the quality assurance/quality control (QA/QC) protocols for this database.

A letter distributed with the database presents relevant information for the updates found in the current release. 


\subsection{Presentation of Data}

GeochemXX.mdb is a relational database, maintained in Microsoft Access ${ }^{\circledR}$. Data have been incorporated into six main tables: tblSampleLoc, tblSampleData, tblSampleResults, tblColloidResults, tblSampleRefs, and tblNFtestsData. These main tables are accompanied by several comment tables, domain tables, and a database logbook. These additional tables have been created for the purpose of clarification and to facilitate the management and extraction of data. The tables described within this section can be viewed through the Database Window within GeochemXX.mdb. The Database Window displays the database objects (Tables, Queries, Forms, Reports, Pages, Macros, and Modules) in tabular panes and can be accessed by simply pressing the F11 key on the keyboard. Selection of "Tables" will then reveal the names of all tables contained within the database. The specific table can then be selected for viewing or modification. A diagram of the relationships between the tables within GeochemXX.mdb is shown in Figure 2-1. To view these relationships within the database, select Tools on the toolbar, then Relationships. Supporting data dictionary documentation for each table can be viewed by right-clicking inside the table and then selecting

Table Design.

The remainder of this section will be spent explaining the contents, database relationships, and intended use of the tables found in the database.

\section{1 tb/SampleLoc}

The tblSampleLoc table contains location information for the sampling sites included within the database. An example of the data contained within the fields in the tblSampleLoc table is presented in Table 2-1. Each field is described as follows:

- Master_ID - Master Identification. Acts as a unique control number for each location. In most cases, the U.S. Geological Survey (USGS) site identification nomenclature has been used. This naming convention combines the geographical (degrees-minutes-seconds) latitude, longitude, and sequence into a numerical string that is unique to each location. In many instances (particularly for locations outside the NTS), this naming convention has been based on an estimated location. Wherever this convention has been used, efforts have been made to ensure that the numerical string can be matched to a corresponding site location in the USGS National Water Information System (NWIS). Some "Master_IDs" use an alpha-numeric text string for their control number. These locations have yet to be reconciled with NWIS or they are not included in NWIS. 


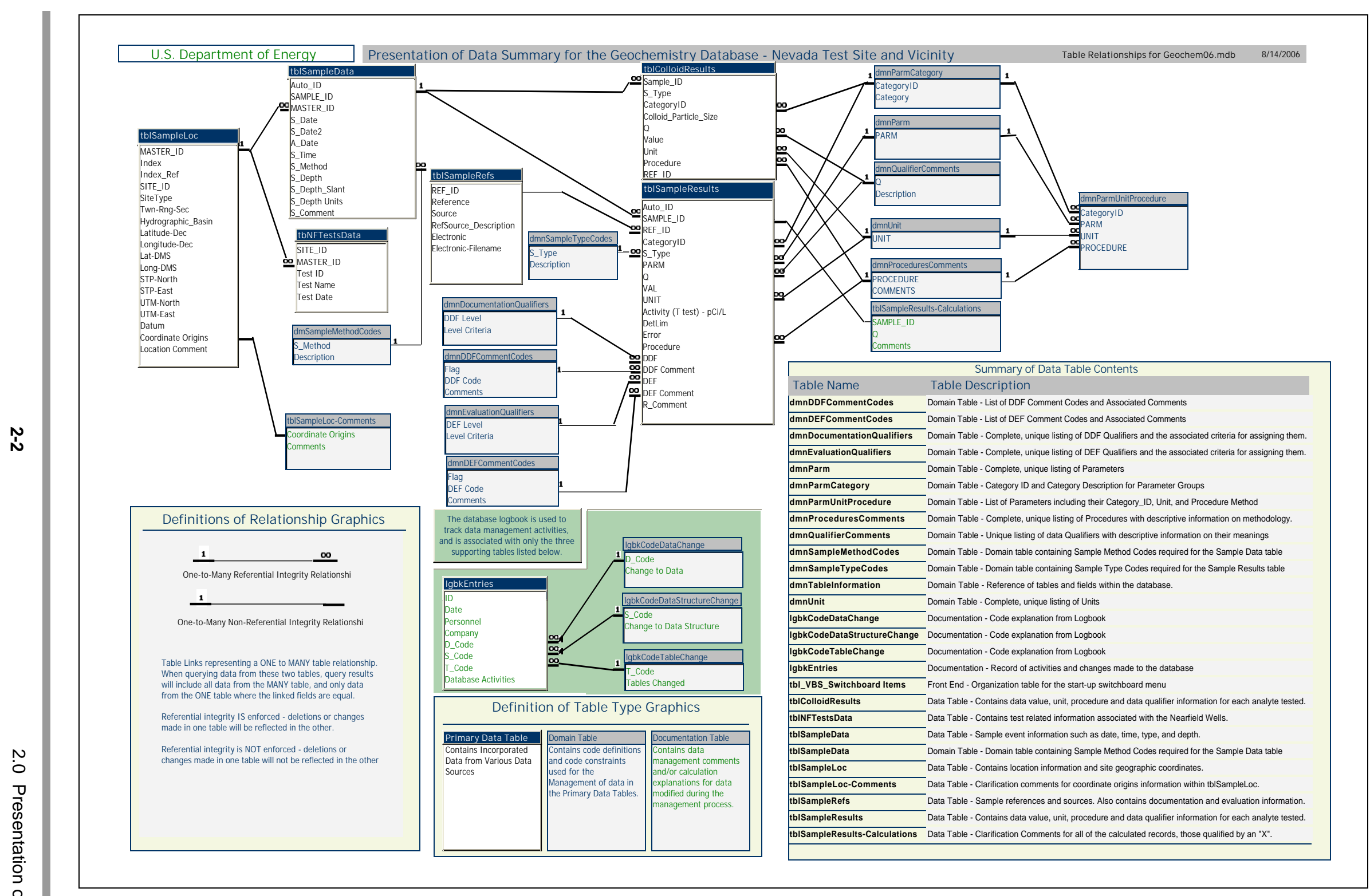

Figure 2-1

Relationships Within GeochemXX.mdb 
Table 2-1

Example of Data Fields in tb/SampleLoc

\begin{tabular}{|c|c|c|c|c|c|c|c|c|c|c|c|}
\hline MASTER_ID & Index & Index_Ref & SITE_ID & \begin{tabular}{|l|} 
Site \\
Type
\end{tabular} & Twn-Rng-Sect & $\begin{array}{c}\text { Hydrographic } \\
\text { Basin }\end{array}$ & $\begin{array}{l}\text { Latitude } \\
\text {-Dec }\end{array}$ & $\begin{array}{l}\text { Longitude } \\
\text {-Dec }\end{array}$ & Datum & $\begin{array}{l}\text { Coordinate } \\
\text { Origins }\end{array}$ & $\begin{array}{l}\text { Location } \\
\text { Comment }\end{array}$ \\
\hline 371117116122801 & 8 & Borehole Index & U12e.03, 9+20, Drift & Seep & 09S/52E-05-6 & $\begin{array}{c}\text { Sand } \\
\text { Spring-Tikaboo } \\
\text { Valleys }\end{array}$ & 37.19 & 116.21 & NAD27 & $\begin{array}{l}\text { USGS-NWIS } \\
(01 / 22 / 02)\end{array}$ & \\
\hline 371537116251501 & 18 & Borehole Index & ER-20-6 \#1 & Well & 08S/50E-08-7 & $\begin{array}{l}\text { Cactus-Sarcobatus } \\
\text { Flats }\end{array}$ & 37.26 & 116.42 & & $\begin{array}{c}\text { USGS-NWIS } \\
(01 / 22 / 02)\end{array}$ & \\
\hline 370116115561301 & 550 & Borehole Index & ER-3-1 \#1, deep & Well & $10 S / 54 E-35-1$ & $\begin{array}{c}\text { Sand } \\
\text { Spring-Tikaboo } \\
\text { Valleys }\end{array}$ & 37.02 & 115.94 & NAD27 & $\begin{array}{l}\text { USGS-NWIS } \\
(01 / 22 / 02)\end{array}$ & \\
\hline ER-3-1 & 550 & Borehole Index & ER-3-1 & Well & & $\begin{array}{l}\text { Sand } \\
\text { Spring-Tikaboo } \\
\text { Valleys }\end{array}$ & 37.02 & 115.94 & NAD27 & $\begin{array}{l}\text { Borehole Index } \\
\quad(10 / 30 / 01)\end{array}$ & \\
\hline 383556114545901 & 725 & DRI Spring Index & $\begin{array}{l}\text { Big Spring, Dry Lake } \\
\text { Valley }\end{array}$ & Spring & $09 N / 63 E-33-1$ & Dry Lake Valley & 38.60 & 114.92 & & $\begin{array}{l}\text { Spring Index } \\
(09 / 09 / 2003)\end{array}$ & $\begin{array}{l}\text { Reconciled with DRI } \\
\text { Spring Index }\end{array}$ \\
\hline 381305116414001 & 837 & DRI Spring Indx & Fourmile Spring & Spring & 04N/47E-10aaa1 & Ralston Valley & 38.22 & 116.69 & & $\begin{array}{l}\text { Spring Index } \\
(09 / 09 / 2003)\end{array}$ & $\begin{array}{l}\text { Reconciled with DRI } \\
\text { Spring Index }\end{array}$ \\
\hline 362324116163900 & 1433 & DRI Spring Index & Jack Rabbit Spring & Spring & $18 \mathrm{~S} / 51 \mathrm{E}-18-1$ & Panamint & 36.39 & 116.28 & & $\begin{array}{l}\text { Spring Index } \\
\text { (09/09/2003) }\end{array}$ & $\begin{array}{l}\text { Reconciled with DRI } \\
\text { Spring Index }\end{array}$ \\
\hline 362230116162001 & 1434 & DRI Spring Index & $\begin{array}{l}\text { Big Spring, Ash } \\
\text { Meadows }\end{array}$ & Spring & 18S/51E-19acb1 & Amargosa River & 36.37 & 116.27 & & $\begin{array}{l}\text { Spring Index } \\
(09 / 09 / 2003)\end{array}$ & $\begin{array}{l}\text { Reconciled with DRI } \\
\text { Spring Index }\end{array}$ \\
\hline Snake_Big & 1473 & DRI Spring Index & $\begin{array}{l}\text { Big Spring, Snake } \\
\text { Valley }\end{array}$ & Spring & & Hamlin & 38.70 & 114.13 & & $\begin{array}{l}\text { Spring Index } \\
(09 / 09 / 2003)\end{array}$ & $\begin{array}{l}\text { Lat/Long revised to } \\
\text { accurately locate } \\
\text { spring. }\end{array}$ \\
\hline 382214115285201 & 1534 & DRI Spring Index & $\begin{array}{c}\text { Big Spring, White River } \\
\text { Valley }\end{array}$ & Spring & $06 \mathrm{~N} / 58 \mathrm{E}-20-1$ & White River Valley & 38.37 & 115.48 & & $\begin{array}{l}\text { Spring Index } \\
(09 / 09 / 2003)\end{array}$ & $\begin{array}{l}\text { Reconciled with DRI } \\
\text { Spring Index }\end{array}$ \\
\hline 383922114375901 & 1535 & DRI Spring Index & $\begin{array}{c}\text { Big Spring North, Dry } \\
\text { Lake Valley }\end{array}$ & Spring & 09N/65E-12bd1 & Dry Lake Valley & 38.66 & 114.63 & & $\begin{array}{l}\text { Spring Index } \\
\text { (09/09/2003) }\end{array}$ & $\begin{array}{l}\text { Reconciled with DRI } \\
\text { Spring Index }\end{array}$ \\
\hline 383915114375901 & 1536 & DRI Spring Index & $\begin{array}{c}\text { Big Spring South, Dry } \\
\text { Lake Valley }\end{array}$ & Spring & 09N/65E-12ca1 & Dry Lake Valley & 38.65 & 114.63 & & $\begin{array}{l}\text { Spring Index } \\
(09 / 09 / 2003)\end{array}$ & $\begin{array}{l}\text { Reconciled with DRI } \\
\text { Spring Index }\end{array}$ \\
\hline 365904115593401 & 1939 & Borehole Index & ER-6-1 & Well & $11 S / 54 E-18-3$ & $\begin{array}{c}\text { Sand } \\
\text { Spring-Tikaboo } \\
\text { Valleys }\end{array}$ & 36.98 & 115.99 & NAD27 & $\begin{array}{l}\text { USGS-NWIS } \\
(01 / 22 / 02)\end{array}$ & \\
\hline 370301116185801 & 3809 & Borehole Index & ER-30-1 \#1, deep & Well & $10 S / 51 E-20-1$ & Upper Amargosa & 37.05 & 116.32 & NAD27 & $\begin{array}{l}\text { USGS-NWIS } \\
(01 / 22 / 02)\end{array}$ & \\
\hline 370301116185802 & 3809 & Borehole Index & ER-30-1 \#2, shallow & Well & $10 \mathrm{~S} / 51 \mathrm{E}-20-2$ & Upper Amargosa & 37.05 & 116.32 & NAD27 & $\begin{array}{l}\text { USGS-NWIS } \\
(01 / 22 / 02)\end{array}$ & \\
\hline
\end{tabular}

Note: The data shown in this table are for demonstrative purposes only and should not be used for further reporting or calculations. The following six data fields are not shown in this example: Lat-DMS, Long-DMS, STP-North, STP-East, UTM-North, UTM-East. 
The site name from the original reporting source has often been retained as an alternative to the USGS numerical identifier.

- Index - Location Index. Numerical value assigned to a given sample site that corresponds to either the Borehole Index or the Desert Research Institute (DRI) Spring Database.

- Index_Ref - Index Reference. Identifies the source of the Index.

- $\quad$ Site_ID - Site Identification. Unique name for a given sample location. Compiling data from multiple information sources has resulted in multiple reporting names for many sample locations. Some data sources use variations on a common name while others use variations on geographical location (e.g., township, range, and section information) as site identifiers. Wherever possible this information has been reconciled into a single reporting name in the "Site_ID" field consistent with the NTS Redbook, NWIS database, or the DRI Spring Database. In order to distinguish locations with similar reporting names, the "Site_ID" is a combination of the common name and either the township, range and section location, or the hydrographic region.

- Twn-Rng-Sect - Township, Range, and Section Information. The township, range, and section information is further qualified by section modifiers. Section modifiers further divide the section into $1 / 4$-section, $1 / 4-1 / 4$-section, and $1 / 4-1 / 4-1 / 4$-section, using a string of letters that corresponds to a predetermined location within the section (Figure 2-2). The first letter in the string (a, b, c, or d) is assigned to a $1 / 4$-section location in a counterclockwise fashion. Subsequent letters in the string continue to modify the location in a similar fashion, providing cartographic resolution down to a $1 / 4-1 / 4-1 / 4$-section scale. For incidences where there are multiple sample locations having the same township, range, section, and section modifier, a numerical sequence number is added to the end of the section modifier-string. Sequence numbers are assigned based on the order in which the sample point was established.

- $\quad$ SiteType - Type of Sampling Location. Identifies the site as either a Nearfield Well, Monitoring Well, Domestic Well, Irrigation Well, Municipal Well, Spring, Seep, Precipitation Station, or Stream.

- Hydrographic Basin - Identifies the specific hydrographic basin in which the site is located.

- $\quad$ Latitude-Dec and Longitude-Dec - Decimal Latitude and Longitude Coordinates. Describes the geographical decimal coordinate locations for each site. Decimal coordinates have been used as the common reporting coordinates for this database. Other reporting coordinates are Lat-DMS, Long-DMS, STP-North, STP-East, UTM-North, and UTM-East. Locations lacking geographic coordinate information will be reconciled with outside sources as additional information becomes available in subsequent versions of the database. 


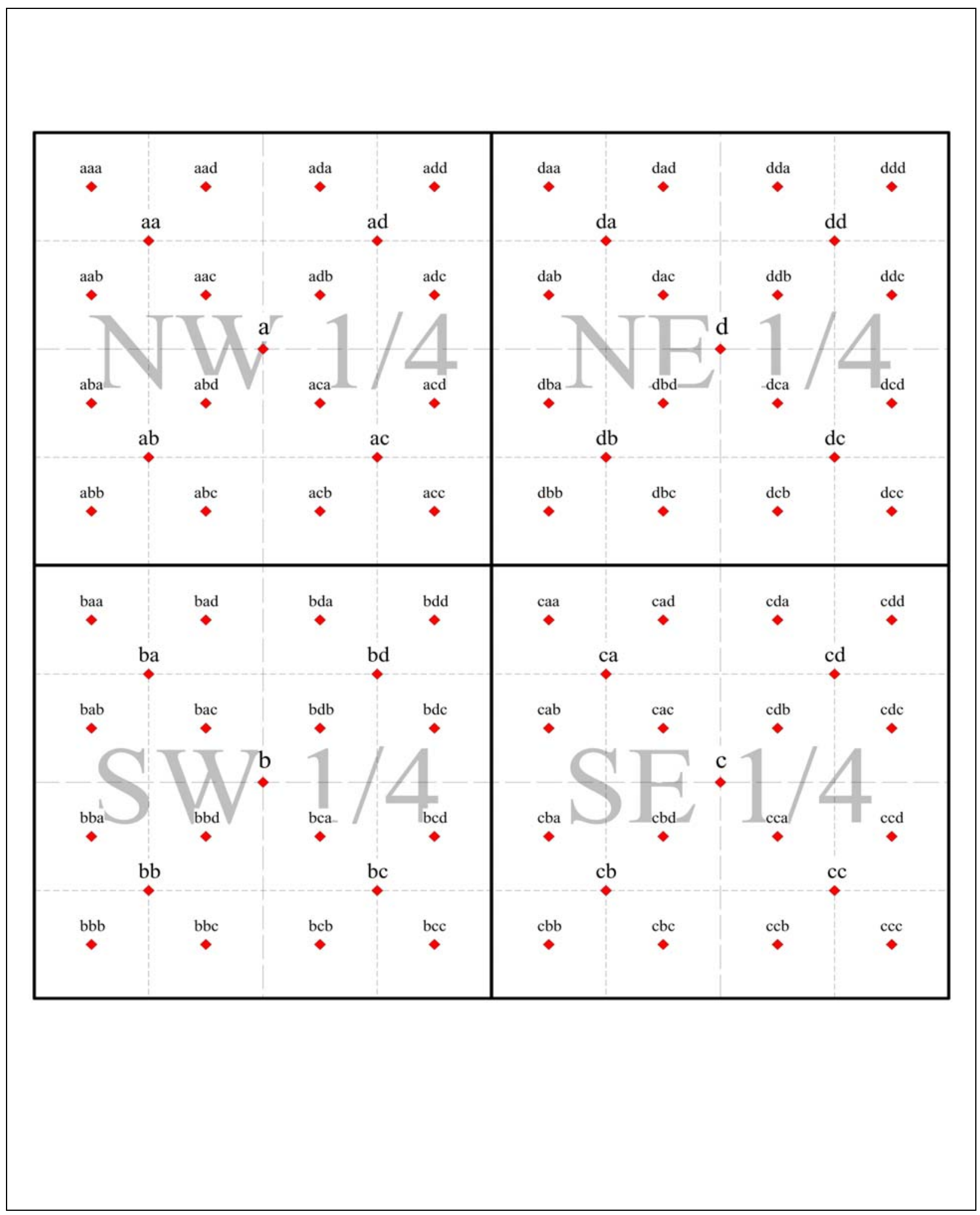

Figure 2-2

Relative Location of Section Modifiers 
- Datum - Coordinate Datum. Identifies the standardized coordinate/elevation datum.

- Coordinate Origins - Describes the source of the coordinates, further described in the tblSampleLocComments table.

- Location Comment - Reports comments regarding the location reconciliation process.

\section{2 tblSampleData}

The tblSampleData table contains information unique to a particular sample or sampling event. An example of this information is provided in Table 2-2.

The "Sample_ID" acts as a unique control number, distinguishing sample events based on sample collection dates, sample collection times, sampling agency, reported activity dates for radionuclide data, sampling methods, and sampling depths. The data contained in the tblSampleData table are linked to geographic location information in the tblSampleLoc table using the "Master_ID." Each field in the tblSampleData table is summarized as follows:

- Auto_ID - AutoNumber Identification. An automatically generated number to enhance database integrity.

- Sample_ID - Sample Identification. Data control number assigned by the database manager for the purpose of linking sampling event information to analytical results for the sample. Note: The "Sample_ID" for a duplicate sample is given an extension of ".5" and a "Sample_ID" for colloid is given an extension of ".7."

- Master_ID - Master Identification. Correlates to the "Master_ID” field in the tblSampleLoc table and is used to link sampling event information to geographic location information.

- S_Date - Sample Date. Sample collection date is reported in a "yyyymmdd" text format. It is possible that the related sample results correspond to a known sampling event for a given location; however, if this information was not reported in the original source, it has been reported as "N/A" (not available) in the database.

- S_Date2 - Sample Date. Sample collection date reported in a "mm/dd/yyyy" numerical format. If this information was not reported in the original source, this field has been left blank.

- A_Date - Activity Date. Distinguishes between reported radionuclide activity dates and sample collection dates. For those radionuclide parameters where this field is blank, it is assumed that the activity date corresponds to the sample collection date. Where it has been confirmed that this is the case, the "A_Date” field reports the same value as the 
Table 2-2

Example of Data Fields in tb/SampleData

\begin{tabular}{|c|c|c|c|c|c|c|c|c|c|c|c|}
\hline Auto ID & Sample_ID & Master_ID & S_Date & S_Date2 & A_Date & S_Time & S_Method & S_Depth_Slant & S_Depth & $\begin{array}{l}\text { S_Depth } \\
\text { Units }\end{array}$ & S_Comment \\
\hline 1 & 4018 & $\begin{array}{c}\text { Jackass Flats Well } \\
\text { No. } 1\end{array}$ & 19570918 & 09/18/1957 & & N/A & $\mathrm{dd}$ & & 1327 & feet BGS & \\
\hline 2 & 304 & 361833115372501 & 19800722 & 7/22/1980 & & 1500 & & & & & \\
\hline 3 & 305 & 361835115153701 & 19950314 & 3/14/1995 & & $\mathrm{N} / \mathrm{A}$ & & & & & \\
\hline 4 & 306 & 361840115153901 & 19820517 & $5 / 17 / 1982$ & & 1230 & dd & & 91.44 & meters & \\
\hline 5 & 307 & 361840115153901 & 19820823 & 8/23/1982 & & 1000 & dd & & 91.44 & meters & \\
\hline 6 & 4016 & 362324116163900 & 19661115 & 11/15/1966 & & $\mathrm{N} / \mathrm{A}$ & & & & & \\
\hline 7 & 4017 & 362324116163900 & 19701015 & $10 / 15 / 1970$ & & N/A & & & & & \\
\hline 8 & 4019 & $\begin{array}{c}\text { Jap Ranch Contact } \\
\text { Spring }\end{array}$ & 19661120 & 11/20/1966 & & 1245 & & & & & \\
\hline 9 & 4020 & Jean Prison Well & 19850621 & 06/21/1985 & & $\mathrm{N} / \mathrm{A}$ & c & & & & \\
\hline 10 & 5145 & 370514116024101 & 19990817 & 08/17/1999 & & $\mathrm{N} / \mathrm{A}$ & $\mathrm{dd}$ & 975 & 914 & meters & \\
\hline 11 & 5146 & 370514116024101 & 19950719 & 07/19/1995 & 19810115 & $\mathrm{~N} / \mathrm{A}$ & & & 549 & meters & \\
\hline 12 & 5147 & 370514116024101 & 19950719 & 07/19/1995 & 19810115 & $\mathrm{~N} / \mathrm{A}$ & & & 584 & meters & \\
\hline 13 & 5148 & 370520116025701 & 19930831 & 08/13/1993 & 19930920 & $\mathrm{~N} / \mathrm{A}$ & & & 496 & meters & \\
\hline 14 & 9016 & 371425116251901 & 19870720 & 07/20/1987 & & $\mathrm{N} / \mathrm{A}$ & & & 2400 & $\mathrm{ft}$ & \\
\hline 15 & 11736 & 371453116205700 & 19950719 & 07/19/1995 & 19810115 & $\mathrm{~N} / \mathrm{A}$ & $\mathrm{dd}$ & & 427 & meters & \\
\hline 16 & 12147 & 370338116011901 & 19770930 & 09/30/1977 & & & c & & $512-527$ & $\mathrm{~m}$ & $\begin{array}{l}\text { well purge volume } \\
\qquad 13.63 \mathrm{~m}^{3}\end{array}$ \\
\hline 17 & 12153 & 370338116011901 & 19770929 & 09/29/1977 & & & c & & $512-527$ & $\mathrm{~m}$ & $\begin{array}{c}\text { well purge volume } \\
3.79 \mathrm{~m}^{3}\end{array}$ \\
\hline
\end{tabular}

Note: The data shown in this table are for demonstrative purposes only and should not be used for further reporting or calculations. 
"S_Date" field. Where the reported activity date precedes the sample collection date, the radionuclide activities are reported according to the indicated time zero $\left(\mathrm{t}_{0}\right)$. Where the reported activity date supersedes the sample collection date, the radionuclide activities are reported to a sample analysis or sample extraction date.

- $\quad$ S_Time - Sample Time. Sample collection time is reported in a 24-hour "hhmm" format. Sample collection times have been included whenever they have been reported in the original source. Sample collection times are useful for distinguishing between multiple sampling events for the same parameters on the same day.

- S_Method - Sample Method. Describes discrete depth or composite sampling. In addition, this field identifies duplicate and replicate samples. Duplicate samples are further distinguished as field duplicates (i.e., separate samples collected in the field) and laboratory duplicates (i.e., a single sample that is collected in the field and split in the laboratory for analysis). Codes assigned are described in the dmnSampleMethodCodes table.

- S_Depth_Slant - Slant Sampling Depth. Describes the slant distance of a sample collection point along the well bore below ground surface.

- S_Depth - Sample Depth. Describes the vertical sampling depth or sampling depth interval information.

- S_Depth Units - Sample Depth Units. Units associated with the sampling depth and sampling depth interval information. In some cases, this field includes distance information relative to a test cavity.

- S_Comment - Sampling Comment. Reports comments provided by the data source regarding sample collection.

\section{3 tblSampleResults}

The tblSampleResults table contains analytical results and methodology for specific samples or sampling events. An example of this information is provided in Table 2-4. The tblSampleResults table is linked to sample information in the tblSampleData table using the "Sample_ID." The tblSampleResults table is the primary data table. There are several domain tables that describe the contents of several of the fields within the tblSampleData table. Each field within the tblSampleResults table and its relationship to other tables is summarized as follows:

- Auto_ID - AutoNumber Identification. A number automatically generated to enhance database integrity and provide unique identification for sample results data. 
- Sample_ID - Sample Identification. Correlates to the "Sample_ID" field in the tblSampleData table and is used to link analytical results and analytical methodology to sample information. Although "Sample_IDs" in the tblSampleData table are unique, they can be repeated multiple times with different parameters in the tblSampleResults table.

- REF_ID - Reference Identification. Correlates to the "Ref_ID" field in the tblSampleRefs table and is used to link analytical results and analytical methodology to the original reporting source. In many instances, there are multiple data sources reporting diverse analytical information for a given sampling event. Similarly, a given data source typically reports data for multiple sampling events or sample locations. Hence, values for "Ref ID," though unique in the tblSampleRefs table, may be repeated multiple times in the tblSampleResults table.

- CategoryID - Parameter Category Identification. The "CategoryID” is used to group types of sample analyses into categories. Used specifically in the front-end user interface options. The eight categories are listed in Table 2-3 as well as in the dmnParmCategory domain table.

Table 2-3

List of Parameter Categories

\begin{tabular}{|c|c|}
\hline CategoryID & Category \\
\hline \hline 1 & Minor and Trace Constituents \\
\hline 2 & Environmental Isotope and Tracers \\
\hline 3 & Radionuclides \\
\hline 4 & Organics and Hydrocarbons \\
\hline 6 & Colloids \\
\hline 7 & QA/QC \\
\hline 10 & Major Constituents \\
\hline 11 & \\
\hline
\end{tabular}

- $\quad$ S_Type - Sample Type. Describes the type of the sample (filtered, unfiltered, tube, grab, drum) associated with the result record.

- PARM - Parameter. Analyte, parameter, and test names from original data sources have been reconciled as much as possible. As a result of this reconciliation process, a parameter domain table, $d m n$ Parm, has been compiled to standardize, wherever possible, the reporting format for the equivalent analyses. The "PARM" field is linked to the $d m n P a r m$ table, ensuring parameter name compatibility for any new data entries or data modifications. Specification of "Total" and "Dissolved" in the parameter name corresponds to whether the sample was not filtered or filtered, respectively. 
Table 2-4

Example of Data Fields in tb/SampleResults

\begin{tabular}{|c|c|c|c|c|c|c|c|c|c|c|c|c|c|c|c|c|c|}
\hline Auto ID & $\underset{\text { ID }}{\text { Sample }}$ & $\begin{array}{l}\text { REF } \\
\text { ID }\end{array}$ & $\begin{array}{c}\text { Category } \\
\text { ID }\end{array}$ & S_Type & PARM & Q & VAL & $\begin{array}{l}\text { Activity } \\
\text { (T test)- } \\
\text { pCilL }\end{array}$ & Unit & DetLim & Error & Procedure & R_Comment & DDF & $\begin{array}{c}\text { DDF } \\
\text { Comment }\end{array}$ & DEF & $\begin{array}{c}\text { DEF } \\
\text { Comment }\end{array}$ \\
\hline 7660 & 1 & 63 & 11 & $f$ & $\mathrm{Cl}$, Dissolved & & 17.8 & & $\mathrm{mg} / \mathrm{L}$ & & & $\begin{array}{c}\text { EPA } 325.1 \text { and } \\
300.0\end{array}$ & & 4 & D1 & u & E1 \\
\hline 7671 & 1 & 63 & 11 & $f$ & Mg, Dissolved & & 2.1 & & $\mathrm{mg} / \mathrm{L}$ & & & EPA 242.1 & & 4 & D1 & $u$ & E1 \\
\hline 7670 & 1 & 63 & 1 & $f$ & SiO2, Dissolved & & 70 & & $\mathrm{mg} / \mathrm{L}$ & & & Not Available & & 4 & D1 & $u$ & E1 \\
\hline 7668 & 1 & 63 & 3 & $f$ & Tritium, Total & & 16 & & $\mathrm{pCi} / \mathrm{L}$ & & & Not Available & & 4 & D1 & $u$ & E1 \\
\hline 7675 & 2 & 41 & 11 & $f$ & $\mathrm{Ca}$, Dissolved & & 115 & & $\mathrm{mg} / \mathrm{L}$ & & & Not Available & & 5 & D1 & $u$ & E1 \\
\hline 7672 & 2 & 41 & 11 & $f$ & HCO3, Dissolved & & 195 & & $\mathrm{mg} / \mathrm{L}$ & & & Not Available & & 5 & D1 & $u$ & E1 \\
\hline 7674 & 2 & 41 & 6 & $f$ & $\mathrm{pH}$ & & 7.95 & & $\mathrm{pH}$ units & & & Not Available & & 5 & D1 & $u$ & E1 \\
\hline 7890 & 22 & 77 & 1 & $f$ & NO3, Dissolved & Trace & -7777 & & $\mathrm{mg} / \mathrm{L}$ & & & Not Available & & 5 & D1 & $u$ & E1 \\
\hline 7903 & 24 & 77 & 11 & $f$ & CO3, Dissolved & ND & -9999 & & $\mathrm{mg} / \mathrm{L}$ & & & Not Available & & 5 & D1 & $u$ & E1 \\
\hline 8669 & 84 & 62 & 11 & $f$ & $\mathrm{Ca}$, Dissolved & & 126 & & $\mathrm{mg} / \mathrm{L}$ & & & USGS 00915 & & 4 & D1 & $u$ & E1 \\
\hline 8672 & 84 & 62 & 11 & $f$ & $\mathrm{Cl}$, Dissolved & & 2010 & & $\mathrm{mg} / \mathrm{L}$ & & & USGS 00940 & & 4 & D1 & $u$ & E1 \\
\hline 8667 & 84 & 62 & 1 & $f$ & F, Dissolved & & 4.8 & & $\mathrm{mg} / \mathrm{L}$ & & & USGS 00950 & & 4 & D1 & $u$ & E1 \\
\hline 8666 & 84 & 62 & 11 & $f$ & SO4, Dissolved & & 763 & & $\mathrm{mg} / \mathrm{L}$ & & & USGS 00945 & & 4 & D1 & $u$ & E1 \\
\hline 90106 & 3911 & 72 & 2 & & $\mathrm{He}-4$ & & $4.89 \mathrm{E}+12$ & & atoms $/ \mathrm{mL}$ & & & $\begin{array}{c}\text { Mass } \\
\text { Spectrometry }\end{array}$ & & 3 & D1 & $u$ & E1 \\
\hline 90125 & 3911 & 72 & 2 & & Sr-87/Sr-86 & & 0.71175 & & ratio & & $\pm 2 \mathrm{E}-5$ & Not Available & & 3 & D1 & $u$ & E1 \\
\hline 90094 & 3911 & 72 & 3 & & Sr-90 & $<$ & 0.5 & & $\mathrm{pCi} / \mathrm{L}$ & & & TIP-RAS-141 & & 3 & D1 & $u$ & E1 \\
\hline 90098 & 3911 & 72 & 3 & uf & Tritium & & 361 & & $\mathrm{pCi} / \mathrm{L}$ & & \pm 34 & TIP-RAS-011 & & 3 & D1 & $u$ & E1 \\
\hline 90129 & 3911 & 72 & 3 & & $\mathrm{U}-234 / \mathrm{U}-238$ & & 0.000275 & & ratio & & $\pm 3 E-7$ & Not Available & & 3 & D1 & $u$ & E1 \\
\hline 135569 & 10309 & 311 & 1 & uf & Mn, Total & $<$ & 0.0025 & & $\mathrm{mg} / \mathrm{L}$ & 0.0025 & & EPA 200.7 & & 5 & D9 & $u$ & E1 \\
\hline 135571 & 10309 & 311 & 11 & uf & $\mathrm{Na}$, Total & & 77 & & $\mathrm{mg} / \mathrm{L}$ & 0.25 & & EPA 200.7 & & 5 & D9 & $u$ & E1 \\
\hline 139386 & 12132 & 373 & 3 & uf & Tritium & & 9890100 & $8.59 \mathrm{E}+07$ & $\mathrm{pCi} / \mathrm{L}$ & & & LSC & & 1 & D1 & & E1 \\
\hline 139387 & 12132 & 373 & 3 & $f$ & U-234, Dissolved & & 10.51947 & $1.05 E+01$ & $\mathrm{pCi} / \mathrm{L}$ & & & calculated & 0.45 um filter & 1 & D1 & & E1 \\
\hline
\end{tabular}

Note: The data shown in this table are for demonstrative purposes only and should not be used for further reporting or calculations. 
- Q - Data Qualifier. Data qualifiers from the original sources have been standardized as much as possible. For qualifiers having the same meaning, changing them to a uniform format facilitates the use of the data. A qualifier domain table, dmnQualifierComments, has been created for the purpose of explaining what each data qualifier means.

- VAL - Value, Analytical Result. This is the numerical value as reported in the original data source. In some cases, conversions of, or calculations based on, the original data have been included. Whenever this has been done, the converted data are qualified appropriately and the record is linked to the tblSampleResults-Calculations table, which describes the rationale behind and the methodology used in converting the original data. In instances where a result has been reported as nondetectable, in the absence of a detection limit, a numerical data flag has been used. Numerical data flags are always used in conjunction with a data qualifier. Accordingly, their use and meanings can be found in the dmnQualifierComments qualifier domain table.

- Activity (T test) - pCi/L - Measured activity corrected to zero time of the nuclear test. The tests and dates of tests corresponding to these activity values are reported in the tblNFTestsData table.

- $\quad$ UNIT - Analytical result reporting units. Reporting units have typically been retained from the original data sources.

- DetLim - Analytical Detection Limit. The limit of detection (or quantitation) that is associated with the measured parameter value.

- Error - Analytical Error. Describes the uncertainty associated with the measured parameter value reported by the original data source.

- Procedure - Reports the analytical method, procedure, or parameter code cited in the original data source where this information was available. Wherever possible, standard methodology (i.e., American Society for Testing and Materials [ASTM] or U.S. Environmental Protection Agency [EPA] methods) has been cited. In some cases, laboratory-specific standard operating procedures or types of analysis have been given. The USGS electronic data transfers used parameter codes for identifying test names and analytical methodology. Where available, these parameter codes have been reported in the "Procedure" field. The associated USGS methodology and a more detailed description of the procedures reported in this field can be found in the $d m n$ ProceduresComments table. The procedure domain table has been linked to the "Procedure" field, ensuring reporting consistency and compatibility for any new data entries or modifications.

- R_Comment - Results Comment. Reports comments regarding parameter measurements and results. 
- DDF - Data Documentation Flag. Numerical criteria based on a scale of 1 to 5 , where a value of " 1 " denotes the highest quality of documentation and a " 5 " is the lowest. Complete descriptions of the established criteria used to assign the Data Documentation Flags (DDFs) are found in the dmnDocumentationQualifiers DDF domain table.

- DDF Comment - Comment codes used to elaborate on the assignment of the DDF for a particular data source or individual results within the data source. These codes are described in the dmnDDFCommentCodes domain table.

- DEF - Data Evaluation Flag. Assigns a text abbreviation based on the quality of the actual data results. A " $\mathrm{C}$ " is used to denote data results that are consistent, an "NC" is used to denote inconsistent data results, and a "U" is used wherever the consistency of the data are unknown. Complete descriptions of the established criteria used to assign the Data Evaluation Flags (DEFs) are found in the dmnEvaluationQualifiers DEF domain table.

- DEF Comment - Comment codes used to elaborate on the assignment of the DEF for a particular data source or individual results within the data source. These codes are described in the dmnDEFCommentCodes domain table.

\section{4 tb/ColloidResults}

The tblColloidResults table contains analytical colloid measurements and methodology for specific samples or sampling events. The colloid data correspond to sampling events for which analytical chemistry data are available within the tblSampleResults table. Table 2-5 provides an example of the tblColloidResults table format. The table-linking relationships and data-field presentation for the tblColloidResults table are similar to that found in the tblSampleResults table. Colloid data are linked to individual sample events in the tblSampleData table. Each field and its relationship to other tables is summarized as follows:

- Sample_ID - Sample Identification. Correlates to "Sample_ID" in the tblSampleData table. This field links analytical colloid measurements and measurement methodology to sample and/or sampling event information. Although the "Sample_IDs" in the tblSampleData table are unique, they can be repeated multiple times with different parameters in the tblColloidResults table.

- Ref_ID - Reference Identification. Links analytical colloid measurements and measurement methodology to the original reported source described in the tblSampleRefs table. A given data source typically reports data for multiple sampling events or sample locations. Hence, values for "Ref_ID," though unique in the tblSampleRefs table, may be repeated multiple times in the tblColloidResults table. 
Table 2-5

Example of Data Fields in tbIColloid Results

\begin{tabular}{|c|c|c|c|c|c|c|c|c|c|}
\hline Sample_ID & Ref_ID & S_Type & CategoryID & Colloid_Particle_Size & Q & Value & Unit & ERROR & Procedure \\
\hline 4922.7 & 237 & uf & 7 & Particle Size, 50-60 nm & $<$ & 801000 & particles/mL & & Not Available \\
\hline 4922.7 & 237 & uf & 7 & Particle Size, $60-70 \mathrm{~nm}$ & & 1034820 & particles $/ \mathrm{mL}$ & & Not Available \\
\hline 4922.7 & 237 & uf & 7 & Particle Size, $70-80$ nm & & 970140 & particles $/ \mathrm{mL}$ & & Not Available \\
\hline 4922.7 & 237 & uf & 7 & Particle Size, 80-90 nm & & 830840 & particles/mL & & Not Available \\
\hline 4922.7 & 237 & uf & 7 & Particle Size, 90-100 nm & & 736320 & particles/mL & & Not Available \\
\hline 4922.7 & 237 & uf & 7 & Particle Size, $100-110 \mathrm{~nm}$ & & 691540 & particles $/ \mathrm{mL}$ & & Not Available \\
\hline 4922.7 & 237 & uf & 7 & Particle Size, $190-200 \mathrm{~nm}$ & & 119400 & particles/mL & & Not Available \\
\hline 4922.7 & 237 & uf & 7 & Particle Size, >200 nm & & 129360 & particles/mL & & Not Available \\
\hline 7465.71 & 237 & & 7 & Particle Size, $50 \mathrm{~nm}$ & & 8685600 & particles $/ \mathrm{mL}$ & & Not Available \\
\hline 7465.71 & 237 & & 7 & Particle Size, 60 nm & & 9184600 & particles/mL & & Not Available \\
\hline 7465.71 & 237 & & 7 & Particle Size, $70 \mathrm{~nm}$ & & 7387600 & particles $/ \mathrm{mL}$ & & Not Available \\
\hline
\end{tabular}

Note: The data show in this table are for demonstrative purposes only and should not be used for further reporting or calculations.

- $\quad$ S_Type - Sample Type. Describes the type of the sample (filtered, unfiltered, tube, grab, drum) associated with the result record uncertainty associated with the colloid parameter measurement.

- CategoryID - Colloid Category Identification. The "CategoryID” is used to group types of sample analyses into categories and is used specifically in the front-end user interface options.

- Colloid_Particle_Size - Particle size or particle size range. Particle size and size ranges represent those reported in the original data sources.

- $\quad$ Q - Data Qualifier. Data qualifiers from the original sources have been standardized as much as possible. For qualifiers having the same meaning, changing them to a uniform format facilitates the use of the data. A qualifier domain table has been created for the purpose of explaining what each data qualifier means.

- VaL - Value, Analytical Result. Measured analytical result as reported in the original data source. In instances where a result has been reported as nondetectable, in the absence of a detection limit, a numerical data flag has been used. Numerical data flags are always used in conjunction with a data qualifier. Accordingly, their use and meanings can be found in the qualifier domain table.

- Unit - Analytical-result reporting units. Reporting units have been retained from the original data sources.

- ERror - Analytical Error. Describes the uncertainty associated with the measured parameter value reported by the original data source. 


\section{5 tbINFTestsData}

- Procedure - Reports the analytical method, procedure, or parameter code cited in the original data source where this information was available. Wherever possible, standard methodology (i.e., ASTM or EPA methods) has been cited. In some cases, laboratory-specific standard operating procedures or types of analysis have been given. A more detailed description of the procedures reported in this field can be found in the dmnProceduresComments table. The procedure domain table has been linked to the "Procedure" field, ensuring reporting consistency and compatibility for any new data entries or modifications.

The tblNFTestsData table contains information pertinent to identifying the test associated with a specific near-field well. The tblNFTestsData table is linked to information in the tblSampleLoc table using the "Master_ID" field. Each field and its relationship to other tables is summarized as follows:

- Master_ID - Master Identification. Correlates to the "Master_ID" field in the tblSampleLoc table and is used to link testing information to geographic location information.

- Site_ID - Site Identification. Correlates to the "Site_ID" field in the tblSampleLoc table.

- Test_ID - Test Identification. Emplacement Hole Identification.

- Test Name - Name of test associated with the near-field well.

- Test Date - Date of detonation.

\section{6 tb/SampleRefs}

The tblSampleRefs table contains information pertinent to identifying the original data source and evaluating the quality of the data. An example of this information is provided in Table 2-6. The tblSampleRefs table is linked to analytical information in the tblSampleResults table using the "Ref_ID" field. Each field and its relationship to other tables is summarized as follows:

- Ref_ID - Reference Identification. Data control number used to link data reference and source information to individual sample results in the tblSampleResults table.

- Reference - For publications, this is the source from which the data were extracted for integration into the database. For electronic data transmittals, personal communications, and other types of unpublished data, this is a description unique to the data source. 
Table 2-6

Example of Data Fields in tblSampleRefs

\begin{tabular}{|c|c|c|c|c|c|c|}
\hline Ref_ID & Reference & RefSource_Description & Bibliography & Source & Electronic & $\begin{array}{l}\text { Electronic } \\
\text { Filename }\end{array}$ \\
\hline 49 & Malmberg and Eakin (1962) & $\begin{array}{l}\text { Nevada Groundwater Resource Reconnaissance } \\
\text { Series Report 10, } 39 \text { pages, US Geological Survey; } \\
\text { Groundwater Appraisal of Sarcobatus flat and Oasis } \\
\text { Valley, Nye and Esmerelda counties. }\end{array}$ & $\begin{array}{l}\text { Malmberg, G.T., and T.E. Eakin. } 1962 . \\
\text { Groundwater Appraisal of Sarcobatus Flat and } \\
\text { Oasis Valley, Nye and Esmerelda Counties, } \\
\text { Groundwater Resource Reconnaissance Series } \\
\text { Report 10. Carson City, NV: State of Nevada. }\end{array}$ & N/A & TRUE & Malmb606.wb1 \\
\hline 50 & McKinley et al. (1991) & $\begin{array}{l}\text { U.S. Geological Survey Open File Report 90-355, } 47 \\
\text { pages; Chemical analyses of Water from Selected } \\
\text { Wells and Springs in the Yucca Mountain area, } \\
\text { Nevada and Southeastern California. Accompanied } \\
\text { by digital copies of the data tables, received March 1, } \\
1993 .\end{array}$ & $\begin{array}{l}\text { McKinley, P.W., M.P. Long, and L.V. Benson. } \\
\text { 1991. Chemical Analyses of Water from Selected } \\
\text { Wells and Springs in the Yucca Mountain Area, } \\
\text { Nevada and Southeastern California, } \\
\text { USGS-OFR-90-355. Denver, CO: U.S. Geological } \\
\text { Survey. }\end{array}$ & Benson et al. (1983) & TRUE & OFR90-355.exe \\
\hline 51 & McKinley et al. (1991) & $\begin{array}{l}\text { U.S. Geological Survey Open File Report 90-355, } 47 \\
\text { pages; Chemical analyses of Water from Selected } \\
\text { Wells and Springs in the Yucca Mountain area, } \\
\text { Nevada and Southeastern California. Accompanied } \\
\text { by digital copies of the data tables, received } \\
\text { March 1, 1993. }\end{array}$ & $\begin{array}{l}\text { McKinley, P.W., M.P. Long, and L.V. Benson. } \\
\text { 1991. Chemical Analyses of Water from Selected } \\
\text { Wells and Springs in the Yucca Mountain Area, } \\
\text { Nevada and Southeastern California, } \\
\text { USGS-OFR-90-355. Denver, CO: U.S. Geological } \\
\text { Survey. }\end{array}$ & $\begin{array}{l}\text { Czarnecki Unpublished } \\
\text { data }\end{array}$ & TRUE & OFR90-355.exe \\
\hline 105 & DRI (1998 Pers. Comm.) & $\begin{array}{l}\text { Courtesy of Ron Hershey, Desert Research } \\
\text { Institute-Water Resource Center, 7010 Dandini Blvd., } \\
\text { Reno, NV 89512; Compilation of field parameters, } \\
\text { sample event information, carbon 13, oxygen 18, and } \\
\text { deuterium data for } 21 \text { sites from the Nov-97 Oasis } \\
\text { Valley sampling event. }\end{array}$ & & Ron L. Hershey (DRI) & FALSE & $\begin{array}{l}\text { Data not available in } \\
\text { an electronic format }\end{array}$ \\
\hline 106 & DRI (1998 Pers. Comm.) & $\begin{array}{l}\text { Courtesy of Ron Hershey, Desert Research } \\
\text { Institute-Water Resource Center, } 7010 \text { Dandini Blvd., } \\
\text { Reno, NV 89512; Compilation of major ion and } \\
\text { dissolved constituent data for } 21 \text { sites from the Nov-97 } \\
\text { Oasis Valley sampling. }\end{array}$ & & $\begin{array}{l}\text { Ron L. Hershey (WRC } \\
\text { Waterlab) }\end{array}$ & FALSE & $\begin{array}{l}\text { Data not available in } \\
\text { an electronic format }\end{array}$ \\
\hline 107 & DRI (1998 Pers. Comm.) & $\begin{array}{l}\text { Courtesy of Ron Hershey, Desert Research } \\
\text { Institute-Water Resource Center, } 7010 \text { Dandini Blvd., } \\
\text { Reno, NV 89512; Compilation of major ion and } \\
\text { dissolved constituent data for } 21 \text { sites from the Nov-97 } \\
\text { Oasis Valley sampling. }\end{array}$ & & $\begin{array}{l}\text { Ron L. Hershey (WRC } \\
\text { Waterlab) }\end{array}$ & FALSE & $\begin{array}{l}\text { Data not available in } \\
\text { an electronic format }\end{array}$ \\
\hline 111 & USGS (1998 Pers. Comm.) & $\begin{array}{l}\text { Courtesy of Jim Paces, U.S. Geological Survey, } \\
\text { Denver, CO; Dissolved uranium activity ratios for the } \\
\text { Nov-1997 Oasis Valley sampling event, summarized } \\
\text { in a table dated January 15, } 1998 .\end{array}$ & & $\begin{array}{l}\text { Jim B. Paces } \\
\text { (USGS-Denver) }\end{array}$ & FALSE & $\begin{array}{l}\text { Data not available in } \\
\text { an electronic format }\end{array}$ \\
\hline 112 & USGS Electronic & $\begin{array}{l}\text { Oliver and Root; unpublished (1997). Electronic } \\
\text { compilation of isotope and ion data for Yucca Mtn; as } \\
\text { per memo from Thomas Oliver (USGS) to Robert } \\
\text { Craig (USGS) on July 21, 1997. }\end{array}$ & & $\begin{array}{c}\text { Thomas Oliver (07/22/97); } \\
\text { YuccaMtn. Data }\end{array}$ & TRUE & Yucca.xls \\
\hline 114 & GCP00485 & $\begin{array}{l}\text { Courtesy of IT Corporation, } 2621 \text { Losee Rd., Bldg B-1, } \\
\text { Suite 3050-01, N. Las Vegas, NV 89030; Sample } \\
\text { results corresponding to the sample identified under } \\
\text { the UGTA-GCP naming convention. Digital data } \\
\text { transmittal originating from the IT Environmental } \\
\text { Monitoring System (ITEMS) Database. }\end{array}$ & & GCP00485 & TRUE & $\begin{array}{l}\text { GCP Trace Metal } \\
\text { Data.xls }\end{array}$ \\
\hline
\end{tabular}

Note: The data shown in this table are for demonstrative purposes only and should not be used for further reporting or calculations. 
- RefSource_Description - Reference Source Description. Description of the data source.

- Bibliography - Bibliographic citations for the data source.

- $\quad$ Source - Agency and/or individual from which the data originated. This may be the laboratory, a contact within an organization, another database, or the primary publication cited as a source within the referenced publication.

- Electronic - A check field to indicate that the data source is available electronically.

- Electronic-Filename - Reference to the specific name of the electronic file.

\subsection{Domain Tables}

Thirteen domain tables have been created primarily for the purpose of database maintenance. These tables have several additional uses aside from data entry and modification applications. Eleven of the domain tables are linked directly to corresponding fields in the main data tables, as described earlier in this report. The remaining two domain tables are qualitative in nature and are intended to give the user a better understanding of data reporting conventions and the type of data available in the database.

\subsubsection{Constraining Domain Tables}

Constraints have been established for the links between the data tables and the domain tables (Table 2-7). These constraints require inclusion in the appropriate domain table before a value, code, or reporting name can be entered in the main data tables. By requiring consistency between data fields in the main data tables and the domain tables, reporting and format inconsistencies have been eliminated from the database.

Before new data are entered into the database, parameter names, reporting units, analytical procedures, DDF and DEF comment codes, and sampling locations are reconciled between the constraining domain tables and the corresponding data table. In the interest of preserving original data, new data items that cannot be reconciled with existing reporting conventions are used to update the domain tables accordingly. Descriptions of each of the constraining domain tables and their relationships to the main data tables are summarized in the following sections. 
Table 2-7

Constraining Domain Table Constituents

\begin{tabular}{|c|c|c|c|}
\hline Domain Table & Imposed Constraint & Main Data Table & Constrained Field \\
\hline dmnParm & $\begin{array}{c}\text { Ensures formatting consistency among } \\
\text { the reported parameter names }\end{array}$ & tblSampleResults & Parm \\
\hline dmnUnit & $\begin{array}{l}\text { Ensures appropriateness and } \\
\text { formatting consistency of reported units }\end{array}$ & tblSampleResults & Unit \\
\hline dmnProceduresComments & $\begin{array}{l}\text { Ensures appropriateness and } \\
\text { formatting consistency for analytical } \\
\text { procedures, methodology, and } \\
\text { parameter codes }\end{array}$ & tblSampleResults & Procedure \\
\hline dmnDocumentationQualifers & $\begin{array}{l}\text { Lists the numerical data documentation } \\
\text { flag-codes and describes the } \\
\text { established criteria for assigning them }\end{array}$ & tblSampleRefs & DDF \\
\hline dmnEvaluationQualifiers & $\begin{array}{l}\text { Lists the codes used as data evaluation } \\
\text { flags and provides descriptions of the } \\
\text { rationale used to assign them }\end{array}$ & tblSampleRefs & DEF \\
\hline dmnQualifierComments & $\begin{array}{l}\text { Provides detailed definitions of specific } \\
\text { data qualifiers }\end{array}$ & tblSampleResults & Q \\
\hline dmnParmCategory & $\begin{array}{c}\text { Ensures appropriateness and } \\
\text { formatting consistency of Parameter } \\
\text { categories. }\end{array}$ & tblSampleResults & Category ID \\
\hline dmnSampleMethodCodes & $\begin{array}{l}\text { Lists the codes used to describe } \\
\text { sample collection methodology }\end{array}$ & tblSampleData & S_Method \\
\hline dmnSampleTypeCodes & $\begin{array}{l}\text { Lists the codes used to describe } \\
\text { sample types }\end{array}$ & tblSampleResults & S_Type \\
\hline dmnDDFCommentCodes & $\begin{array}{l}\text { Lists the codes and comments } \\
\text { associated with the DDF Qualifiers }\end{array}$ & tblSampleResults & DDF Comment \\
\hline dmnDEFCommentCodes & $\begin{array}{l}\text { Lists the codes and comments } \\
\text { associated with the DEF Qualifiers }\end{array}$ & tbISampleResults & DEF Comment \\
\hline
\end{tabular}

\subsubsection{Additional Domain Tables}

The dmnParmUnitProcedure table lists a unique combination of fields from the tblSampleResults table. It was created for the explicit purpose of showing the user what types of data are available. Specifically, the table shows what type of analytical results are available, how they are reported, and how they were analyzed. Because this table lists different combinations of information from the tblSampleResults table, none of the fields within this domain table contain unique information, which excludes this table from use as a constraining domain table. The final domain table is the dmnTableInformation table, which provides a reference of available information within the database by summarizing table descriptions and detailing table contents.

\subsection{Comment Tables}

Two comment tables have been created within the database. The tblSampleLocComment table elaborates and provides detailed descriptions of the abbreviations used in the "Coordinate Origins" field of the tblSampleLoc table. 
The tblSampleResults-Calculations table describes the rationale behind including calculated or converted data results in addition to the formulas used to convert from originally reported units.

\subsection{Database Logbook}

The lgbkEntries table is used to document any additions, deletions, or modifications to the database. The logbook documents database activities since 1998. The first field, "ID," assigns a sequential value to each of the logbook entries. The next three fields track the database activity dates, the individual(s) responsible for the modifications, and the agency with whom they are affiliated. The following three fields use numerical codes for describing the nature of changes made and the tables affected by the particular database activity. The lgbkEntries table is linked to three supporting tables (i.e., lgbkCodeDataChange, lgbkCodeDataStructureChange, and lgbkCodeTableChange), which provide explanations for these numerical codes. The final field provides a detailed description of the database activity.

To make utilization and review of the logbook more efficient, entries are viewed using a query named "New Logbook Entry." This is an updatable query that displays the main logbook table and all three of the supporting logbook change-code tables. Because this query displays all of the change descriptions and comments at one time, it is recommended for monitoring recent database activities.

A printable report titled "rptlogbook" is also available in GeochemXX.mdb. This report summarizes all database maintenance activities. This logbook is available through either the Reports option in the Database Window or by using the Navigation Menus within GeochemXX.mdb. These options are described in Section 3.0. 


\subsection{Database Installation and Navigation}

Recognizing that not all potential database users are proficient in the application of querying capabilities within Microsoft Access ${ }^{\circledR}$, the database has been distributed with a series of forms (front ends) for facilitating navigation through, and extraction from, the primary data and domain tables within the database. This section offers an overview of the front-end capabilities and provides detailed instruction as needed for ensuring effective and successful navigation of the database.

\subsection{GeochemXX.mdb Installation Instructions}

1.) Save the Microsoft Access ${ }^{\circledR}$ file, GeochemXX.mdb, to a directory with both read and write access (e.g., a personal computer hard drive or a user-accessible network drive).

2.) Open up Microsoft Explorer ${ }^{\circledR}$ or file manager and locate the GeochemXX.mdb file.

3.) Select the GeochemXX.mdb file. Access the file Properties by right-clicking on the GeochemXX.mdb file. Alternatively, single-click on the GeochemXX.mdb to make it selectable, then left-click on File on the menu bar at the top of the screen. Scroll down and left-click on Properties.

4.) Select the General file properties tab. File access attributes are displayed at the bottom of the General file properties tab.

5.) Remove the check mark from the Read-Only attribute check box and click the Archive check box. This will enable write/rewrite capabilities within the GeochemXX.mdb file, and is necessary for proper operation of the database navigation menu items.

6.) The remaining documentation files on the distribution CD can be opened directly from the CD, or from a user accessible hard drive or network drive, using Adobe Acrobat ${ }^{\circledR}$ Reader. Acrobat ${ }^{\circledR}$ Reader is available as a free download from the Adobe website, http://www.adobe.com. 


\subsection{Start-Up Navigation and Available Menu Options}

Upon opening the database, the user will be presented with a switchboard listing the available menu options (Figure 3-1). The switchboard serves as the control center for all of the front-end applications. Selecting a button on the main switchboard takes the user automatically to a form for the associated task.

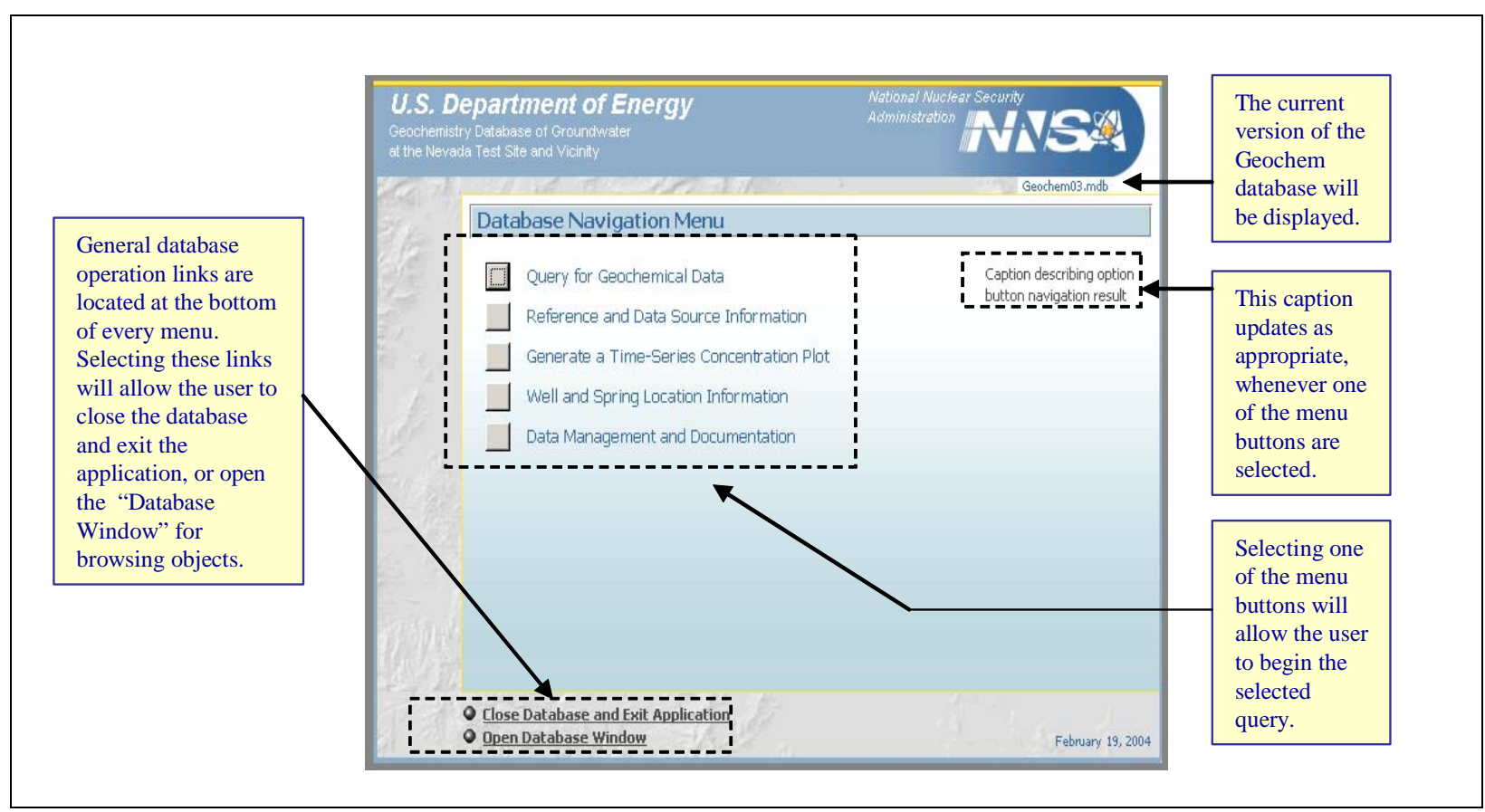

Figure 3-1

Switchboard Option Menu

The menu options available within GeochemXX are:

Query for Geochemical Data - This option enables the user to conduct a query of the primary data tables coupled with a capability of viewing and exporting datasets in a variety of formats.

Reference and Data Source Information - This option allows the user to view reference and data source descriptions, in addition to documentation and evaluation criteria assessments for individual sources. Moreover, the capabilities exist to view individual datasets attributed to each of the unique referenced data sources in either a record or a cross-tabular format.

Generate a Time-Series Concentration Plot - This option provides the user with the capability of viewing temporal concentration data, based on one of three search/display formats:

- $\quad$ Single Location - Single Parameter

- $\quad$ Single Location - Multiple Parameter

- Multiple Location - Single Parameter 
Well and Spring Location Information - This option allows the user to view geographical information for sample locations. Information regarding ongoing location reconciliation processes are also included.

Data Management and Documentation - This option allows the user to view the database logbook, domain tables, and other data documentation forms.

Detailed instructions for using each of these menu options are included in the sections that follow.

Once the user is directed to the form associated with each of the main menu options, return access to the main switchboard can be achieved by selecting the Return to Main Navigation Menu button located at the bottom left-hand corner of each option-form.

For those with a working familiarity with Microsoft Access ${ }^{\circledR}$, and for those who have become accustomed to using earlier versions of the database, navigation of the objects within the database can be conducted through the Database Window (Figure 3-2). The Database Window can be viewed at anytime, simply by pressing the F11 key on the keyboard or by selecting the link on the bottom of the navigation menu. The Database Window organizes and displays the database objects in tabular panes and provides an alternative means for navigating through the database objects. A separate pane exists for Tables, Queries, Forms, Reports, Pages, Macros, and Modules. Within each pane, individual database objects can be opened for viewing or modification (Figure 3-2).

\subsection{Querying for Geochemical Data}

The Query for Geochemical Data option provides the user with the capability of querying for comprehensive geochemical datasets using a limited and basic search criterion. Following selection of this option, the navigation window will be updated to the form shown in Figure 3-3. The predesigned geochemical data query offered through the navigation forms is completed through a series of four steps:

Step 1. Define Location Criteria. Five options are available for the selection of locations to be included in the query (Figure 3-3):

- Select From List of All Site Names - Allows for the selection of a maximum of four locations from a list of all sample locations included in the database.

- Select From List Grouped by Site Type - Allows for the selection of a maximum of four locations from a list of specific types of locations (Surface Water, Ground Water, or Precipitation Stations).

- Select From List Grouped by Region - Allows for the selection of a maximum of four hydrographic regions.

- Use Coordinate Boundaries - Allows for a query of sample locations within a specified range of boundaries.

- Keyword Search on Site Name - Allows for a query of locations based on a specific keyword. 


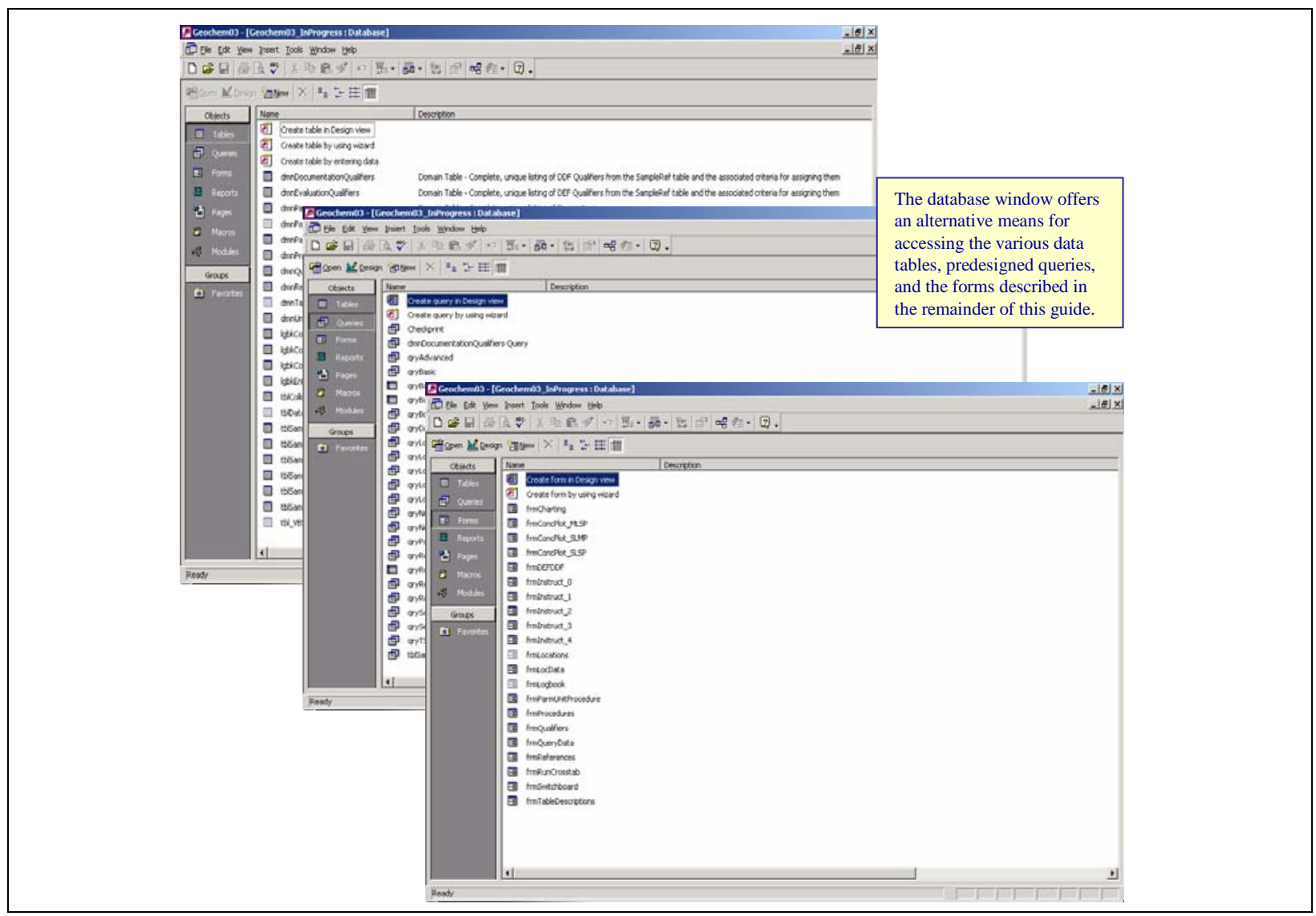

Figure 3-2

Viewing Objects Within the Database Window

Left-clicking on the first option, Select From List of All Site Names, will update the navigation window to include a list of sample location Site IDs as shown in Figure 3-4. Up to four selections can be made. To select more than one location, simply select the first location, hold down the Ctrl key, then select the next desired location.

Left-clicking on Select From List Grouped by Site Type will update the navigation window to include a list of options describing the various location types as shown in Figure 3-5. Once the Site Type of interest is selected, update the list of the associated Site IDs by left-clicking on the Re-Group Site ID List button. Similarly, a list of hydrographic regions will be revealed upon the selection of a specific hydrographic region. The Site IDs associated with the selected hydrographic region will be updated by left-clicking on the Re-Group Site ID List button. Up to four hydrographic regions may be selected.

Selection of Use Coordinate Boundaries allows the user to enter a range of coordinates in one of three coordinate systems (Decimal Degrees, Nevada State Planar, and Universal Transverse Mercator [Figure 3-6]). Decimal degrees are the common reporting coordinate within GeochemXX.mdb. Selection of decimal degrees will therefore result in the most complete set of query results. 


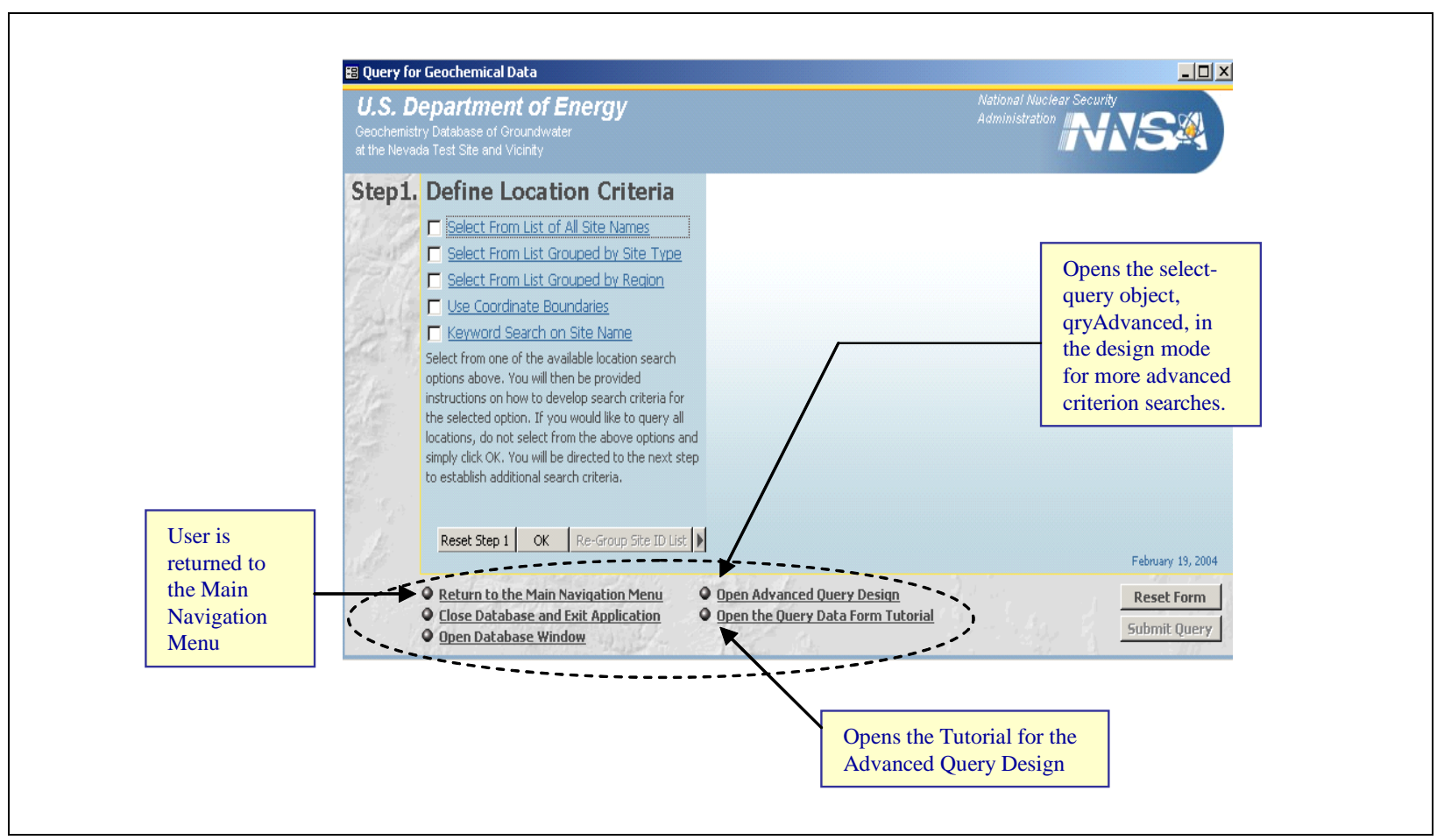

Figure 3-3

Query for Geochemical Data Form

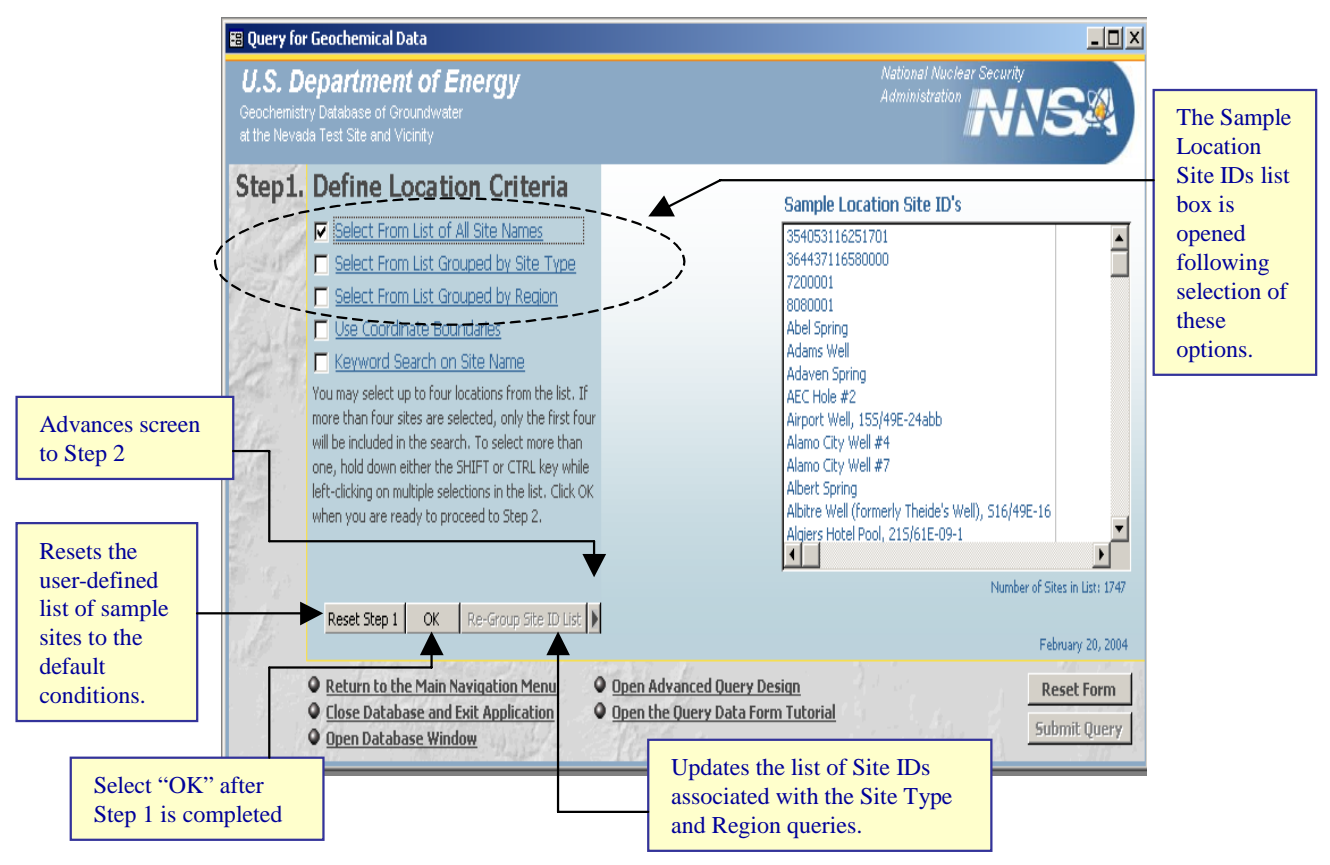

Figure 3-4

Location-Based Query Form 


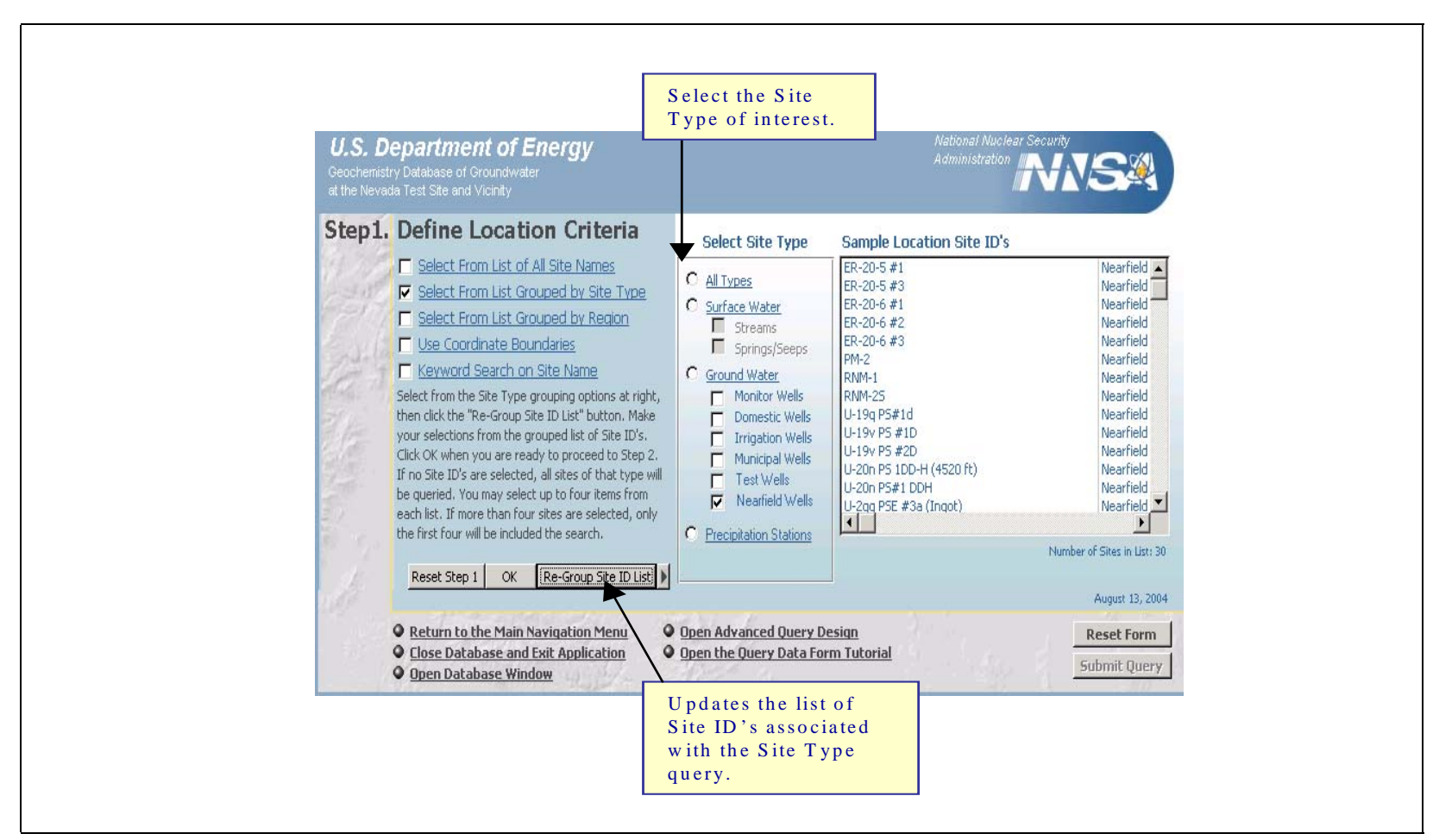

Figure 3-5

Query Based on Site Type

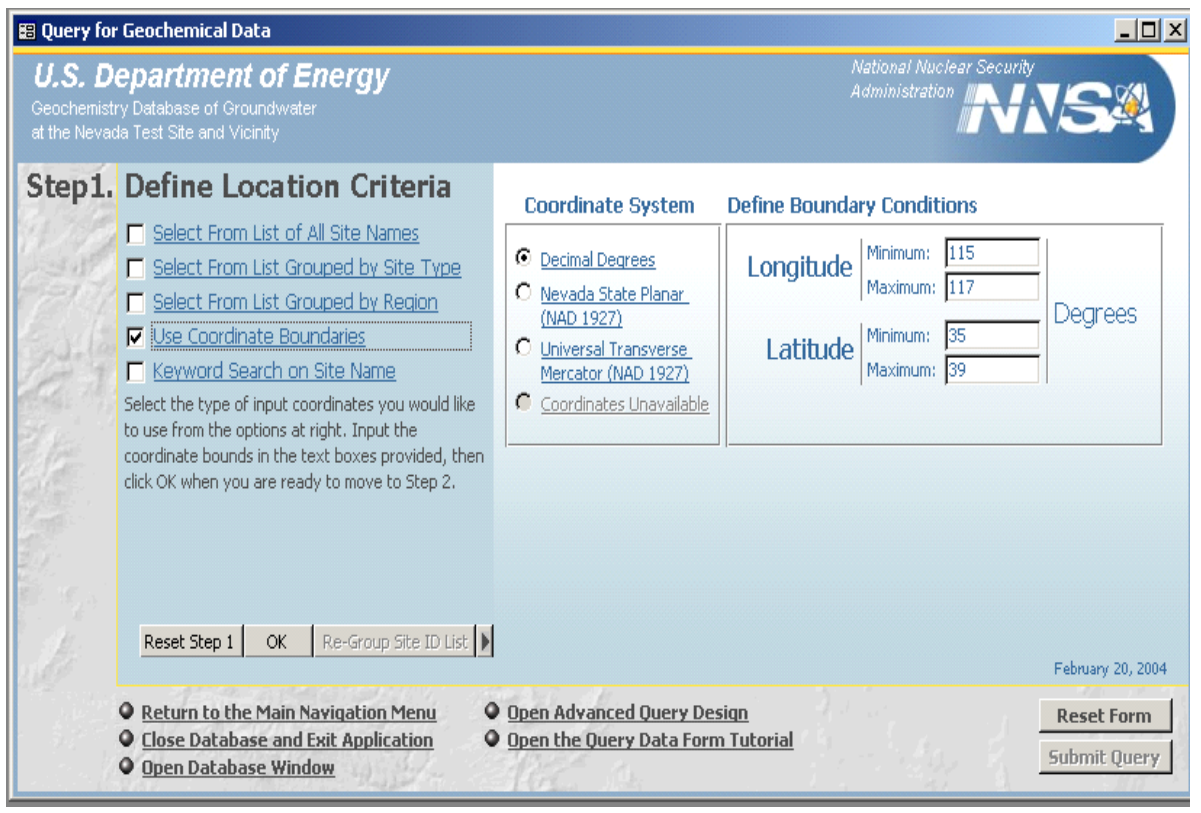

Figure 3-6

Query Based on Coordinate Boundaries 
Selection of Keyword Search on Site Name allows for a query of sample locations or a group of similarly named locations based on a user-defined keyword. As shown in Figure 3-7, a keyword as well as an operator is entered. Users are given the capability of using one of three operators: "LIKE," "NOT LIKE," or “=”. The asterisk $(*)$ should be used as a wildcard when qualifying the location search criteria with either "LIKE" or "NOT LIKE." Conversely, when using the "=” qualification, the user must type in the Site_ID exactly.

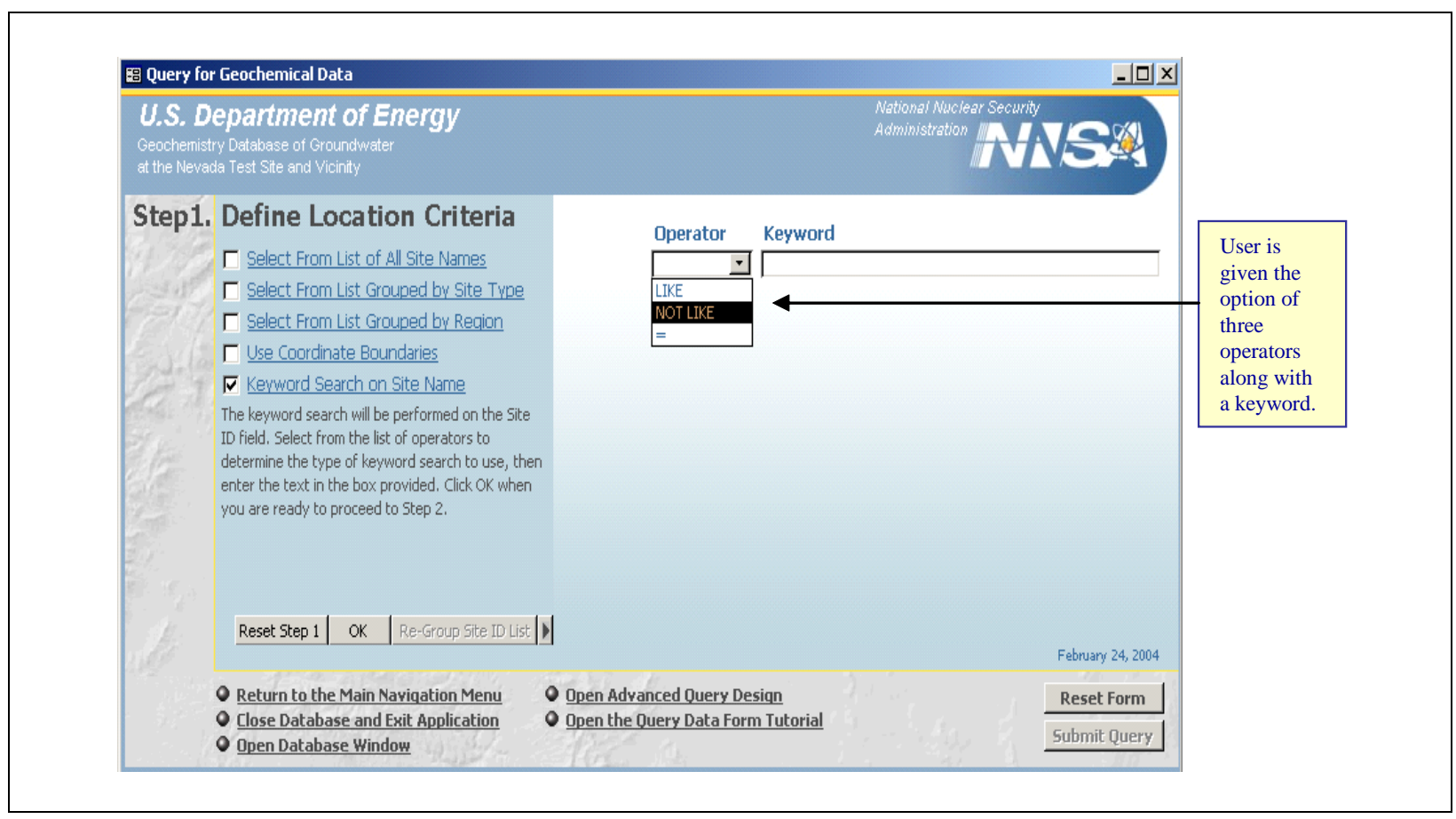

\section{Figure 3-7 \\ Query Based on Site Name Keyword}

Following the completion of Step 1, select $\mathbf{O K}$.

Step 2. Define Date Criteria. Three options are available for the selection of sample dates to be included in the query (Figure 3-8).

- Search for All Sample Dates - Query results will list data for all sampling events associated with the location(s) and parameter(s) established in the search criteria. Choosing this option will not establish a limiting search criteria based on sample collection dates.

- Select from a List of Sample Dates - The user has the capability of selecting up to four specific sampling dates from the scrolling list box.

- Specify a Range of Sample Dates - The user has the capability of searching for data from a particular time period. Query results will list data for samples collected AFTER a certain date, BEFORE a certain date, or a combination that bounds the search to data collected within a specific time interval. 


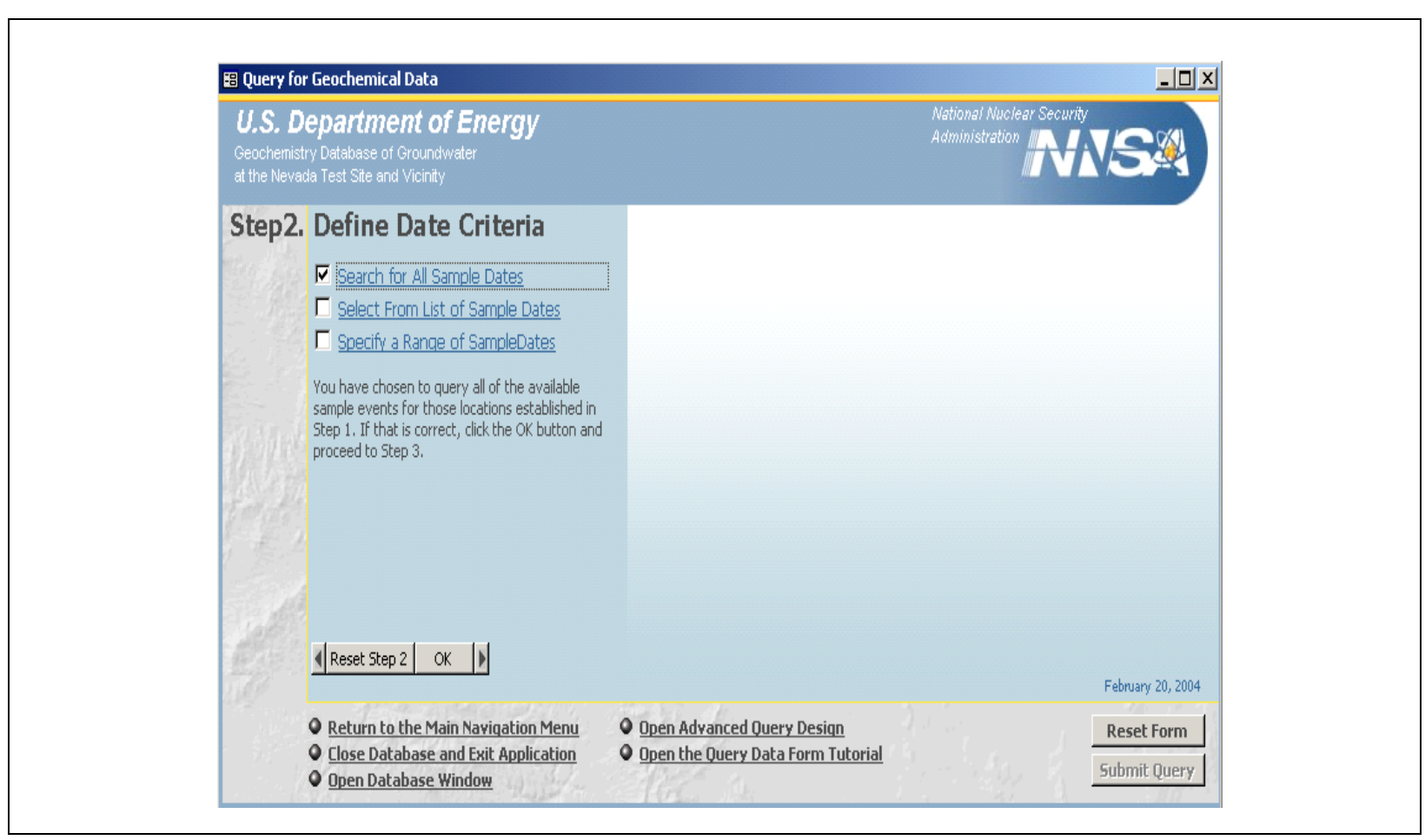

\section{Figure 3-8 \\ Define Date Criteria}

Choosing either Select from a List of Sample Dates or Specify a Range of Sample Dates will update the navigation window to include a list of all sample dates available within the database. When you choose to specify a range of sample dates, you will be allowed the entry of a range of sample dates (Figure 3-9).

Following the completion of Step 2, select $\mathbf{O K}$.

Step 3. Define Parameter Criteria. Three options are available for parameter selection (Figure 3-10).

- $\quad$ Select From a List of All Parameters

- Select From a Group of Parameters

- Keyword Search on Parameter Name

Selecting one of the first two options will update the screen to include a list of all parameters available, with the exception of colloids, within the database. An additional box, Parameter Groupings, is shown when the Select From a Group of Parameters option is selected (Figure 3-11). This box contains a list of the eight available categories of parameters. The Select From a Group of Parameters option is required to update the parameter list to contain colloid data. Upon selection of one of the categories, the parameter list will be updated to include only the parameters within the specific category. The user is then allowed to select up to four parameters from the list. To select more than one parameter from the parameter list, left-click on the first parameter, hold down the Ctrl key, then click on the next desired parameter. 


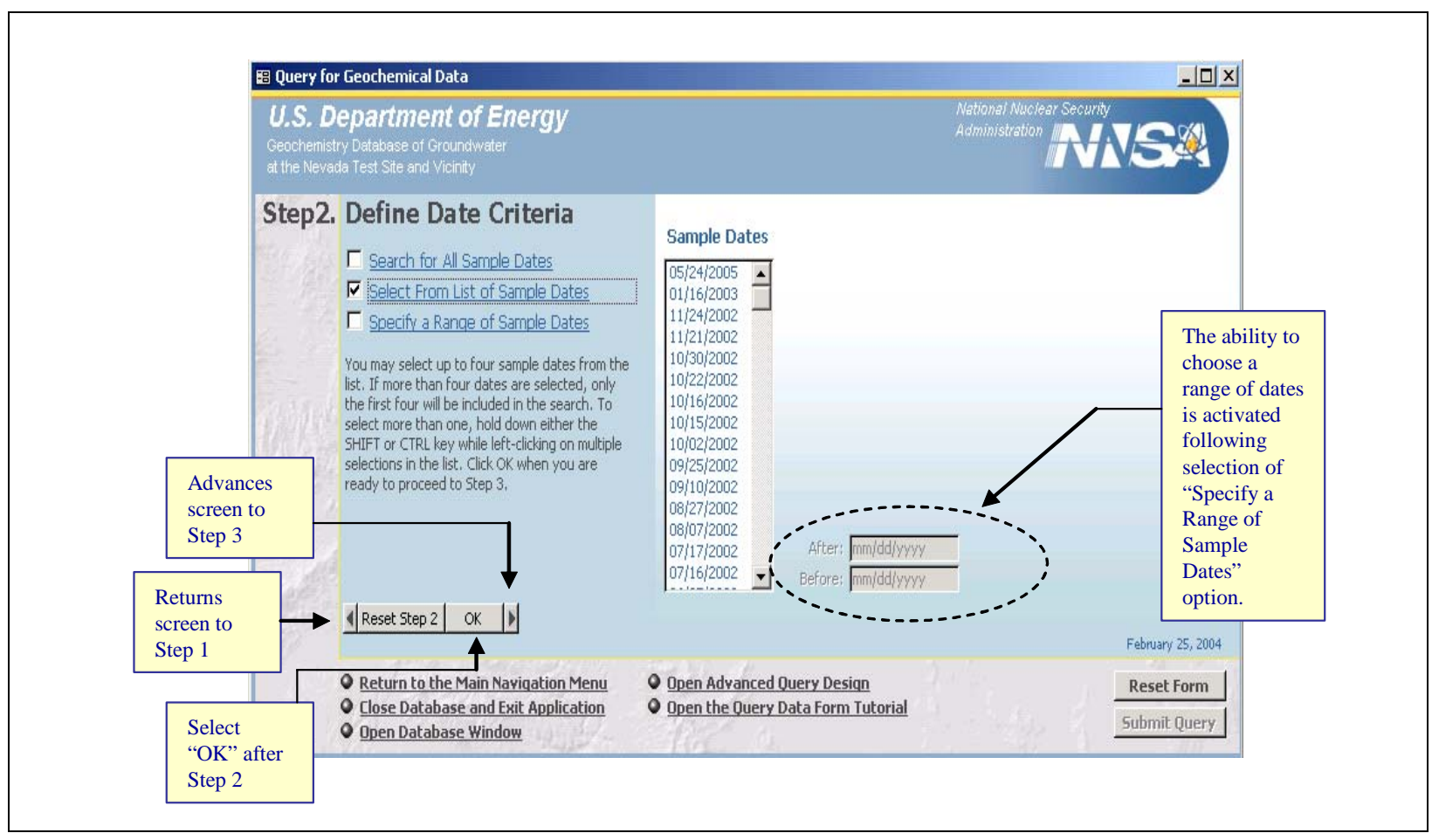

Figure 3-9

Define Date Criteria Including List of Sample Dates

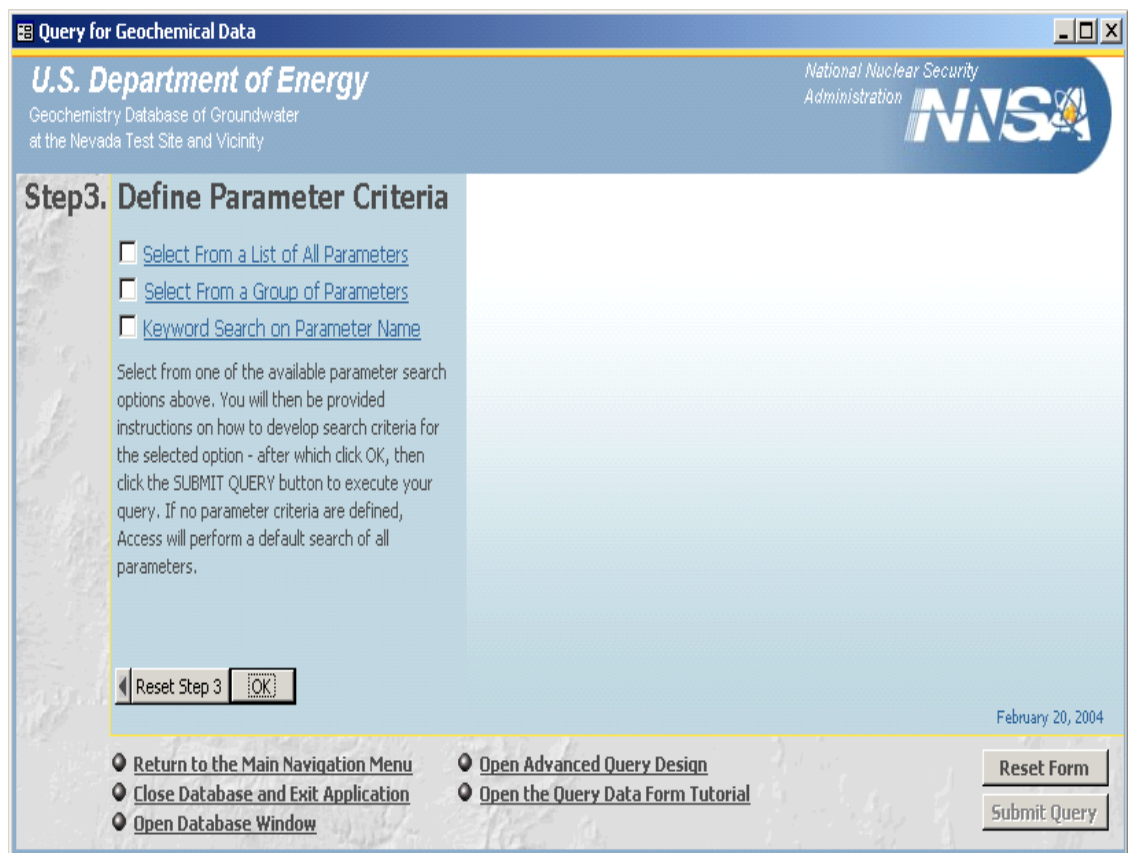

Figure 3-10

Define Parameter Criteria 


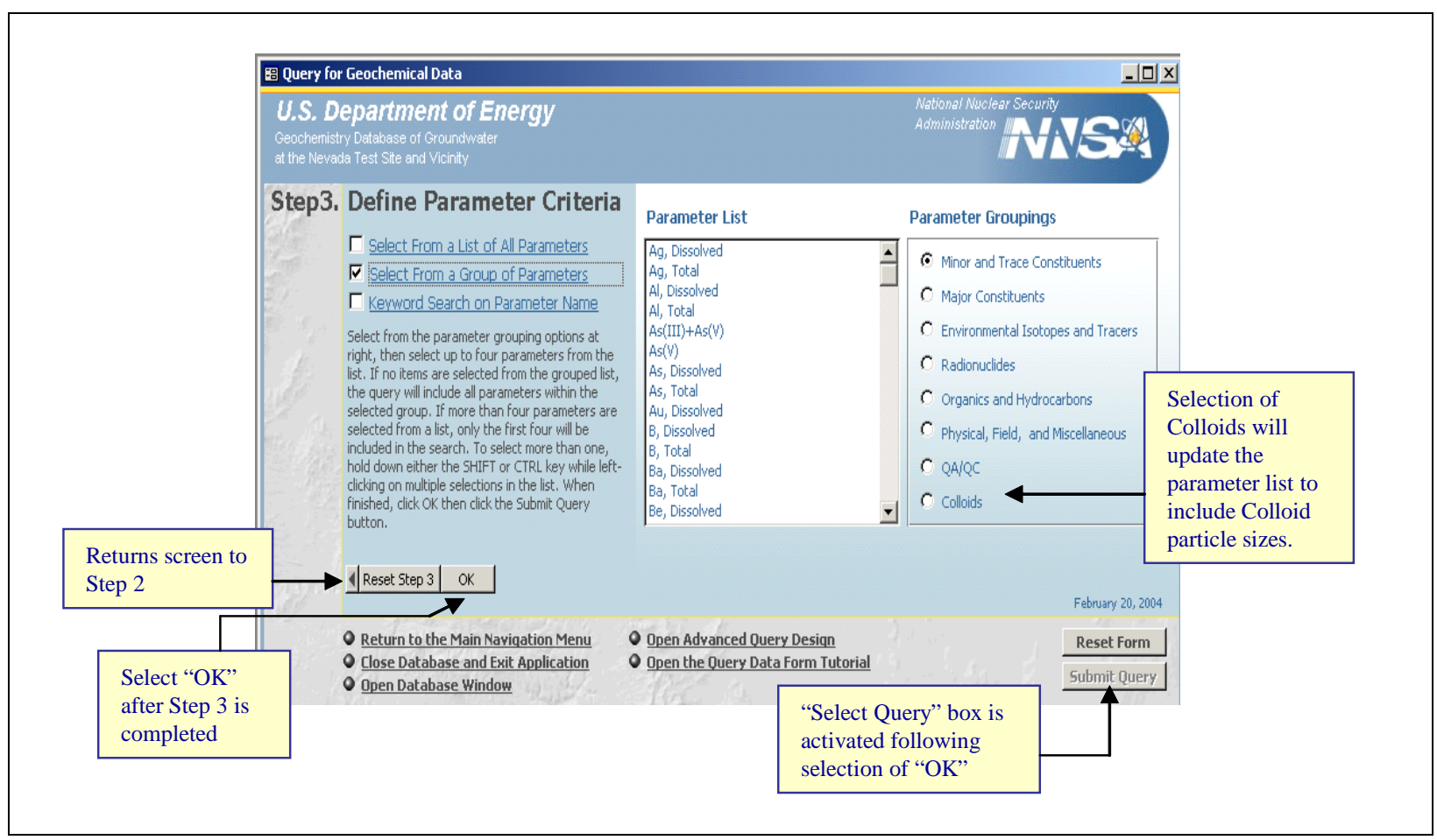

Figure 3-11

Define Parameter Criteria Including Parameter Groupings

In addition to the list box selections, a user-defined keyword search criteria can be used to search for a particular parameter or a group of similarly named parameters. The Keyword Search on Parameter Name option is performed identically to that for the location site names. The three operators ("LIKE," "NOT LIKE,” and “=”) can be used to select parameters that contain the keyword, do not contain the keyword, or are identical to the keyword, respectively.

Select $\mathbf{O K}$ following the completion of Step 3.

Step 4. Submit Query. Once the user is satisfied with the defined search criteria, the user clicks on the Submit Query button to execute the query. Microsoft Access $^{\circledR}$ will run the query and return a dataset matching the search criteria. Two options will be presented for viewing the dataset in a cross-tabular format. The user is given the option of including the reference and procedural information with the query results. The cross-tabular format groups parameter, value, and unit information into columns, with a separate column for each analysis (Figure 3-12).

The user is also provided with the option to Open Advanced Query Design and Open the Query Data Form Tutorial. These options may be selected from the bottom of the Query for Geochemical Data form. These options allow the user to view the tutorials that are available within GeochemXX.mdb and prepare an advanced query design. 


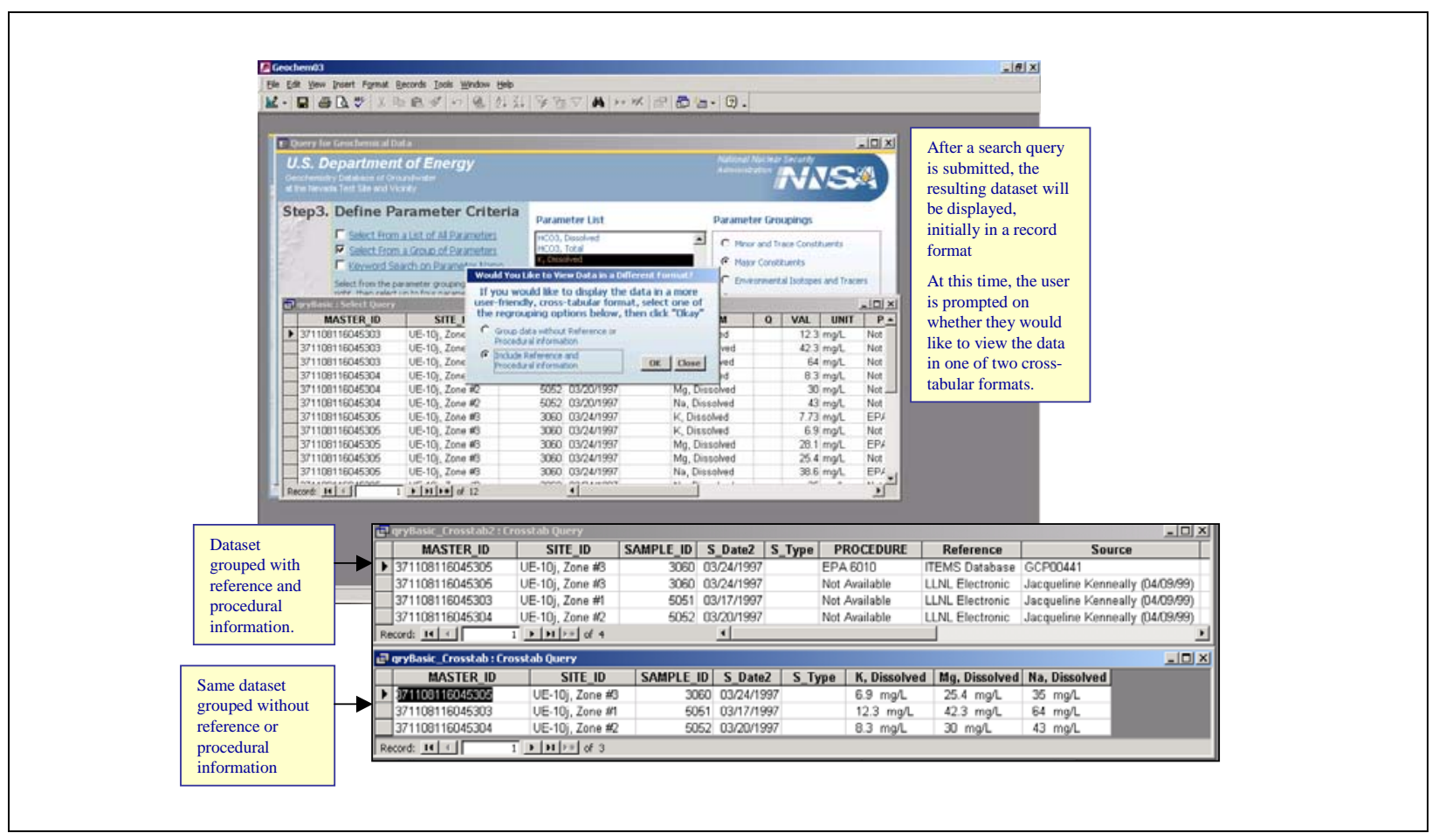

\section{Available Options for Viewing the Query Results}

The tutorials that are available within the Query for Geochemical Data form (Figure 3-13) consist of a series of forms that offer a general overview for navigation of each screen and detailed instructions for developing specific search criteria for each of the available search conditions. Additionally, tips for creating and defining feasible search criteria and generating successful datasets are available throughout the tutorial.

For those with a working familiarity with the development of search criteria and database navigation through the Database Window panes, clicking on the Open the Advanced Query Design button will open the select-query object, qryAdvanced, in the design mode (Figure 3-14). Execution and navigation of query options in the advanced query window of the Query for Geochemical Data form are no different from normal operation of queries conducted through the Database Window. This select-query has been predesigned to include the four primary data tables and is intended to act as a starting point for those wishing to generate a complete dataset using more advanced search capabilities. Within the design view of qryAdvanced, additional search criteria can be defined for categories such as sample type, data value qualifiers, procedural or parameter code information, and/or information pertaining to referenced data sources. Once the user is satisfied with the search criteria that is defined, the user clicks "!" on the Microsoft Access ${ }^{\circledR}$ toolbar to run the query. The query will return a dataset matching the search criteria. The dataset will be displayed in the default record format - one analysis, parameter, value, unit, and procedure per row. 


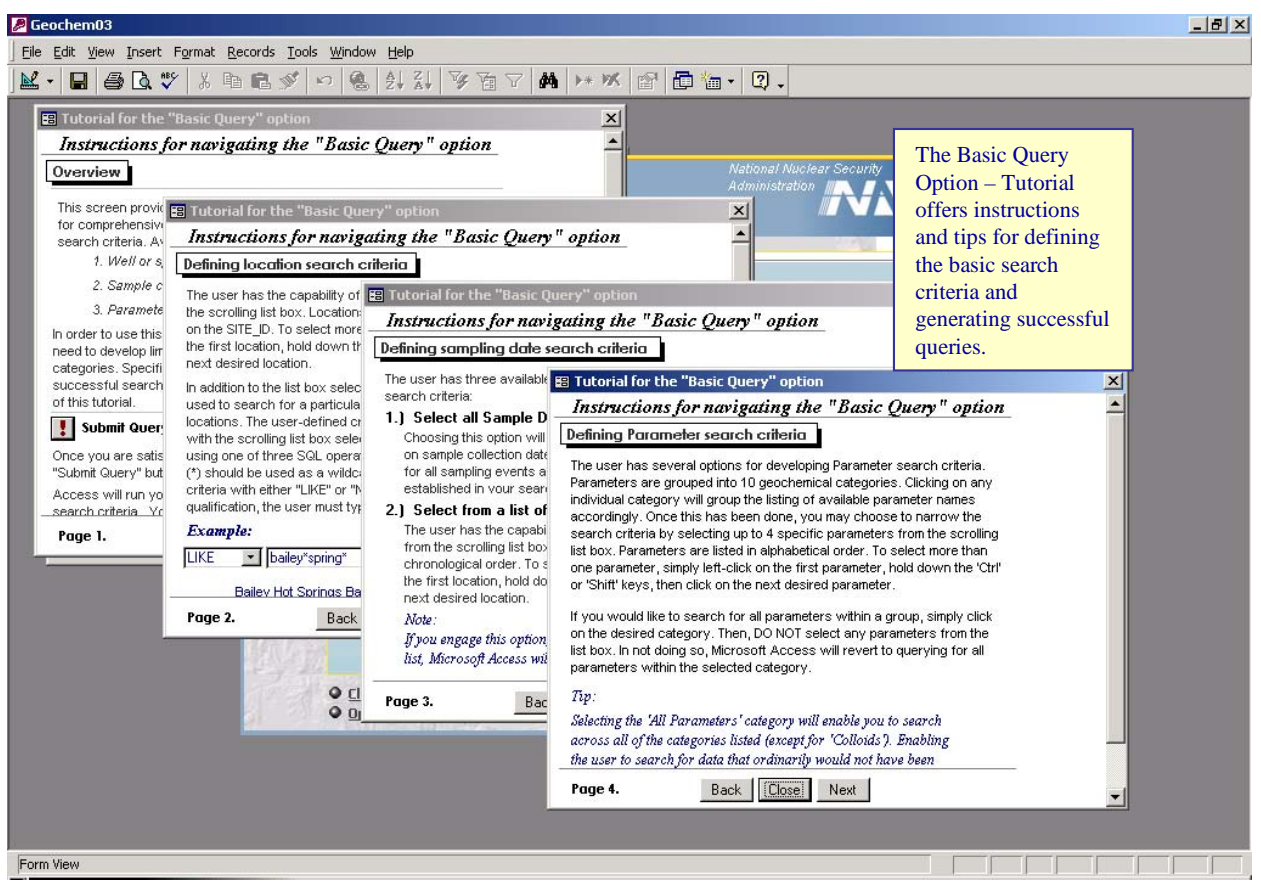

Figure 3-13

Query Data Form Tutorial

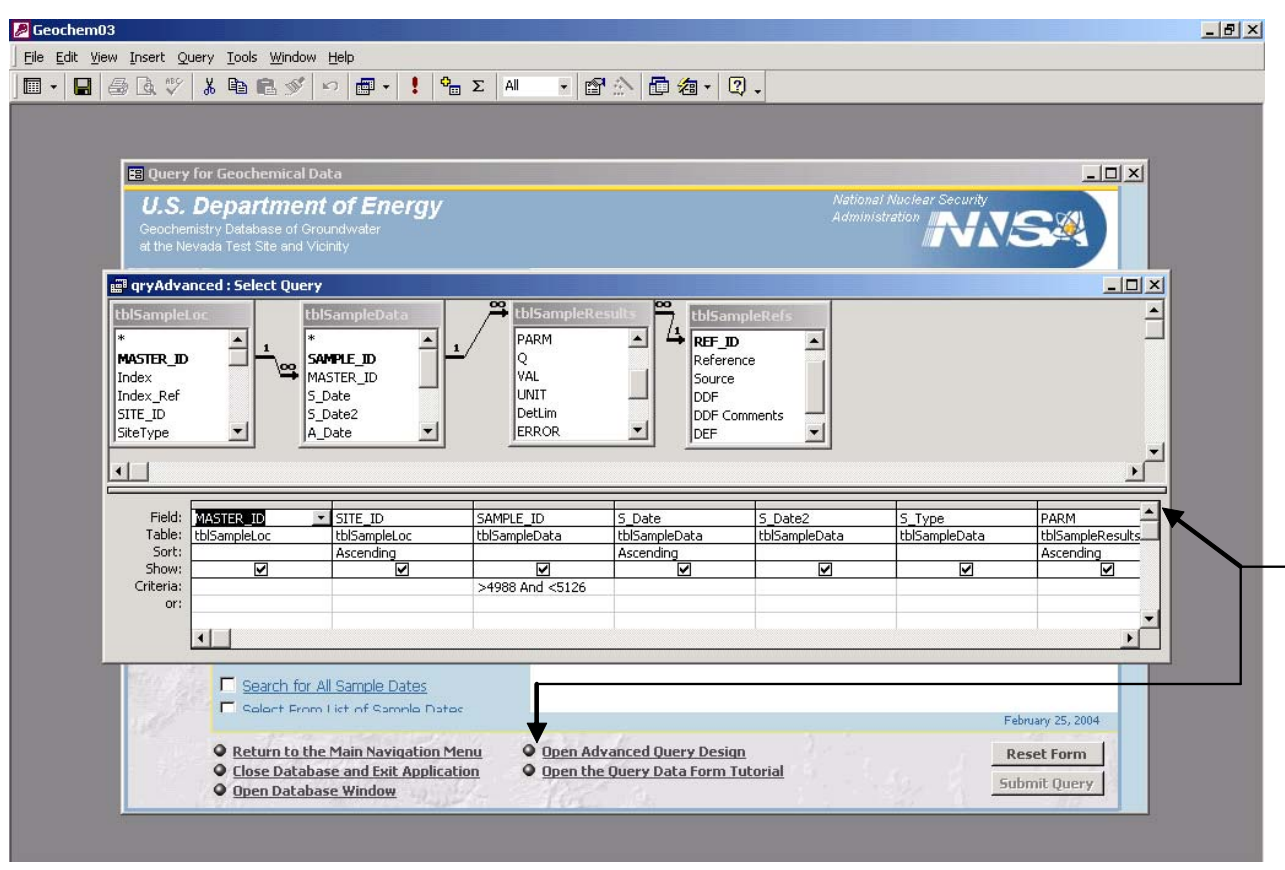

Selecting the

Advanced

Query icon

will open up a default,

predesigned query format in the selectquery design mode.

Figure 3-14

Advanced Query Design 


\subsection{Reference and Data Source Information}

This menu option provides the user with the capability of viewing reference and data source descriptions in addition to documentation and evaluation criteria assessments for individual data sources. Moreover, the Reference and Data Source Information form offers the capability to view individual datasets attributed to each of the unique referenced data sources in either a record or a cross-tabular format. Selection of this option reveals the form shown in Figure 3-15.

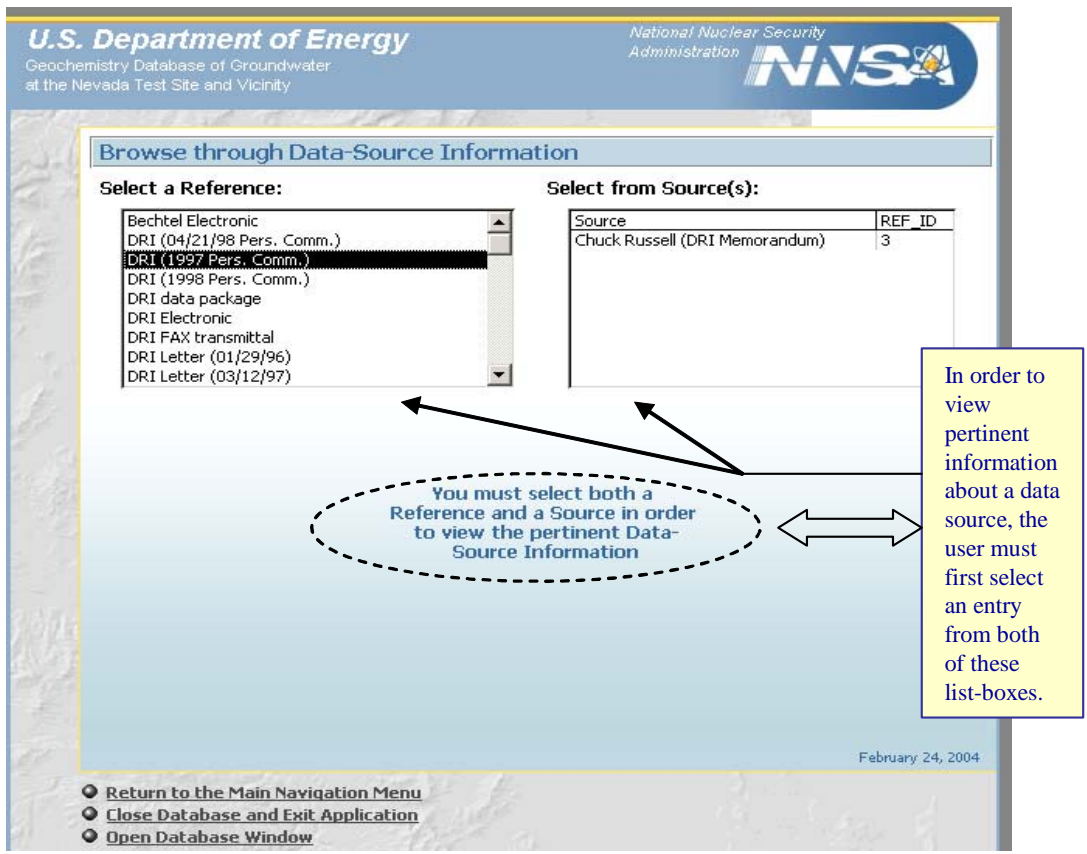

Figure 3-15

Reference and Data Source Information

Navigation of this form is relatively straightforward. Simply scroll through and select from the list of references, then select from the corresponding list of data sources attributed to the selected reference. Once a Reference and a Source have been selected, bibliographic description information will be displayed automatically at the bottom of the form. A tab box will also appear at the bottom of the form summarizing the pertinent information for the selected data source (Figure 3-16).

If the user would like to view the actual dataset, as it exists within the database, attributed to the selected data source, simply click on the View Data tab and two options will be presented for viewing the data. The user will be given the option to view the data in a record format or a cross-tabular format. Simply click on the button to the left of the desired viewing option, then click on the View Data tab. Microsoft Access ${ }^{\circledR}$ will query the dataset and display it in the manner indicated (Figure 3-17). 


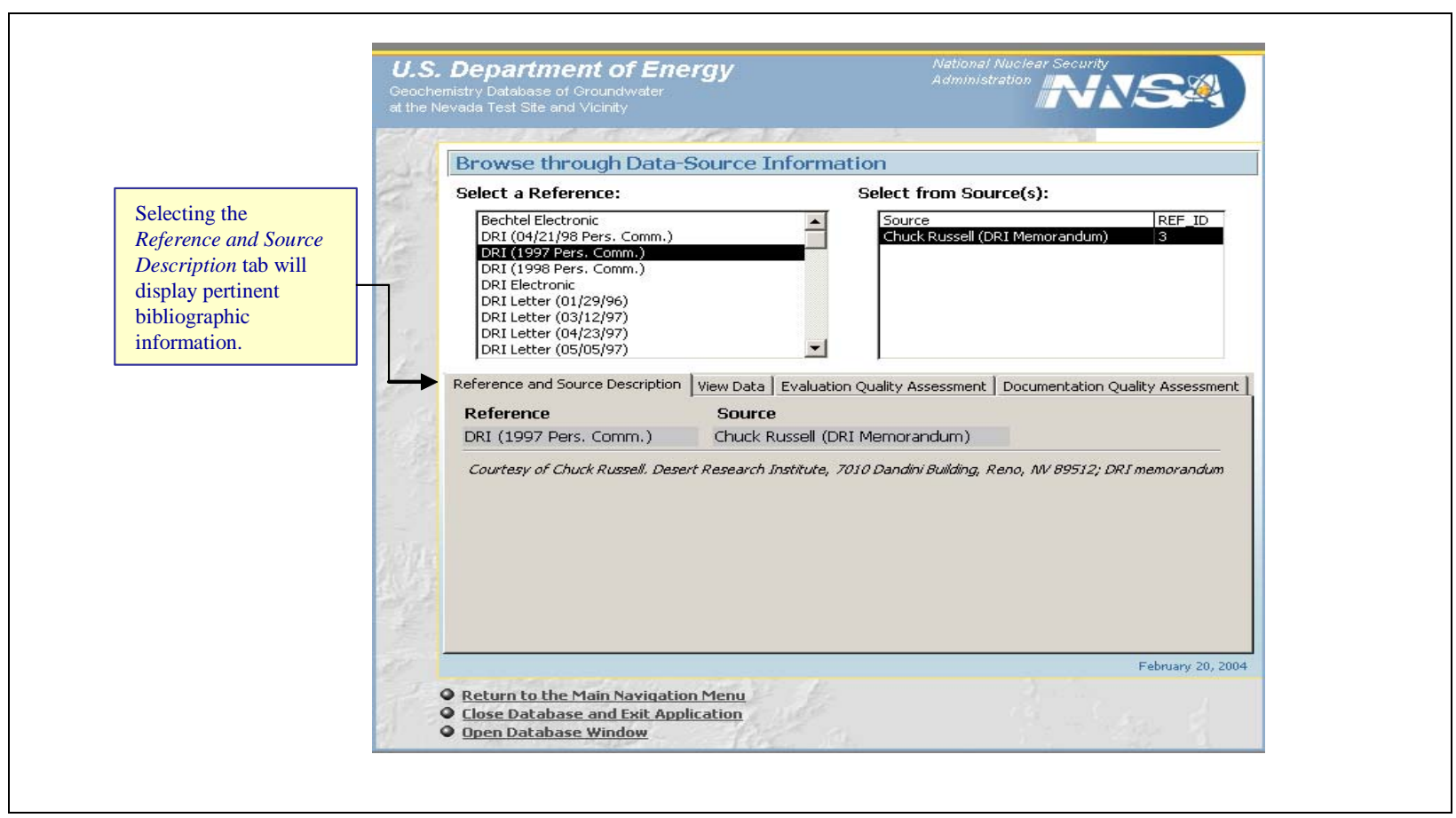

Figure 3-16

Viewing Reference and Available Data Source Information

\subsection{Generating a Time-Series Concentration Plot}

This menu option provides the user with the capability of generating a dataset viewable as a temporal plot of geochemical concentrations using one of three search/display formats, including:

- Single Location - Single Parameter

- Single Location - Multiple Parameter

- Multiple Location - Single Parameter

Navigation of the Generate a Time Series Concentration Plot form (Figure 3-18) is relatively self-explanatory. The user simply develops a search criterion by making selections from each of the search controls on the form.

Step 1. Select the Chart-Type. In addition to qualifying the dataset and determining the graph's display format, this will determine what additional options will become available as described in the following steps.

If one of the Single Location chart-type options is selected, the user will only be able to highlight one location from the list. Enabling the Multiple Location chart-type option will allow the user to select up to four locations from the list. If one of the Single Parameter chart-type options is selected, the user will only be able to highlight one parameter name from the list. Enabling the Multiple Parameter chart-type option will allow the user to select up to four parameter names from the list. 


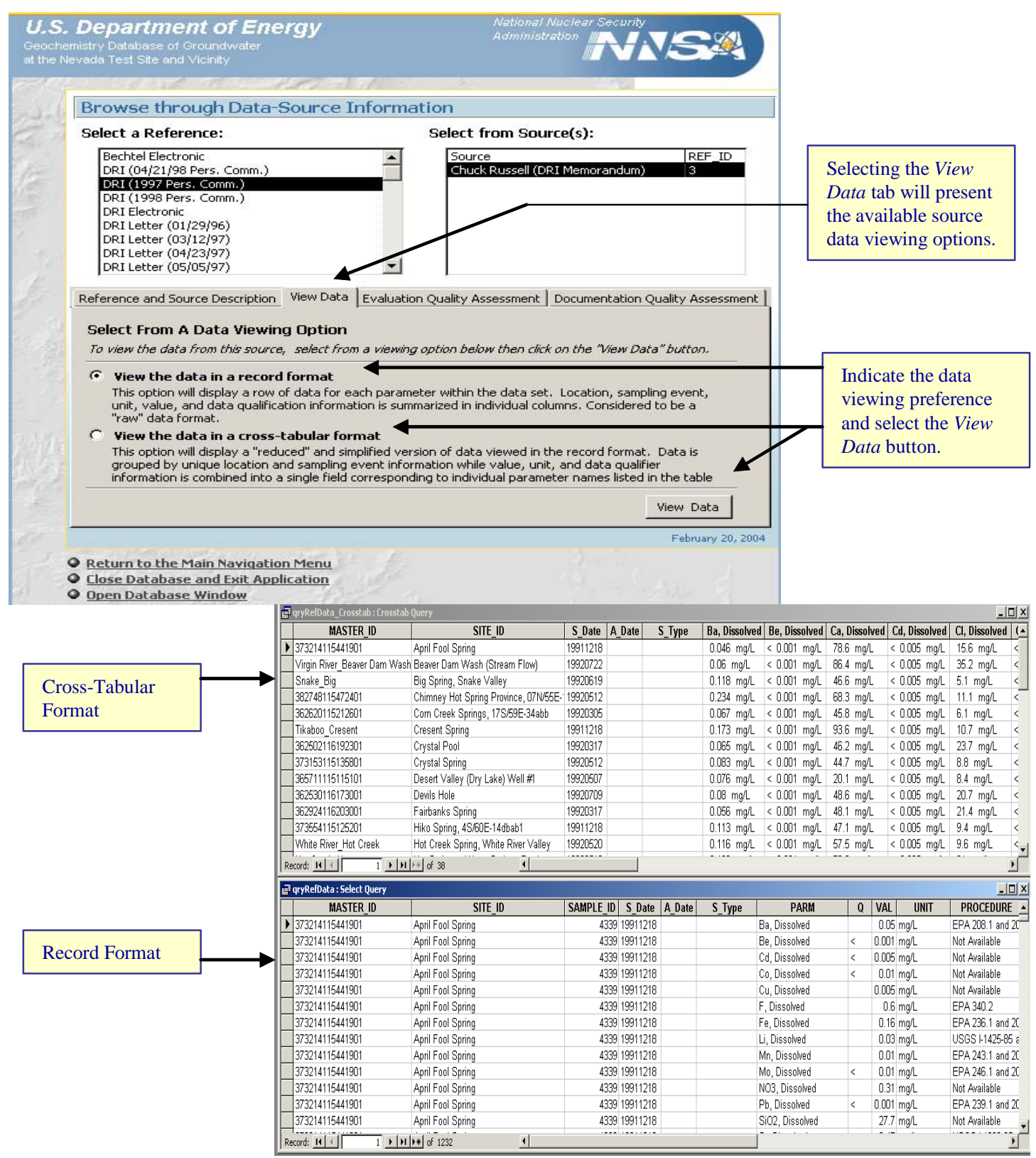

Figure 3-17

Options for Viewing the Data Associated with the Selected Reference and Data Source 


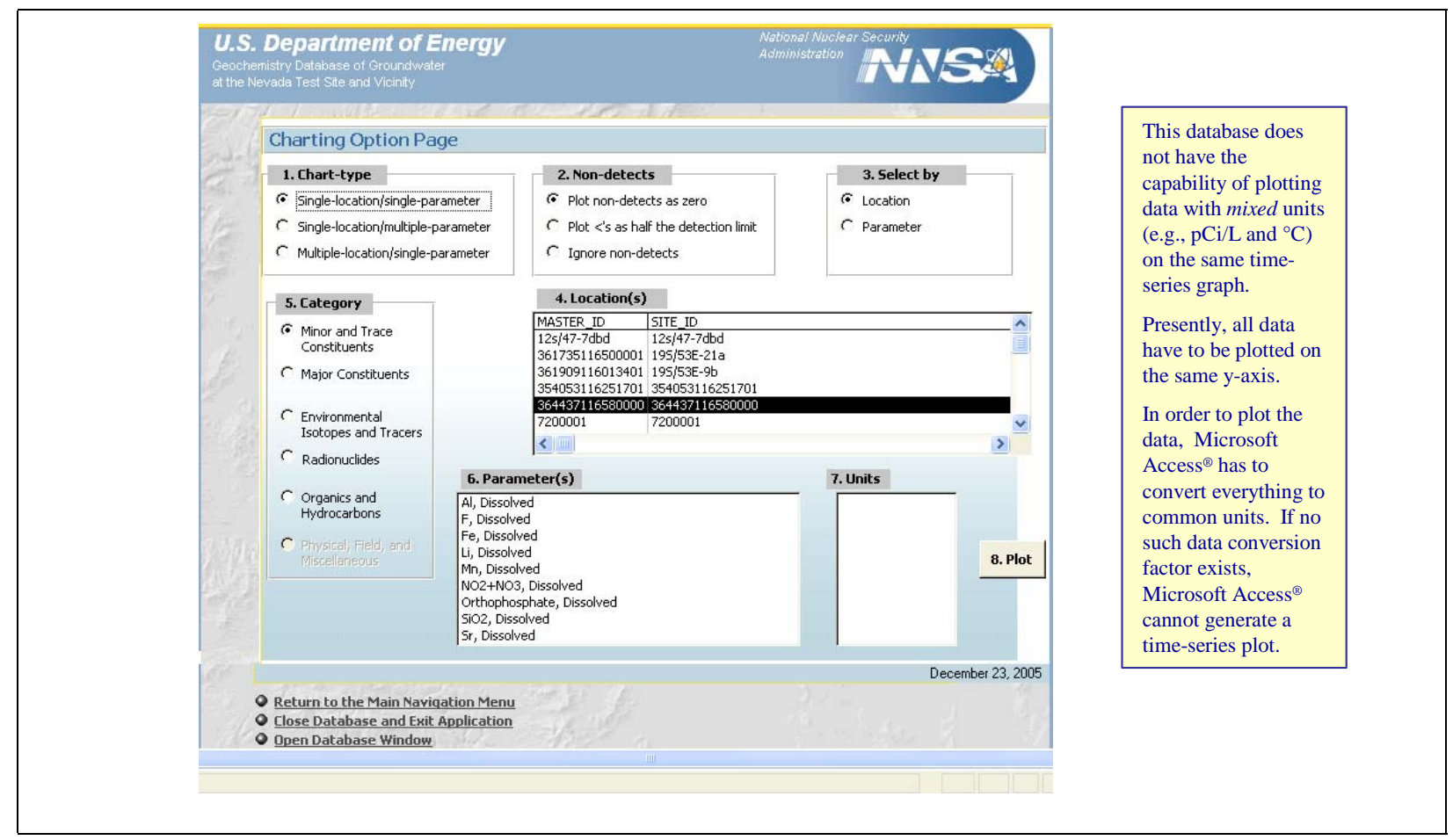

Figure 3-18

Generating a Time-Series Concentration Plot

Step 2. Determine How Nondetects Should Be Displayed on the Graph.

Nondetects may be displayed as zero, half the detection limit, or simply ignored.

Step 3. Select by Location or Parameter. Choose whether to select by location or by parameter. Choosing to select by location will provide the location list and display parameters available for the location(s) selected. Choosing to select by parameter will provide the parameter list and display locations with data available for the parameter(s). In order to make multiple selections from the list of locations, click on the first location, press the Ctrl key on the keyboard and continue making selections. Locations are organized alphabetically according to "Site_ID."

Step 4. Select from a Grouping of Parameters according to the Category descriptions to see a unique list of corresponding parameters.

Step 5. Select a Parameter, or parameters, from the list. In order to make multiple selections from the list, click on the first parameter name, press the Ctrl key on the keyboard, and continue making selections. Parameter names are organized alphabetically.

Step 6. Determine the Unit To Display the Data in a Graph. By selecting a unit from the list, the user provides Microsoft Access ${ }^{\circledR}$ with a means for converting data values as appropriate to match the selection. The current release of this form does not have the capability of plotting data with mixed units (e.g., picocuries per liter $[\mathrm{pCi} / \mathrm{L}]$ and degrees Celsius $\left.\left[{ }^{\circ} \mathrm{C}\right]\right)$ on the same time-series 
graph. All data must be plotted on the same y-axis. In order to plot the data, Microsoft Access ${ }^{\circledR}$ has to convert everything to common units. If no such conversion factor exists, Microsoft Access ${ }^{\circledR}$ cannot generate a time-series plot. Therefore, the user should avoid selecting multiple parameters for which there is no common reporting convention (e.g., temperature and radium-226). While the categorization of parameters has eliminated the occurrence of many of the incompatible reporting conventions, some incompatibilities still exist. Most of these can be avoided by relying on the user's knowledge and reasonable expectations for data reporting and graph-display conventions.

Step 7. Execute the Query. Once the data search criteria is complete, click on the Plot button in order to execute the query. Microsoft Access ${ }^{\circledR}$ will compile the dataset and display the data graphically on one of three graphs, depending on the Chart-Type selected in Step 1 (Figures 3-19, 3-20, and 3-21).

When initially displayed, a tabular form of the dataset that is generated by the query is contained in a minimized window at the bottom-left corner of the screen. The source of the graphed data are contained within this minimized window (qrytsconcplotdata) and can be scrutinized by maximizing the query object. The graph is displayed with a default range and scale of sampling dates along the $\mathrm{x}$-axis. If the data are plotted on either side of this range of sampling dates, the $\mathrm{x}$-axis will need to be modified in order to view all of the data.

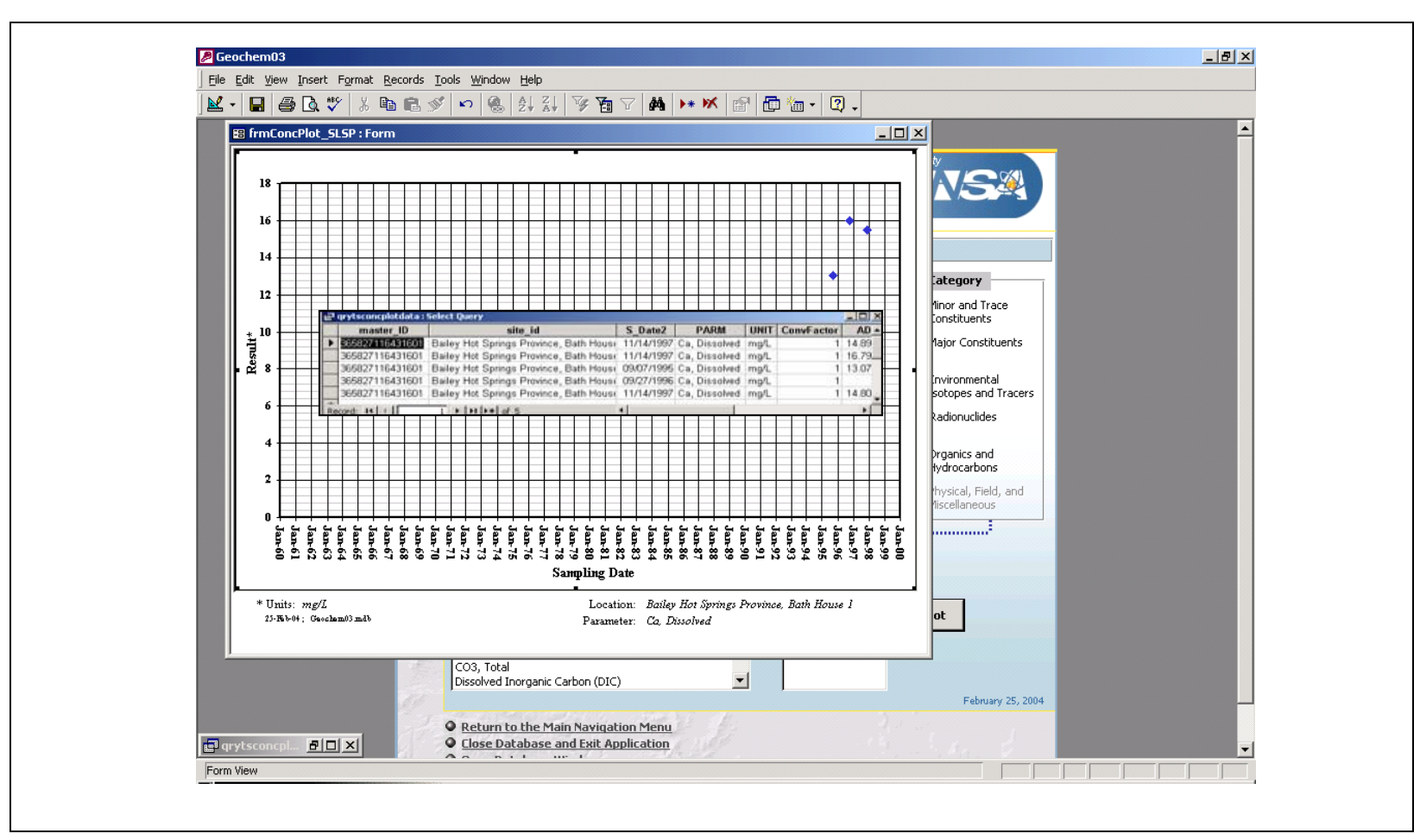

Figure 3-19

Time-Series Concentration Plot Single Location, Single Parameter 


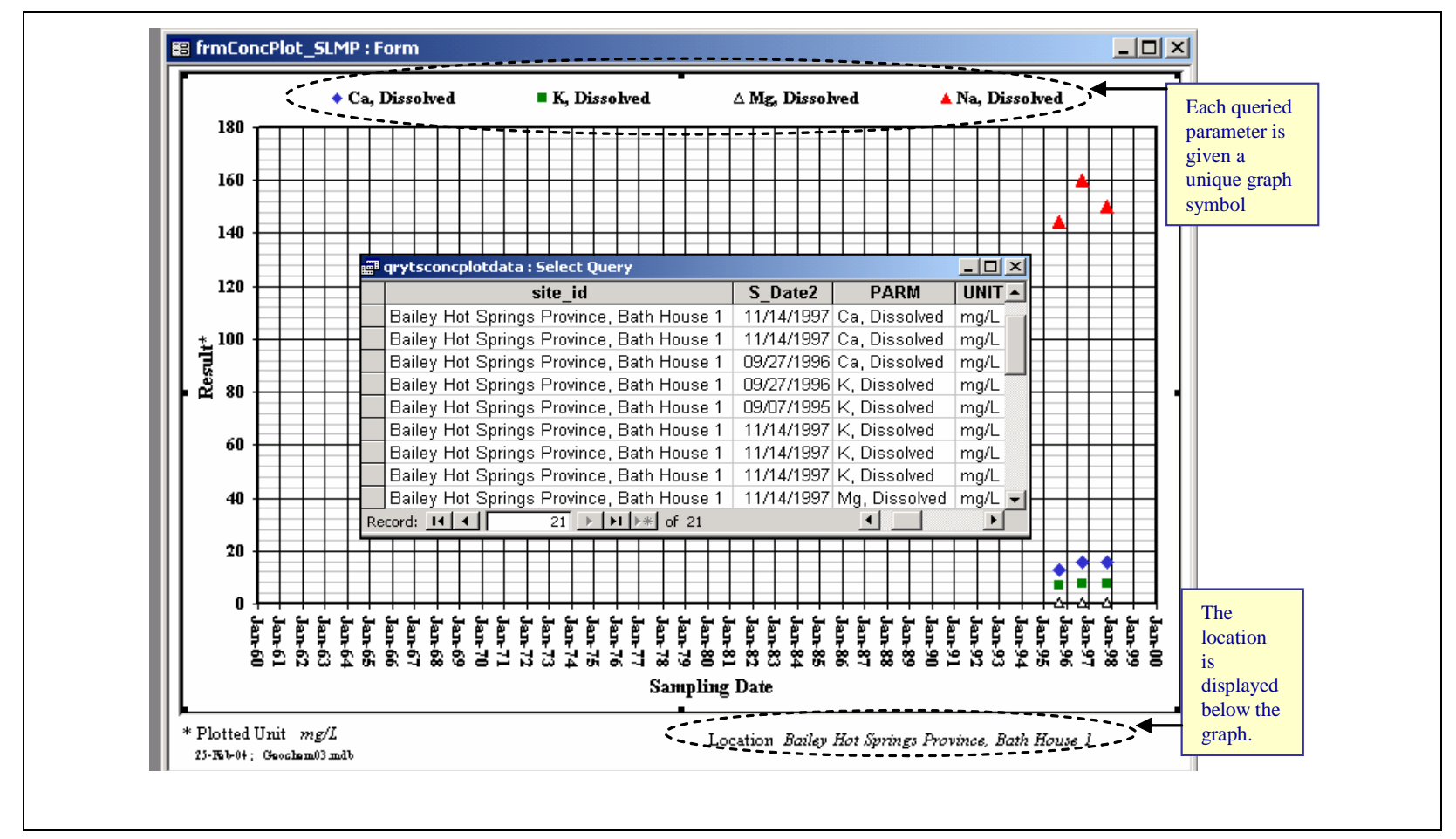

Figure 3-20

Time-Series Concentration Plot Single Location, Multiple Parameter

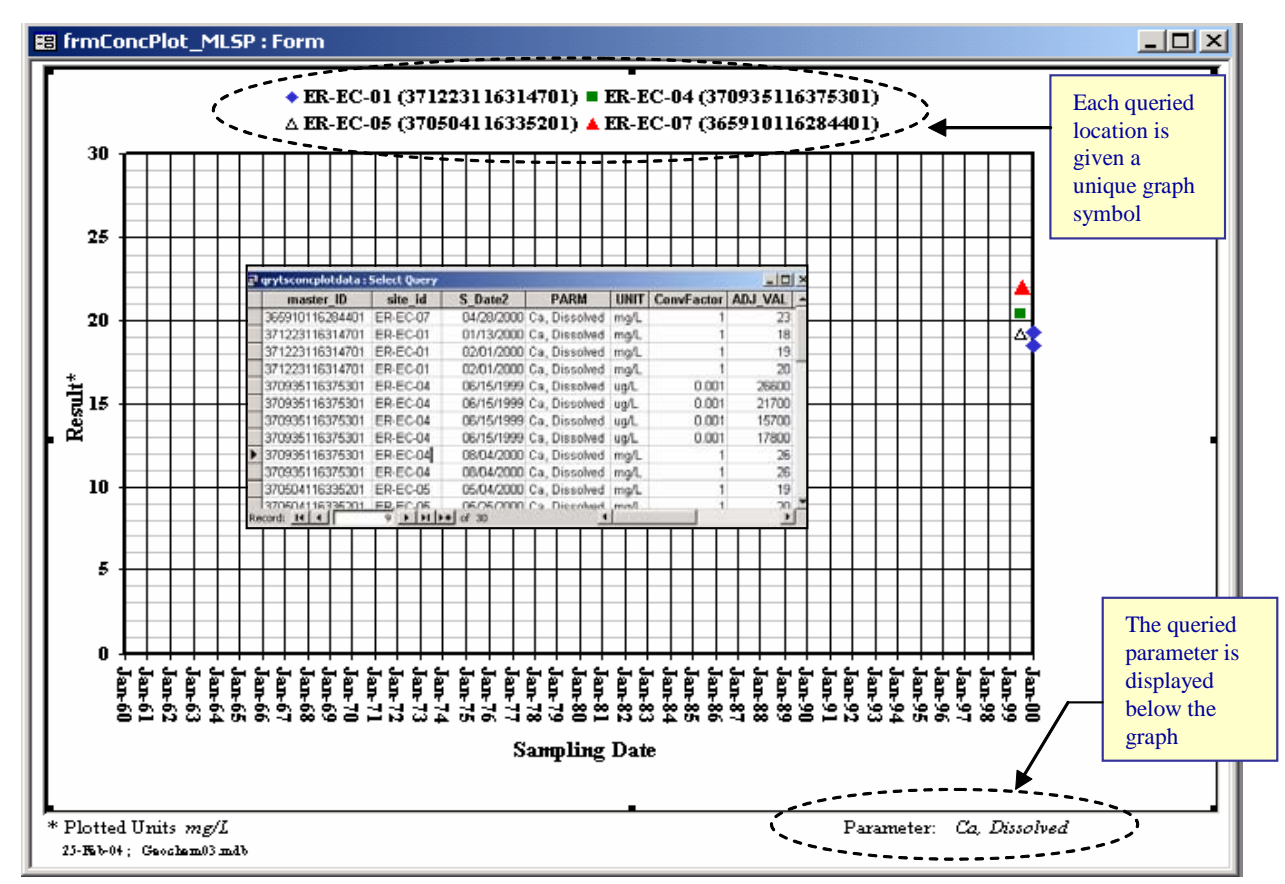

Figure 3-21

Time-Series Concentration Plot Multiple Location, Single Parameter 
Microsoft Access ${ }^{\circledR}$ relies on Microsoft Graph ${ }^{\circledR}$ for the plotting capabilities offered by the Generate a Time-Series Plot form. While the Microsoft Graph ${ }^{\circledR}$

capabilities are limited in some respects (e.g., automatic axis ranges, multiple axis graphing) it does offer familiarity to users that are comfortable with the graphing capabilities of Microsoft Excel ${ }^{\circledR}$.

In order to modify the graphic display of data, the objects within the graph must be made selectable. This is accomplished by simply double-clicking on the graph itself. Once the graph objects are selectable, the user can right-click on objects within the graph, at which time a number of editing options will be presented.

For example, right-clicking on the outer edge of the chart will present options to Format Chart Area..., change the Chart Type..., or modify the Chart Options. Selecting Chart Options will enable the user to add/edit titles, modify the axis ranges, reformat gridlines, change the display of the data legend, and add data labels (Figure 3-22).

Any time another search is executed when plotting data, the modifications made to the graphical display will be overwritten. In order to avoid losing the graph display modifications, the user must save the modified chart under a different name.

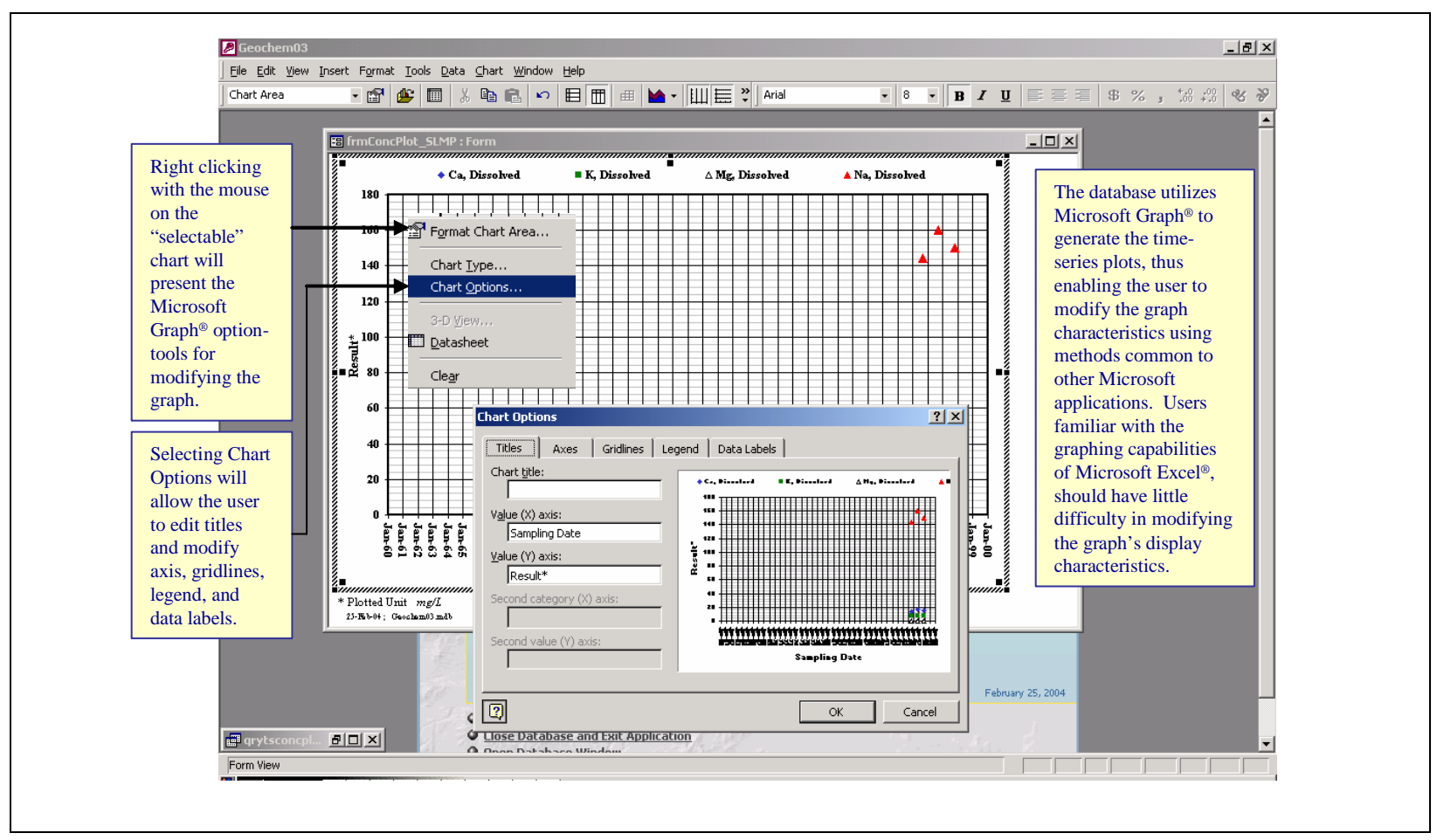

Figure 3-22

Modifying Chart Display Options 


\subsection{Well and Spring Location Information}

This menu option provides the user with the capability of viewing the geographic coordinate information and any location reconciliation comments pertaining to the listing of available well and spring locations. Operation and navigation of the Well and Spring Location Information form is relatively self-explanatory. Available selection options and their resulting operation are illustrated in (Figure 3-23).

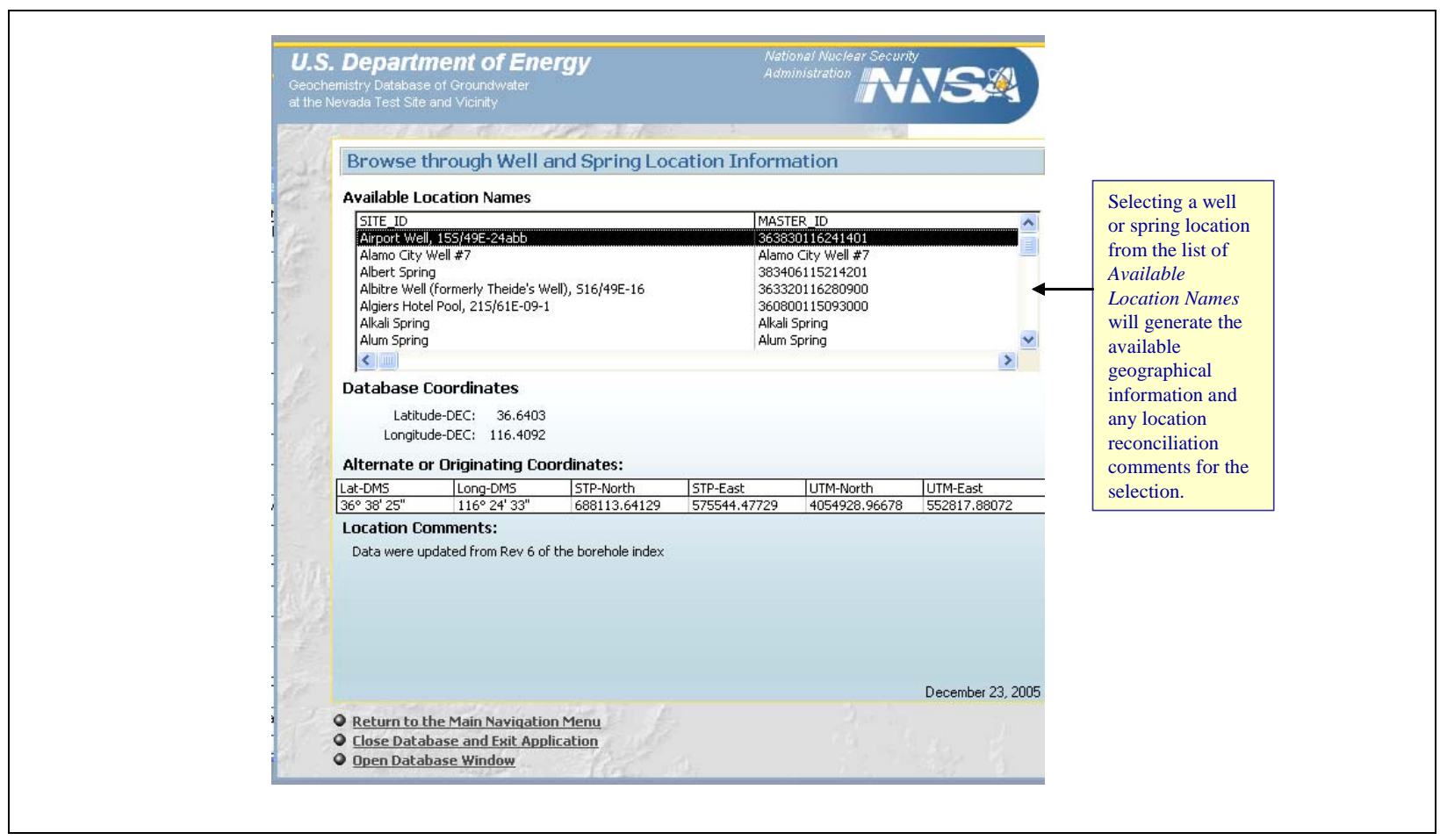

Figure 3-23

Browsing Well and Spring Location Information

\subsection{Data Management and Documentation}

The Data Management and Documentation form allows the user to browse database documentation and domain tables. These options are shown in Figure 3-24 and are described within this section.

Browse Database Documentation - Selection of this option provides three choices to the user (Figure 3-25):

- View a Summary of Table Contents

- View All Entries from the Database Logbook

- Return to the Previous Menu

Selection of View Summary of Table Contents will update the screen to the Table Summary and Data Field Information form shown in Figure 3-26. This form 


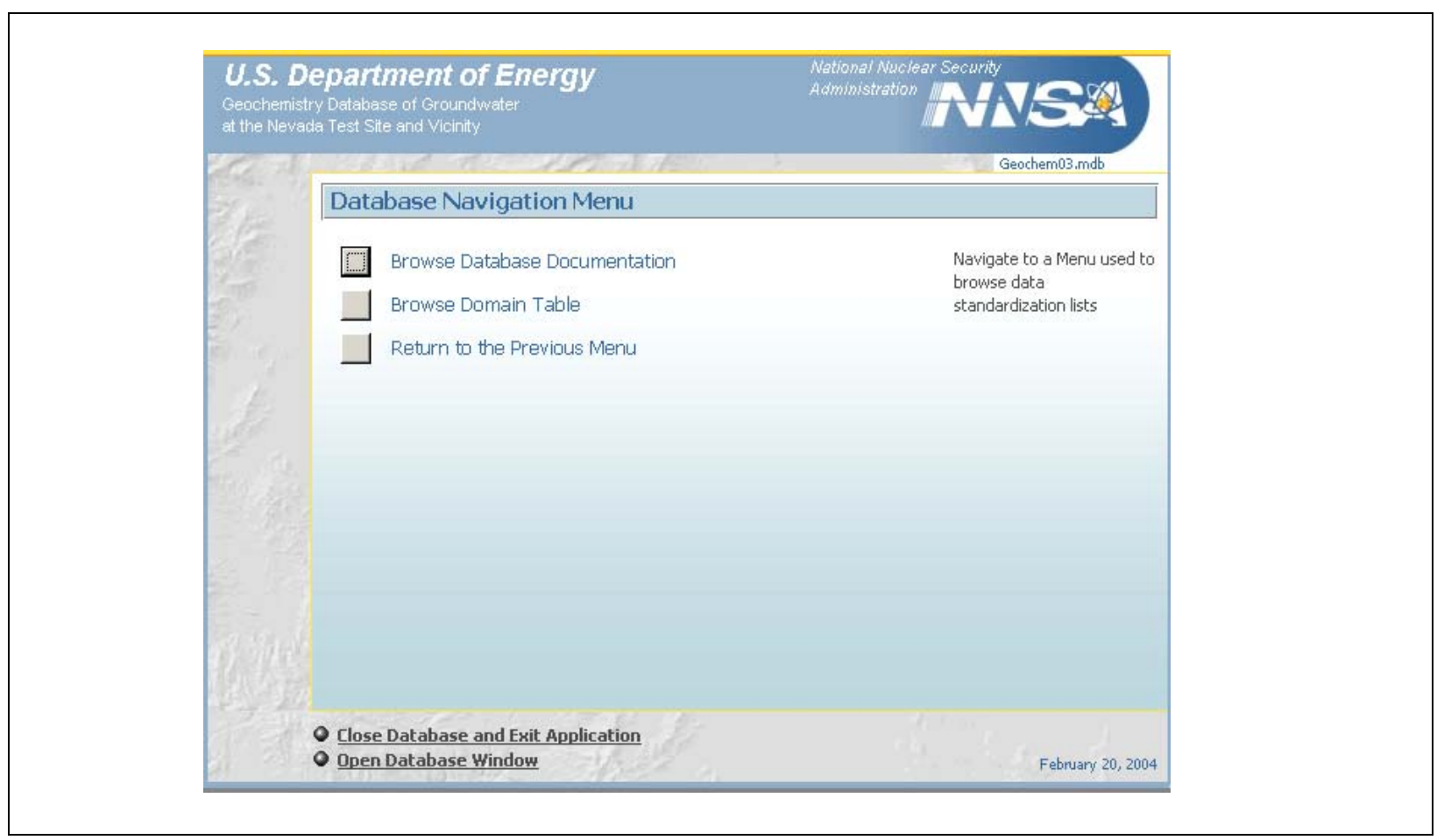

Figure 3-24

Browse Database Documentation and Domain Tables

allows the user to select a specific table and field within that table. A short description is presented.

Selection of View all Entries from the Database Logbook enables the user to view a list of data additions, data deletions, and any modifications made to the database since June 1998 (Figure 3-25). At present, the logbook entries are not searchable using this menu option. The user will be able to scroll through the pages of the report using the navigation controls in the lower left-hand corner of the report window. Logbook entries are organized according to the date in which they were made. This option is illustrated in Figure 3-25.

Browse Domain Table - Selection of this option provides five choices to the user (Figure 3-27):

- Parameter, Unit, and Procedural Information

- View Qualifier Information

- View Procedural Information

- DEF and DDF Qualification Criteria

- Return to Previous Menu

Parameter, Unit, and Procedural Information- Provides available procedural information within the database. Operation and navigation of the Parameter, Unit, and Procedural Information form is relatively self-explanatory. Available selection options and their resulting operation are illustrated in Figure 3-28. 


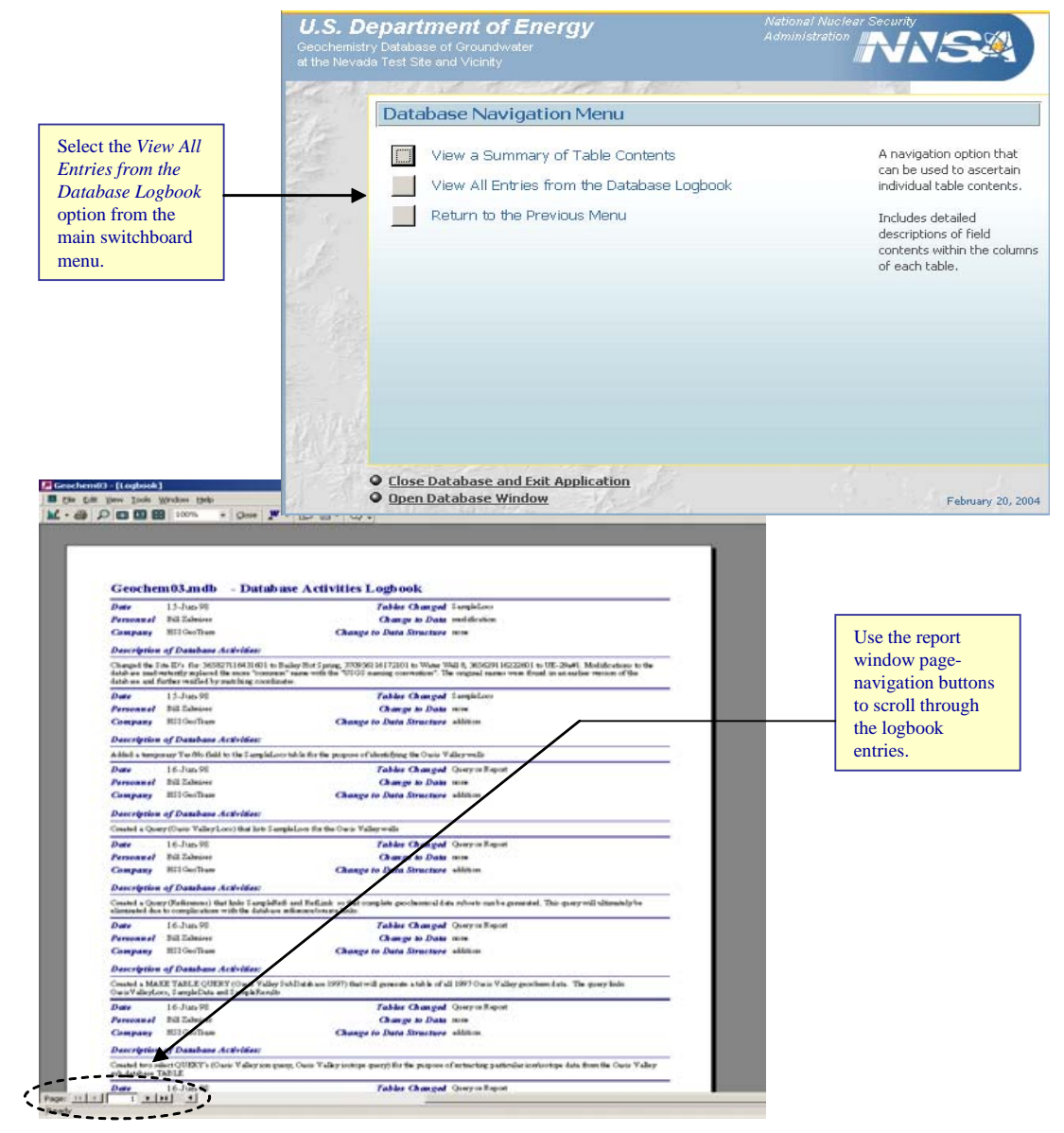

Figure 3-25

Browse Database Documentation

View Qualifier Information - This menu option provides the user with the capability of viewing a unique list of all of the data qualifiers used within the database. Upon making a selection from the Qualifier list, the Qualifier Information form will display a complete data qualifier description as well as its application within this database (Figure 3-29).

View Procedural Information - This menu option provides the user with the capability of viewing full methodology citations for all of the analytical procedure and parameter codes used in the database. Upon making a selection from the Procedure list, the Procedural Information form will display a complete explanation, where available, of the selected procedure (Figure 3-30).

DEF and DDF Qualification Criteria - This menu option provides the user with the capability of viewing the criteria established for evaluating the quality of referenced data sources. Upon making selections from the DEF Level and the DDF Level lists, the DEF and DDF Qualification Criteria form will display the criteria associated with the respective list-box selections (Figure 3-31). 


\section{U.S. Department of Energy}

Geochemistry Database of Groundwater

at the Nevada Test Site and Vicinity

National Nuclear Security

Aciministration

Table Summary and Data Field Information

Select a Table:

tblSampleLoc

Data Table - Contains location information and site geographic

coordinates.

Select a Data Field:

Foordinate Oriqins

Identifies the source and format for the original coordinates

- Return to the Main Nayigation Menu

- Close Database and Exit Application

- Open Database Window

Figure 3-26

Table Summary and Data Field Information

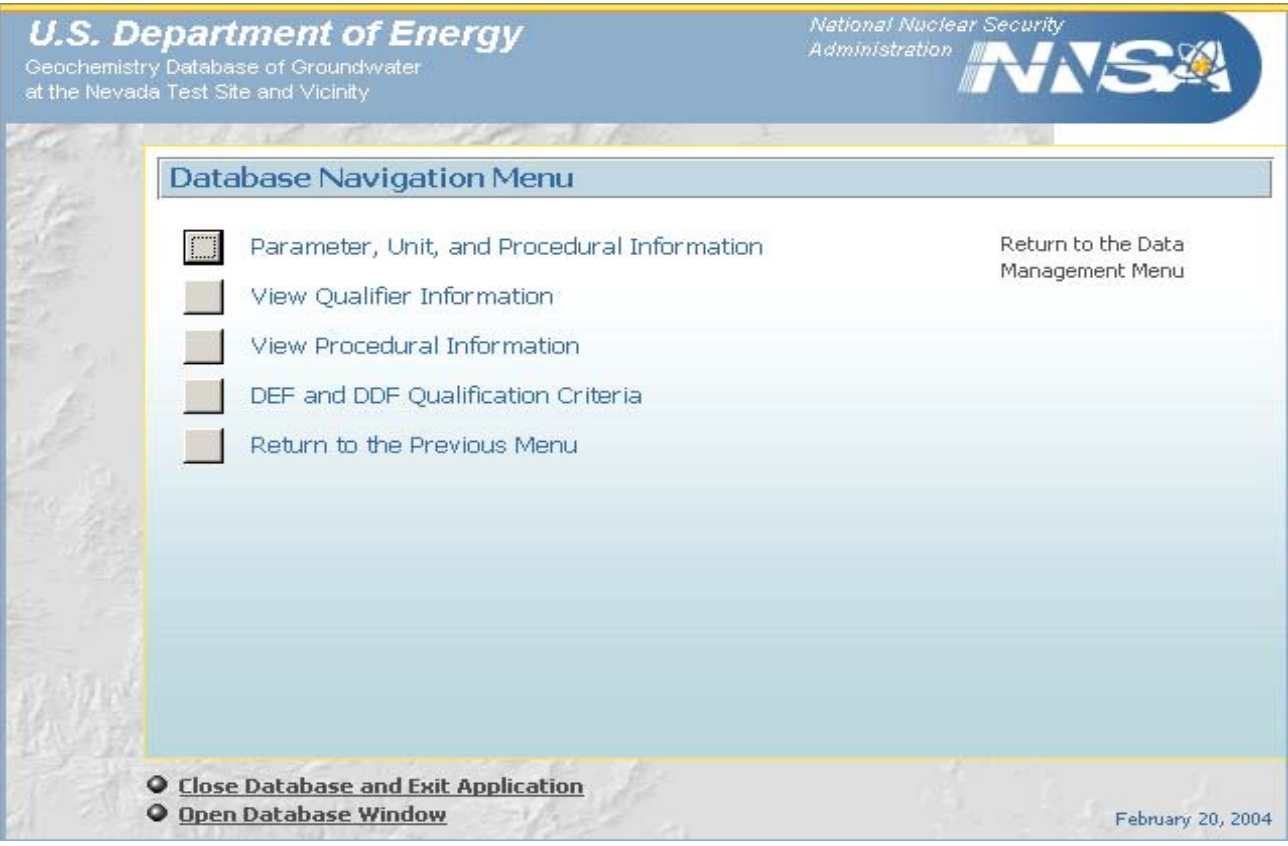

Figure 3-27

Viewing Domain Tables 


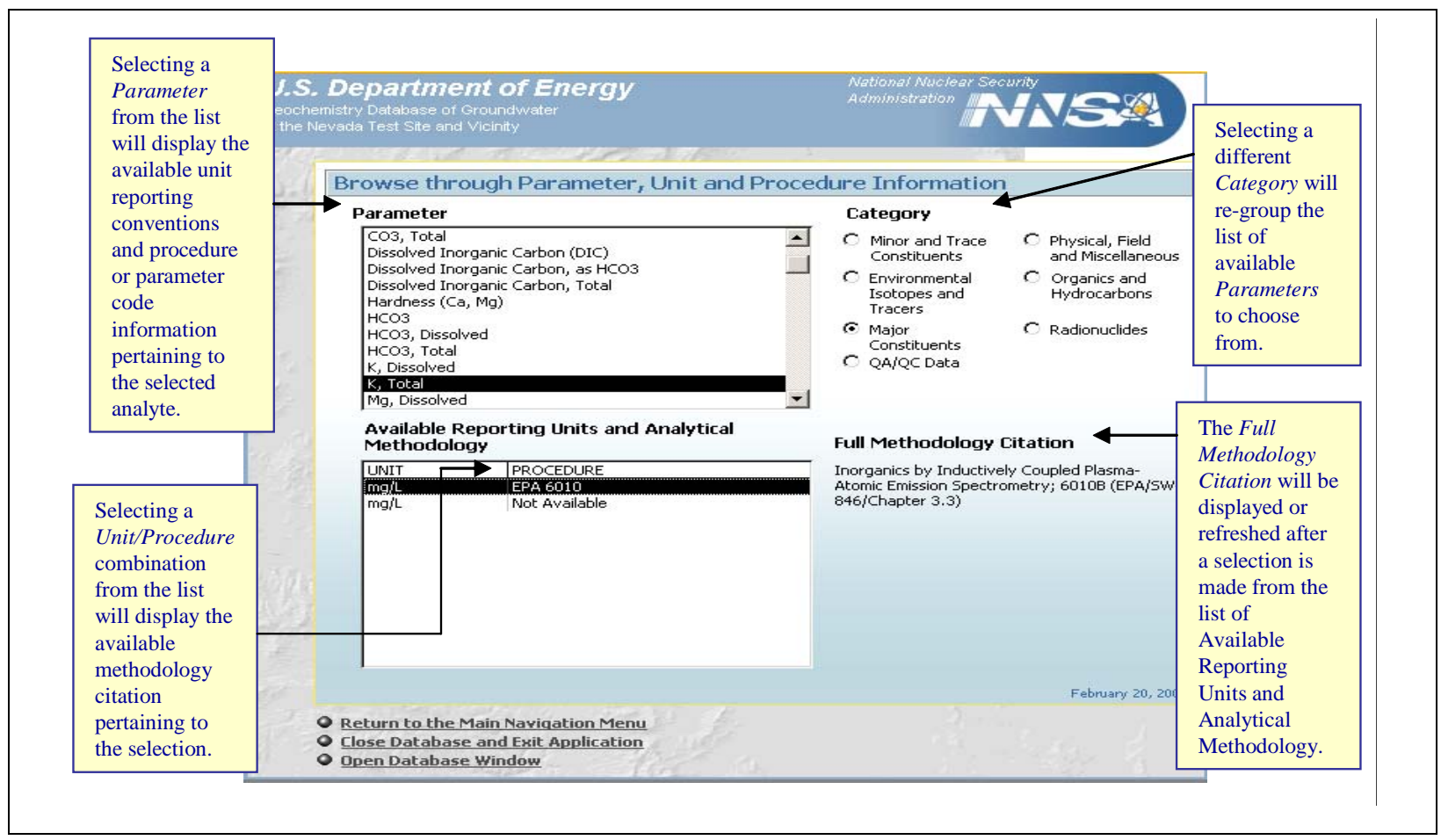

Figure 3-28

Parameter, Unit, and Procedural Information

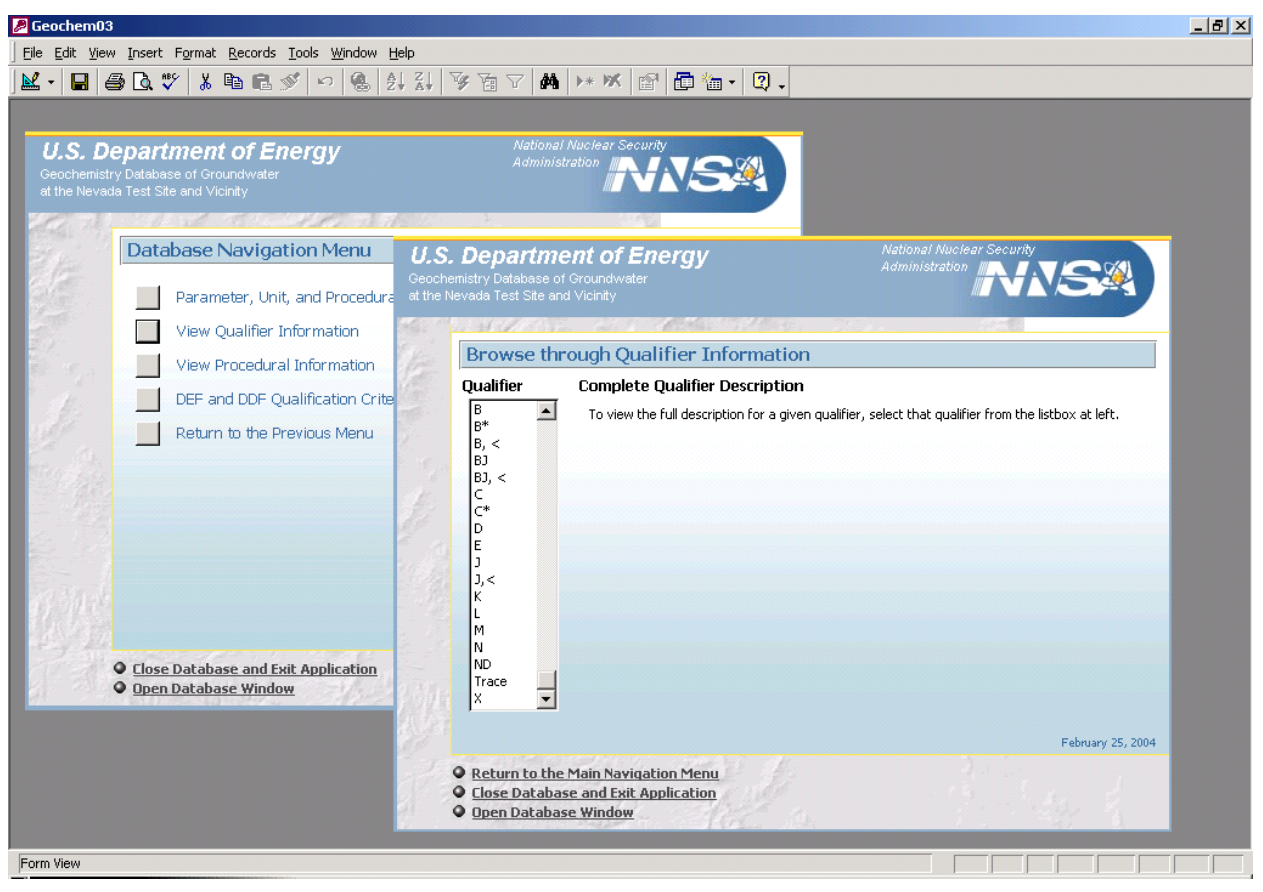

Figure 3-29

Viewing Qualifier Information 


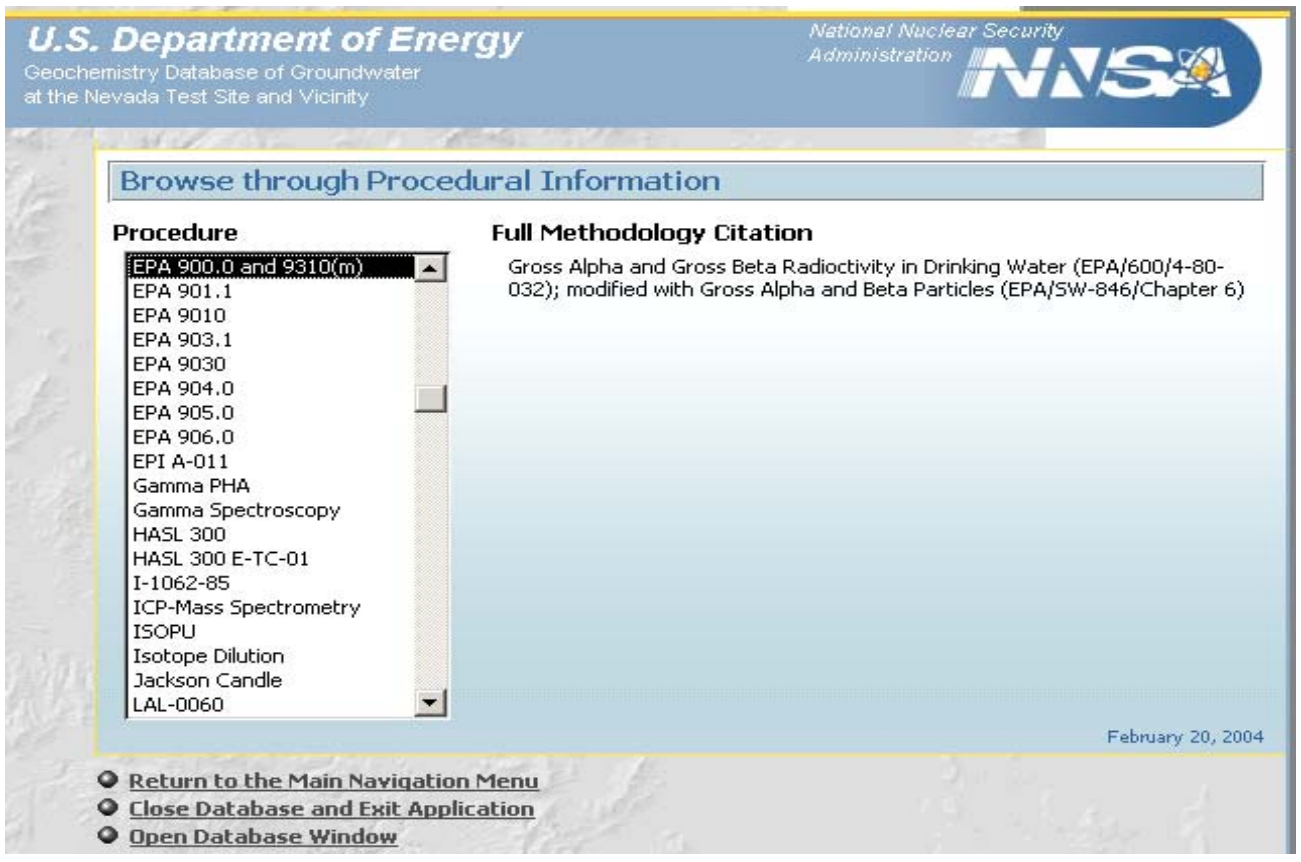

Figure 3-30

Browsing Procedural Information

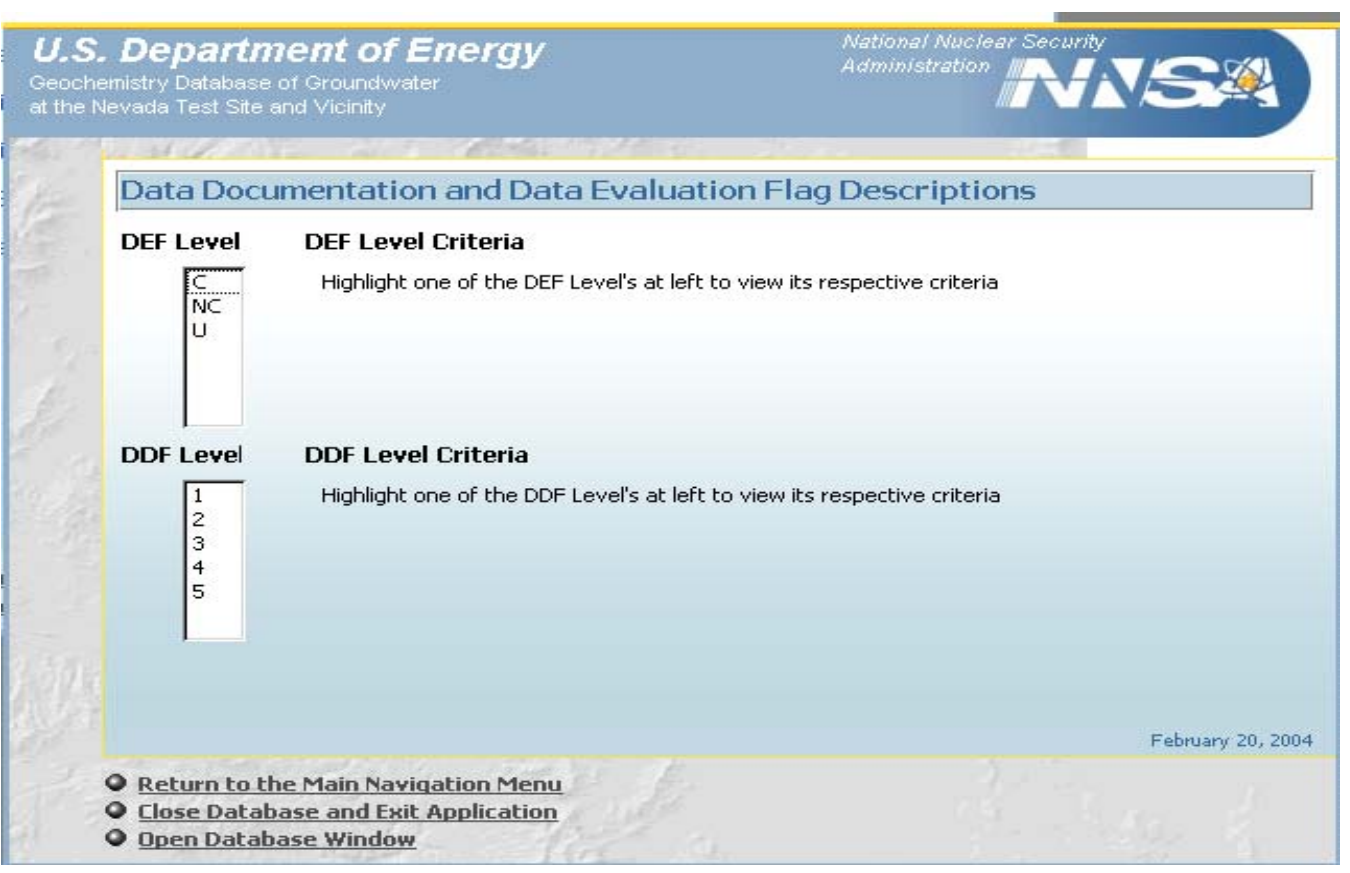

Figure 3-31

Data Documentation and Data Evaluation Flag Descriptions 


\subsection{Summary}

GeochemXX.mdb was designed to provide the user with the capability to search for comprehensive geochemistry data in a user-friendly style. Switchboards were generated to logically navigate the user through this process. Pre-designed queries have been built into the database while allowing flexibility to the user to search on on a variety of different objects (measured parameters, sampling locations, as wells as sampling dates). In addition to the query capabilities built into the database, a high level of documentation associated with the database building process has been maintained and is readily accessible to the user. Domain tables have been generated to provide the user with descriptions of all data, qualifiers, and codes contained within the database.

GeochemXX.mdb is continually being updated and is released annually. Each annual update will provide the user with newly acquired data, additional historical data, as well as improvements through sample/sample location reconciliation processes. 


\subsection{Data Sources and the Quality Control Program}

Data electronically transmitted from the USGS, DRI, EPA, Lawrence Livermore National Laboratory (LLNL), Los Alamos National Laboratory (LANL), Reynolds Electrical \& Engineering Co., Inc. (REECo), Bechtel Nevada (BN), U.S. Air Force (USAF), IT Corporation (IT), Stoller-Navarro Joint Venture (SNJV), and the Harry Reid Center for Environmental Studies (HRCES) constitutes the majority of data found in the database. The remainder of the data originates from published literature and a variety of data generated in support of the NNSA/NSO. Full citations of the published data sources are listed in the reference section of this report. Discriminating reference and source names have been assigned to the digital and unpublished data sources and are reported, along with the data source, in a table (tblSampleRefs) that is linked to their corresponding analytical results (tblSampleResults).

When new data are received, they are first reviewed for quality and completeness. If deemed appropriate for inclusion in the database, the database is examined to ensure that the data have not been entered through another referenced source. Electronic and hand-entered data are first compiled into a working data file where location, parameter, and procedure information is reconciled for consistency with existing text and data formats from the main data tables in the database. The working data files are then returned to the data source for final verification before importation into the database. The data are also checked against the existing domain tables and appropriate modifications are made before the new data are appended to the main data tables. The working copy is then stored in an external location so that it can be used to recreate the data reference if necessary. After the data are included in the main data tables, specified queries, designed to extract the new data, are run. Once extracted, the data are then compared with the original data source, the working copy is modified as necessary, and the process is repeated until all errors are eliminated from the working copy.

Each results record is assigned a DDF indicative of the level of documentation available for the data. The DDF is implicitly based on the data source, quality assurance procedures in place at the time of data collection, and the availability of supporting documentation. Similarly, each record is also assigned a DEF indicative of the consistency of the data. Comments supporting the rationale behind the assignment of these data flags are added as needed. The data flags correspond to each results record in the tblSampleResults table and therefore describe the availability of documentation and data quality for each chemical parameter (Section 2.3). The established criteria for each of the flags are summarized in their corresponding domain tables, dmnDocumentationQualifiers and dmnEvaluationQualifiers. 


\subsection{Editing and Reconciliation Procedures}

This database was created in 1994 and maintained in a flat-file format. Essentially, all of the data were contained in a single table. As the database grew, it became more efficient to maintain and control data entry in a relational-table format. Accordingly, the flat-file database was separated into the four main data tables and linked together using unique data control fields (e.g., "Master_ID," "Sample_ID," "Ref_ID"). In the transition from the flat-file format to the relational format, some data records may have been inadvertently altered in the process. A verification program was implemented in order to evaluate the effectiveness of this transition. This program included a qualitative and quantitative review of the following data:

- Verification of Resource Conservation and Recovery Act (RCRA)regulated metals against the original data sources

- Verification of radionuclides against the original data sources

- Verification of isotopes against the original data sources

- Systematic manipulation of the data to identify anomalous values within the database, followed by appropriate verifications against their original data sources

All systematic data manipulation has been completed. Verification of RCRA-regulated metals, isotopes, and radionuclides are in various stages of completion. Significant efforts during the 2005 fiscal year were placed on verifying data in participation with the USGS, DRI, LLNL, and BN.

Modifications to the data that have taken place during this process have been logged in the lgbkEntries table. Information regarding data documentation and quality is presented using DDFs and DEFs.

As part of the transition to a relational-table format, the supporting domain tables were created. These tables represent unique listings of certain data fields and are used for data control and data extraction purposes (Section 2.7). Before these tables could be established as controls for data entry, it was necessary for the database to undergo a process of name reconciliation. The reconciliation process resulted in a number of text-formatting changes to standardize the "Site_ID," "Parm," and "Procedure" fields. In addition to establishing consistent reporting formats within the database, this process resulted in the identification and elimination of a considerable amount of duplicated data. It is important to note that these text-format changes have not significantly altered the data within the database. All of the data records can still be traced back to their original data source. 


\subsection{Database Limitations}

As with most databases of this sort, the use of multiple and historical data sources have given rise to some inherent data limitations. Water sampling, analytical, and reporting methodologies are typically tailored to specific objectives. These objectives and methodologies can occupy a broad range of possible alternatives that change as a function of program goals and the tools available. The identification of key water quality parameters and the capability to detect them at significant concentration levels is an evolutionary process. Data documentation and qualification are also dependent on the context in which the samples were collected. The data contained in the database come from diverse sources and were generated over a period of time for a wide range of purposes. Therefore, inconsistencies are common in the original data. The establishment and utilization of the DDF and DEF qualification criteria can be used to identify many of the generalized inconsistencies between data sources. The data user is urged to take the DDF and DEF qualifiers under advisement when evaluating data from multiple sources.

There are a few inconsistencies in the reporting of data that have been maintained for many of the older data sources. For instance, it has not always been explicitly stated that reported concentrations represent dissolved ion concentrations.

Because it is impractical to verify all of these data entries, and in the light of inconsistencies in historical data reporting conventions, it was assumed that all reported concentrations represent dissolved constituents unless otherwise noted in the original reports. Similarly, the distinction between field and laboratory measurements for $\mathrm{pH}$ and the differentiation between the types of inorganic carbon analyses (bicarbonate, carbonate, total dissolved inorganic carbon, and alkalinity) is not always clear. If there was uncertainty associated with the reconciliation of locations, parameter names, units, or procedures, the original reporting convention was incorporated as the default condition into the database. As a consequence, this may have given rise to the occurrence of duplicate data. A concerted effort was made to eliminate duplicated information. Nonetheless, users are cautioned to exercise scientific judgment and familiarity with the region when using data in this regard.

As with most databases of this sort, the use of multiple and historical data sources has given rise to some inherent data limitations. The analyses presented are of variable quality and completeness, and data users are reminded to exercise judgment when using data in this regard. While every reasonable effort has been made to ensure completeness and accuracy, it is anticipated that database users will identify errors and omissions. 


\section{0 summary}

GeochemXX.mdb has been developed as part of the UGTA Program with the cooperation of several agencies participating in evaluation and characterization activities under contract to the DOE. The database has been constructed to provide up-to-date, comprehensive, and quality controlled data in a uniform format for the support of current and future projects. Annual updates will keep the database current with respect to ongoing data gathering activities. Posting the database on the CDR (DTN 884) will make the database available to all agencies with DOE intranet access.

Water quality data have been compiled for wells and springs at the NTS and the surrounding region. The data are available as a relational Microsoft Access ${ }^{\circledR}$ database. Updated versions of the database will be given titles indicative of their release date and will be accompanied by appropriate documentation, describing the differences between each version.

The database consists of six primary data tables: tblSampleLoc, tblSampleData, tblSampleResults, tblColloidResults, tblNFTestsData, and tblSampleRefs. These main data tables are supported by a variety of domain and comment tables. There are two types of domain tables, those which provide control over the entry and modification of data, and those which provide the user with a better understanding of data reporting conventions and the type of data sources available within the database.

Primary sources of data constitute electronic data transmittals from the USGS, DRI, LLNL, LANL, REECo, EPA, BN, USAF, SNJV, IT, and HRCES.

Additional data sources include open publications and data communications in support of the NNSA/NSO programs.

Data reporting concerns arising from the conversion of the database from a flat-file format to a relational-data table format have been addressed through a separate QA/QC program. This program was supported by comprehensive verification for RCRA-regulated metals, radionuclides, and isotopes. Inconsistent data reporting identified during the verification program have since been corrected and documented.

Additional editing of the database has elicited a variety of text-format changes, most of which have been made in support of the various location-name, parameter, unit, and procedure information reconciliation. All of these editing activities have been described within the database itself. Appropriate changes and all QA/QC checkprinting documentation have been maintained separate from the database and in accordance with DOE or NNSA/NSO standard operating procedures. 


\subsection{Acknowledgements}

We acknowledge the cooperation of the USGS, the DRI, LLNL, LANL, BN, SNJV, USAF, and the HRCES in providing data transmittals. In particular, we would like to thank the following individuals: Tim Rose, Mavrik Zavarin, Robert Peppard, David Hudson, Chuck Russell, Jim Thomas, Karen Thomas, Ron Hershey, Gail Eaton, Jackie Kennealley, Dave Finnigan, Lloyd Desotell, Zell E. Peterman, Stephen Kung, Paul Reimus, Tom Oliver, Robert Graves, James Paces, Larry Koch, and Dave Wood. Funding for this project has been made available from the U.S. Department of Energy.

\section{Data Correction / Transfer Contact Information:}

Irene Farnham

Stoller-Navarro Joint Venture

7710 W. Cheyenne, Bldg 3

Las Vegas, NV 89129

(702) 295-3694

(702) 295-5393 (Fax)

Irene.Farnham@nv.doe.gov
John McCord

Stoller-Navarro Joint Venture

7710 W. Cheyenne, Bldg 3

Las Vegas, NV 89129

(702) 295-1881

(702) 295-5393 (Fax)

John.McCord@nv.doe.gov 


\section{Distribution}

W.R. Wilborn

4 (CDs)

Environmental Restoration Division

U.S. Department of Energy

National Nuclear Security Administration

Nevada Site Office

P.O. Box 98518 M/S 505

Las Vegas, NV 89193-8518

Technical Library

1 (CD)

U.S. Department of Energy

National Nuclear Security Administration

Nevada Site Office

P.O. Box 98518, M/S 505

Las Vegas, NV 89193-8518

Drew Coleman

1 (CD)

US DOE, OCRWM/ORD

M/S 523

1551 Hillshire Drive

Las Vegas, NV 89134-6321

Michael King

HYDROdynamics Group

(1CD)

16711 76th Ave. West

Edmonds, WA 98026

David Sassani

Golder Associates Inc, MTS

M/S 523

1551 Hillshire Drive

Las Vegas, NV 89134-6321

Robert Gamble

Nye County (NRFF)

M/S 523, Room 375B

1551 Hillshire Drive

Las Vegas, NV 89134-6321

98RANW

Yvonne Gresnik

1 (CD)

3770 Duffer Drive

Nellis, AFB, NV 89191-7001

Larry Koch

1 (CD)

SRS Technologies

P.O. Box 569

Indian Springs, NV 89018 
Naomi Becker

1 (CD)

Los Alamos National Laboratory

Box 1663, M/S F665

Los Alamos, NM 87545

Dave Finnegan

1 (CD)

Los Alamos National Laboratory

Box 1663, M/S J514 CST-7

Los Alamos, NM 87545

Ed Kwicklis

Los Alamos National Laboratory

1 (CD)

Box 1663, M/S T003

Los Alamos, NM 87545

Paul Reimus

1 (CD)

Los Alamos National Laboratory

Box 1663, M/S-J534 CST-7

Los Alamos, NM 87545

Tim Rose

1 (CD)

Lawrence Livermore National Laboratory

P.O. Box 808, L-231

Livermore, CA 94551

Gayle Pawloski

Lawrence Livermore National Laboratory

P.O. Box 808, L-221

Livermore, CA 94551

Mavrik Zavarin

Lawrence Livermore National Laboratory

P.O. Box 808, L-221

Livermore, CA 94551

Ken Ortego

1 (CD)

National Security Technologies, LLC

P.O. Box 98521 M/S NSF-082

Las Vegas, NV 89193-8521

David Hudson

1 (CD)

National Security Technologies, LLC

1 (CD)

P.O. Box 98521 MS NTS-273

Las Vegas, NV 89193-8521

Don Van Etten

1 (CD)

National Security Technologies, LLC

1 (CD)

Remote Sensing Laboratory

Nellis Air Force Base

M/S RSL-47

Las Vegas, NV 89191 
Ron Hershey

1 (CD)

Desert Research Institute

2215 Raggio Parkway

Reno, NV 89512

Jim Thomas

1 (CD)

Desert Research Institute

2215 Raggio Parkway

Reno, NV 89512

Chuck Russell

1 (CD)

Desert Research Institute

755 E. Flamingo Road

Las Vegas, NV 89119-7363

Zell Peterman

1 (CD)

U.S. Geological Survey

21 Center Ave

Denver Federal Center

Denver, CO 80225

Jim Paces

1 (CD)

U.S. Geological Survey

Denver Federal Center

Box 25046, MS-963

Lakewood, CO 80225

Tom Oliver

1 (CD)

U.S. Geological Survey

Denver Federal Center

Box 25046, MS-421

Denver, CO 80225

Bonnie Thompson

1 (CD)

U.S. Geological Survey

Water Resources Division

160 N. Stephanie St.

Henderson, NV 89074-8829

Dave Wood

1 (CD)

U.S. Geological Survey

Water Resources Division

160 N. Stephanie St.

Henderson, NV 89074-8829

Irene Farnham

1 (CD)

Stoller-Navarro Joint Venture

7710 W. Cheyenne

Las Vegas, NV 89129 
John McCord

Stoller-Navarro Joint Venture

7710 W. Cheyenne

Las Vegas, NV 89193

Christie Miller

Stoller-Navarro Joint Venture

7710 W. Cheyenne

Las Vegas, NV 89193

Manager, Northern Nevada FFACO

Public Reading Facility

c/o Nevada State Library \& Archives

100 N. Stewart Street

Carson City, NV 89701

Southern Nevada Public Reading Facility

c/o Nuclear Testing Archive

P.O. Box 98521, M/S 400

Las Vegas, NV 89193-8521
1 (CD)

1 (CD)

1 (CD)

1 (CD) 